MARISA AILIN HONG

\title{
Resposta imune celular contra peptídeos crípticos do HIV-1
}

Tese apresentada à Faculdade de Medicina da Universidade de São Paulo para obtenção do título de Doutor em Ciências

Programa de Alergia e Imunopatologia Orientador: Prof. Dr. Ésper Georges Kallás

São Paulo

2014 


\section{Dados Internacionais de Catalogação na Publicação (CIP)}

Preparada pela Biblioteca da

Faculdade de Medicina da Universidade de São Paulo

Creprodução autorizada pelo autor

Hong, Marisa Ailin

Resposta imune celular contra peptídeos crípticos do HIV-1 / Marisa Ailin Hong. -- São Paulo, 2014.

Tese(doutorado)--Faculdade de Medicina da Universidade de São Paulo.

Programa de Alergia e Imunopatologia.

Orientador: Ésper Georges Kallás. HIV

Descritores: $1 . H I V-1$ 2.Infecções por HIV 3.ELISPOT 4.Antígenos

USP/FM/DBD-407/14 
NOME: Hong, Marisa Ailin

TíTULO: Resposta imune celular contra peptídeos crípticos do HIV-1

Tese apresentada à Faculdade de Medicina da Universidade de São Paulo para obtenção do título de Doutor em Ciências

Aprovado em:

Banca examinadora

Prof. Dr. Instituição:

Julgamento:

Assinatura:

Prof. Dr. Instituição:

Julgamento:

Assinatura:

Prof. Dr. Instituição:

Julgamento:

Assinatura:

Prof. Dr. Instituição:

Julgamento:

Assinatura:

Prof. Dr. Instituição:

Julgamento:

Assinatura: 
"Agradeço todas as dificuldades que enfrentei; não fosse por elas, eu não teria saído do lugar. As facilidades nos impedem de caminhar. Mesmo as críticas, nos auxiliam muito."

(Chico Xavier) 


\section{DEDICATÓRIA}

Ao meu pai Han Chiung (in memorian) e minha mãe Jin Yuh (in memorian), pelo amor com que me trouxeram ao mundo, me criaram e torceram, sem interferir nas minhas decisões. Por me ensinarem a enfrentar meus medos e vencer os desafios e, a cada dia tentar ser uma pessoa melhor do que fui ontem.

Aos meus irmãos Kouhen e Roberto e, em especial ao meu filho Miller, com amor, admiração e gratidão pela compreensão, carinho, tolerância e apoio durante toda a minha vida.

A Loder (in memorian) por me fazer enxergar a vida por um outro prisma.

A duas grandes amigas, que chamaria de mãe e irmã, Mirthes Ueda e Adriana P. Vicentini, por tornar possível a continuidade deste trabalho no dia-a-dia, através de seus carinhos, palavras de incentivo, cobranças, trocas de idéias e por me lembrarem o tempo todo de que tinha que terminar logo.

Ao Senhor por dar-me força para não desistir no meio do caminho. 


\section{AGRADECIMENTOS}

Ao Prof. Dr. Ésper G. Kállas por me trazer de volta a ciência ao confiar e aceitar me orientar, tendo paciência, incentivando e ensinando a ter acima de tudo confiança e calma.

Ao Prof. Dr. Douglas Nixon e Stéphane Champiat pela oportunidade de estagiar, aprender e trocar idéias na Universidade da Califórnia de São Francisco.

À equipe do laboratório LIM-60, Priscilla, Fernanda, Cláudia, Karina, Issler, Cândida, Helena e especialmente ao Leandro F. S. Tarosso por tornar possível a execução do trabalho e discussão.

À Dra. Marta L. Salomão, enquanto Diretora do Instituto Adolfo Lutz, pelo apoio e incentivo para a busca de aprimoramento profissional.

Aos membros da equipe do Laboratório de Citometria de Fluxo e amigos do Instituto Adolfo Lutz, por "cuidar" do nosso laboratório enquanto eu me ausentava para conduzir o trabalho e por apoiar nos momentos críticos.

À Dra. Myrthes Toledo Barros, da disciplina de Alergia e Imunopatologia, pela orientação no estágio de pedagogia e lembrar-me indiretamente que por trás de toda pesquisa há o ser humano para quem devemos olhar.

À diretoria do Centro de Imunologia e do Instituto Adolfo Lutz, por permitir momentos de dedicação ao trabalho.

Aos amigos do Centro de Imunologia que rezaram muito para que eu pudesse terminar logo e deixasse de estressá-los. 
Esta tese está de acordo com as seguintes normas, em vigor no momento desta publicação:

\section{Referências:}

Adaptado de International Committee of Medical Journals Editors (Vancouver). Universidade de São Paulo. Faculdade de Medicina. Divisão de Biblioteca e Documentação. Guia de apresentação de dissertações, teses e monografias. Elaborado por Anneliese Carneiro da Cunha, Maria Julia de A. L. Freddi, Maria F. Crestana, Marinalva de Souza Aragão, Suely Campos Cardoso, Valéria Vilhena. 3a ed. São Paulo: Divisão de Biblioteca e Documentação; 2011.

Abreviaturas dos títulos dos periódicos de acordo com List of Journals Indexed in Index Medicus. 


\section{SUMÁRIO}

Lista de abreviaturas

Lista de Tabelas e Figuras

Resumo

Abstract

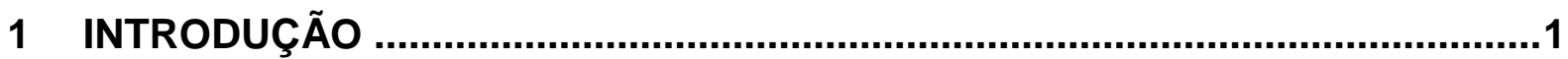

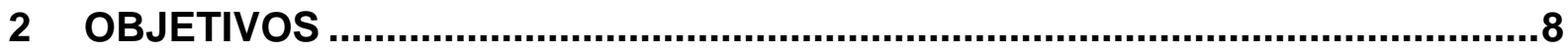

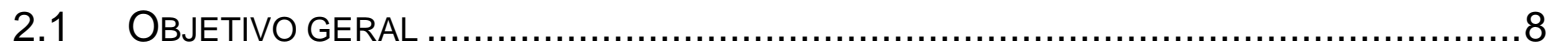

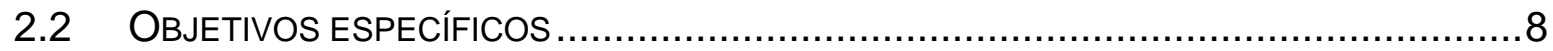

3 CASUÍSTICA E METODOLOGIA ..........................................................

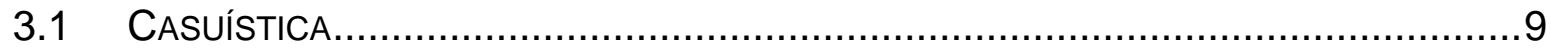

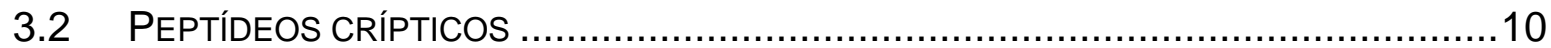

3.3 ENSAIOS DE ELISPOT (ENZYME-LINKED IMMUNOSPOT ASSAY) .....................12

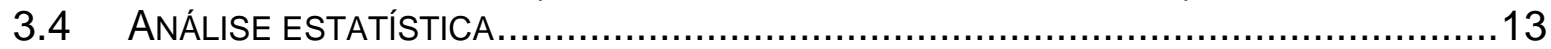

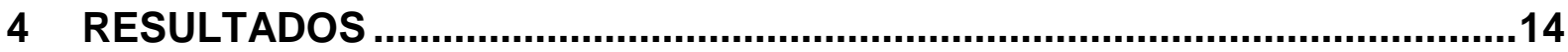

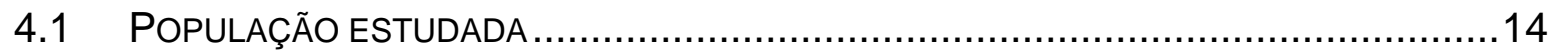

4.2 FREQUÊNCIA DE RESPOSTA IMUNOLÓGICA CELULAR ESPECÍFICA CONTRA PEPTÍDEOS CRÍPTICOS.............................................................................. 17

4.3 AMPLITUDE E MAGNITUDE DA RESPOSTA IMUNOLÓGICA CELULAR ESPECÍFICA

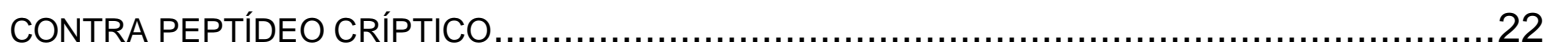

4.4 CORRELAÇÃO DA RESPOSTA IMUNE CELULAR CONTRA PEPTÍDEOS CRÍPTICOS E CONTAGEM DE LINFÓCITOS T CD4+, T CD8+ E VIREMIA PLASMÁTICA ........................28

4.5 ESPECIFICIDADE DA RESPOSTA IMUNE CELULAR ESPECÍFICA CONTRA PEPTÍDEO

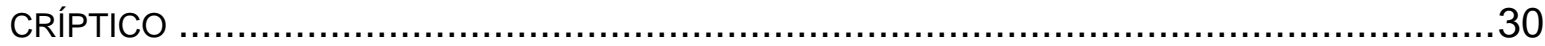

4.6 RESPOSTA IMUNE CELULAR CONTRA PEPTÍDEO CRÍPTICO NA FASE TARDIA DA

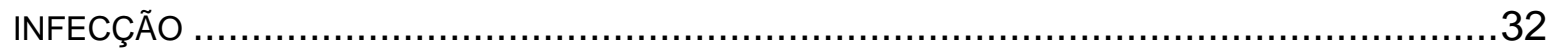

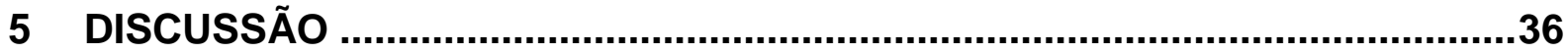

6 CONCLUSÕES .........................................................................................43

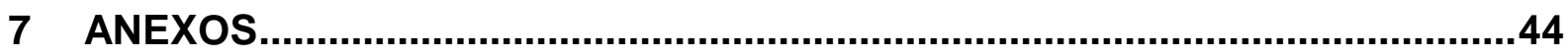

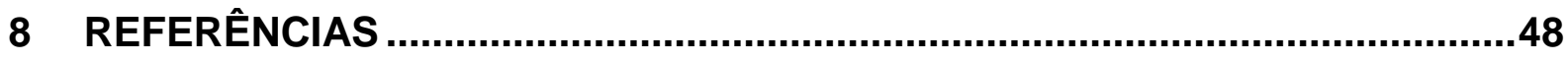

Apêndices 


\section{LISTA DE ABREVIATURAS}
AIDS
Acquired Immunodeficiency
Syndrome
I Síndrome
da Imunodeficiência Adquirida
ARF
Alternative reading frame
ART
Antirretroviral
ELISPOT
Enzyme-linked Immunospot Assay
HAART
High Active Antiretroviral Therapy
HIV
Human Immunodeficiency Virus
HLA
Histocompatibility leukocyte antigen
$\mathrm{MHC}$
Major histocompatibility complex
ORF
Open reading frame
$\mathrm{PC} / \mathrm{CP}$
Peptídeos Críptico / Cryptic Peptide
STARHS
Serologic Testing Algorithn for Recent HIV Seroconversion 


\section{LISTA DE FIGURAS, TABELAS E GRÁFICOS}

Tabela 1 - Características da população estudada após agrupamento baseado no controle da carga viral plasmática ao longo do acompanhamento clínico......16

Figura 1 - Genoma da HXB2 do HIV-1. As três leituras alternativas possíveis da sequência do gene da cepa HXB2 do HIV-1, no sentido senso (5'-3') e antisenso (3'-5'). Em azul, estão representadas as sequências codificadoras de proteínas conhecidas do HIV-1, em verde, as sequências de leitura senso e em lilás, as sequências de leitura antisenso que originaram os peptídeos crípticos avaliados neste estudo. (Figura gentilmente cedida por Champiat S. e cols).....

Figura 2 - Determinação da contagem de linfócitos T CD4+ e T CD8+ e carga viral plasmática de HIV-1 nos pacientes respondedores e nãorespondedores aos peptídeos crípticos. (A) contagem de linfócitos T CD4+, (B) contagem de linfócitos T CD8+, e (C) Carga viral plasmática, nos pacientes respondedores e não-respondedores contra algum pool de peptídeos crípticos. Análise estatística foi realizada utilizando teste $t$-Student.............................18

Figura 3 - Porcentagem de resposta imune contra peptídeos crípticos na população estudada. Número de amostras provenientes de pacientes de cada grupo que responderam ou não a pelo menos um pool de peptídeos crípticos. Análise estatística foi realizada utilizando teste $t$-Student, $p=0,031$ 19

Figura 4 - Porcentagem de pacientes que expressam alelos de HLA ligantes dos peptídeos crípticos avaliados. Os peptídeos crípticos avaliados neste estudo são apresentados por um dos quatro alelos: HLA-A*02, - $B^{\star} 07$, $B^{\star} 57$ e $-B^{\star} 58$. Não foi levado em consideração se o alelo estava presente em hetero ou homozigose. Nesta figura os pacientes estão representados conforme o grupo (controladores e progressores) e a resposta a pelo menos 1 pool de peptídeos crípticos $((-)=$ não-respondedores e $(+)=$ respondedores)...20

Figura 5 - Número de pacientes que responderam a cada pool de peptídeo críptico avaliado neste estudo. ARF\# é o número de pool de peptídeos crípticos estudado. Os resultados representam o número de pacientes do grupo de controladores (barra azul) e do grupo de progressores (barra rosa) que responderam a determinado pool. Um total de nove pacientes de cada grupo responderam a pelo menos um pool de peptídeos crípticos.....21

Figura 6 - Número de pools de peptídeos crípticos contra os quais cada paciente dos grupos de controladores e progressores respondeu. CA e $\mathrm{CV}=$ pacientes do grupo de controladores, respectivamente avirêmicos e virêmicos, e Prog= pacientes do grupo de progressores, seguidos da identificação do pacientes codificado. 
Figura 7 - Magnitude de resposta imunológica celular específica contra pools de peptídeos crípticos. Os resultados estão representados pela média de CFS $/ 10^{6} \mathrm{CMN}$ de cada grupo de pacientes para cada pool. A média do resultado do grupo de pacientes controladores foi de $290 \pm 115 \mathrm{CFS} / 10^{6} \mathrm{CMN}$ e do grupo de pacientes progressores, de $147 \pm 150 \mathrm{CFS} / 10^{6} \mathrm{CMN}$. ARF= número do pool de peptídeos crípticos. A diferença entre os grupos foi significativa, com $\mathrm{p}=0,00003$, pelo teste $t$-Student. 24

Figura 8 - Magnitude de resposta imunológica apresentada por células mononucleares de pacientes que responderam contra apenas um pool de peptídeos crípticos. Pacientes do grupo de controladores (representado em azul) e de progressores (representado em rosa) que responderam contra apenas um pool de peptídeos crípticos. ARF= número do pool de peptídeos crípticos contra o qual o paciente respondeu. 25

Figura 9 - Magnitude de resposta imune apresentada por células mononucleares provenientes de pacientes controladores que responderam contra mais de um pool de peptídeos crípticos. Colunas em azul representam resultados positivos e colunas em cinza representam magnitude de resultados negativos de cada paciente. 26

Figura 10 - Magnitude de resposta imune apresentada por células mononucleares provenientes de pacientes progressores que responderam contra mais de um pool de peptídeos crípticos. Colunas em rosa representam resultados positivos e colunas em cinza representam magnitude de resultados negativos de cada paciente. 27

Figura 11 - Correlação da magnitude de resposta imunológica contra peptídeos crípticos e contagem de linfócitos T CD4+ (A) e T CD8+ (B) e carga viral plasmática de HIV-1 (C) nos pacientes dos grupos controladores e progressores. Análise estatística apresentou $p>0,05$ para todas as comparações apresentadas .29

Figura 12 - Magnitude da resposta imunológica específica contra peptídeos crípticos que compõem os pools testados. Resposta de CMN proveniente dos pacientes controladores 1098 (A), 1173 (B) e 1099 (C) e, paciente progressor $(C)$, este testadas contra peptídeos componentes de dois pools (ARF\# 2 e 6). Todos os peptídeos crípticos foram avaliados nas concentrações de 10 e $100 \mu \mathrm{g} / \mathrm{mL}$. Os resultados positivos estão representados em azul (paciente controlador) ou rosa (paciente progressor). Colunas rajadas representam a concentração de $10 \mu \mathrm{g} / \mathrm{mL}$ de peptídeo críptico testado e colunas sólidas, concentração de $100 \mu \mathrm{g} / \mathrm{mL}$ 
Figura 13 - Magnitude da resposta imunológica específica contra peptídeos crípticos na fase aguda e tardia da infecção pelo HIV. Resposta de CMN proveniente dos pacientes controladores (A) pacientes progressores (B). Os resultados estão expressos pela somatória de resposta de cada paciente contra os peptídeos crípticos estudados, em CFS $/ 10^{6} \mathrm{CMN}$. No gráfico (A) dois pacientes têm suas respostas de fase aguda não-visíveis, devido a grandeza dos valores em relação à escala, sendo eles os pacientes $1122 \mathrm{e}$ 2044, cuja resposta na fase aguda foi de 6.635 e $5.100 \mathrm{CFS} / 10^{6} \mathrm{CMN}$, respectivamente

Figura 14 - Magnitude da resposta imunológica específica contra Gag na fase aguda e tardia da infecção pelo HIV. Resposta de CMN proveniente dos pacientes controladores (A) pacientes progressores (B). Os resultados estão expressos pela somatória de resposta de cada paciente contra os peptídeos crípticos estudados, em $\mathrm{CFS} / 10^{6} \mathrm{CMN}$. No gráfico $(\mathrm{A})$ dois pacientes têm suas respostas de fase aguda não-visíveis, devido a grandeza dos valores em relação à escala, sendo eles os pacientes 1122 e 2044, cuja resposta na fase aguda foi de 6.635 e $5.100 \mathrm{CFS} / 10^{6} \mathrm{CMN}$, respectivamente. 34

Figura 15 - Magnitude da resposta imunológica específica contra Gag na fase aguda e tardia da infecção pelo HIV. Resposta de CMN proveniente dos pacientes controladores (A) pacientes progressores (B). Os resultados estão expressos pela somatória de resposta de cada paciente contra os peptídeos crípticos estudados, em $\mathrm{CFS} / 10^{6} \mathrm{CMN}$. No gráfico $(\mathrm{A})$ dois pacientes têm suas respostas de fase aguda não-visíveis, devido a grandeza dos valores em relação à escala, sendo eles os pacientes 1122 e 2044, cuja resposta na fase aguda foi de 6.635 e $5.100 \mathrm{CFS} / 10^{6} \mathrm{CMN}$, respectivamente. 35 


\section{RESUMO}

Hong M.A. Resposta imune celular contra peptídeos crípticos do HIV-1 [tese]. São Paulo: Faculdade de Medicina, Universidade de São Paulo; 2014.

INTRODUÇÃO E OBJETIVOS: Uma fonte secundária e não convencional de peptídeos que se ligam as moléculas MHC de classe I tem sido descrita como responsável por produzir peptídeos crípticos. Esses peptídeos são imunogênicos e portanto, capazes de induzir uma resposta imunológica por células $T$ e assim, contribuir com a resposta total exercida pelas células $T$ CD8+, colaborando na pressão que leva HIV-1 ao processo de mutação, e consequentemente ao escape viral. Alguns pacientes, que correspondem a menos de $5 \%$ da população infectada, são capazes de naturalmente controlar a progressão da doença, mantendo a contagem de célula T CD4+ acima de 500 células/uL ou mantendo a carga viral abaixo de 2.000 cópias $/ \mathrm{mL}$, por ao menos 12 meses, sem ser submetido a tratamento com antirretrovirais ou esquema HAART. Avaliar a resposta imunológica destes pacientes, controladores da infecção, contra peptídeos crípticos pode nos fornecer informações importantes que colaborem com o desenvolvimento de novas estratégias preventivas. METODOLOGIA: A resposta imunológica contra peptídeos crípticos, estes derivados da transcrição da seqüência consenso e da seqüência inversa do gene do HIV-1, foram avaliados em vários conjuntos (pools), utilizando amostras coletadas de pacientes controladores, tanto avirêmicos, também conhecidos como controladores de elite (carga viral < limite de detecção), bem como virêmicos (carga viral $<2.000$ cópias $/ \mathrm{mL}$ ) e, de pacientes progressores. Foi observada que a resposta imunológica contra peptídeos crípticos é mais freqüente, com maior amplitude e magnitude entre os pacientes controladores comparados ao que foi observado entre pacientes progressores. Esta resposta, entretanto, parece inverter ao longo da infecção, como observada utilizando as amostras coletadas em momento tardio da infecção, onde os controladores parecem perder sua capacidade de responder aos peptídeos crípticos, enquanto que os progressores desenvolveram resposta, ressaltando que os pools indutores de resposta nas duas fases foram diferentes. Sugerindo que a resposta imunológica contra peptídeos crípticos pode exercer papel importante de pressão sobre o vírus, levando-o ao processo de escape viral. CONCLUSÔES E IMPORTÂNCIA: Peptídeos crípticos são capazes de induzir resposta imunológica e colaborar para explicar como ocorre a seleção de alguns vírus, seja este devido à mudança na expressão das proteínas principais do HIV-1, seja diretamente gerando vírus defeituoso e não infectante. Os peptídeos crípticos podem ser incluídos em desenhos de vacina, com o intuito de aumentar a amplitude e a magnitude da resposta imunológica por células $\mathrm{T}$ e consequentemente, aumentar a proteção contra infecção ou progressão da infecção pelo HIV-1.

\section{DESCRITORES:}

HIV-1; Infecções por HIV, ELISPOT; Antígenos HIV 


\begin{abstract}
ASTRACT
Hong M.A. Cellular immune response against HIV-1 cryptic peptides [thesis]. São Paulo: "Faculdade de Medicina, Universidade de São Paulo"; 2014.

BACKGROUND: A second and unconventional source of peptides that bind to MHC class I molecule has been described to produce cryptic peptides, which are immunogenic and are able elicit $\mathrm{T}$ cell response, that contributes to total CD8+ $T$ cell immune response and then exert mutation pressure on HIV-1, leading to virus escape. Some rare patients, less than $5 \%$ of infected population, are naturally able to control disease progression, either maintaining CD4+ T cells over 500 cells/uL or viral load under 2,000 copies/mL, without being treated with HAART, for at least 12 months. Understanding their immune response to cryptic peptides might be a great value to help on developing better prevention strategies. METHODOLOGY: Immune response to cryptic peptides, derived from sense and antisense transcription of HIV-1, was evaluated in pools using samples from Elite (aviremic) or HIV (viremic, $<2,000$ copies $/ \mathrm{mL}$ ) controllers and progressors. Immune response to cryptic peptides are more frequent, with a larger breadth and of greater magnitude in controllers than in progressors, and this response is inversed seen in a later time point, when controllers seems to lose this response, while progressors developed it, showing cryptic peptides immune response to different pools, suggesting that immune response to cryptic peptides might play some role in pressuring the virus mutation escape. CONCLUSIONS AND SIGNIFICANCE: cryptic peptides can elicit immune response and help to explain how some virus selection happens, either by changing expression of crucial HIV-1 proteins or generating defective virus. They can be included in vaccine design for enhancing the magnitude and breadth of $\mathrm{T}$ cell immune response and consequently the protection against infection or progression of HIV-1 infection.
\end{abstract}

\title{
DESCRIPTORS:
}

HIV-1; HIV infections; Enzyme-linked Immunospot assay; HIV antigens 


\section{INTRODUÇÃO}

No início da década de 1980, uma nova doença caracterizada pela diminuição do número de linfócitos $T \mathrm{CD} 4+$ no sangue periférico foi descrita e observada entre indivíduos homossexuais, usuários de drogas injetáveis, hemofílicos e transfundidos. Atualmente, a Organização Mundial de Saúde (OMS) estima que o vírus da imunodeficiência adquirida humana (HIV), causador dessa doença, chamada de Síndrome da Imunodeficiência Adquirida (AIDS), atinja mais de 35,3 milhões de pessoas ao redor do mundo, levando à morte mais de um milhão de pacientes em 2012 (UNAIDS, 2013).

Os primeiros casos de AIDS foram descritos nos Estados Unidos, sendo que o maior número de casos tem sido registrado em países subdesenvolvidos ou em desenvolvimento, como por exemplo, os países da África sub-Saariana, onde estima-se que haja cerca de 25 milhões de pessoas infectadas (UNAIDS, 2013).

No Brasil, de 1980 a junho de 2013, foram notificados aproximadamente 718 mil infectados, dos quais $55,2 \%$ residem na região Sudeste. Por outro lado, o crescimento do número de casos tem sido observado mais na região Sul do país, com uma taxa de incidência anual de 30,9 novos casos a cada 100.000 habitantes, e na razão de 1,7 homens para cada mulher infectada. (PNDST/AIDS, 2013).

Embora seja observada uma queda do número de novas infecções na maioria das regiões do mundo, tanto entre adultos quanto entre crianças e recémnascidos, entre os anos de 2001 e 2012, a incidência de infecção pelo HIV é heterogênea e continua aumentando em alguns países, como ocorre no Leste Europeu, Ásia e Norte da África. (UNAIDS, 2013). Portanto, a infecção pelo HIV-1 ainda permanece como um grave problema de saúde pública, devido ao forte impacto sócio-econômico, uma vez que a maioria dos indivíduos infectados encontra-se em idade produtiva, ou seja, na faixa etária entre 20 e 45 anos (Vass, 2002; Kembo, 2010).

Desde a descoberta do HIV, já se passaram mais de 30 anos de estudos, com grandes avanços no entendimento da classificação do vírus (HIV-1 e HIV-2), da patogênese da infecção (especialmente para HIV-1) e no 
desenvolvimento de mais de 20 tipos de medicamentos (Montaner et al., 2010; Piot \& Quinn, 2013). Entretanto, apesar da eficácia dos medicamentos antirretrovirais no controle da replicação viral, com consequente diminuição dos sintomas e aumento da sobrevida dos pacientes, a terapia antirretroviral (ART) representa um desconforto aos seus usuários devido ao rigoroso regime de tratamento, aparecimento de variantes resistentes às drogas utilizadas (Roge et al., 2004), e existência de efeitos colaterais, tais como hepatite, lipodistrofia e doenças degenerativas (Thorner \& Rosenberg, 2003; Zuk et al., 2009; Adlakha et al., 2011; McGrath et al., 2011).

Medidas preventivas, seja por meio de educação, uso de preservativos ou por meio de uso de antirretrovirais pré e pós-exposição, entre outros, representam, até o momento, as medidas de maior eficácia no controle da infecção pelo HIV-1 (Lawn \& Meinties, 2011). Ainda, a imunização através de uma vacina preventiva ou terapêutica permanece como um importante campo de pesquisa. Mesmo que estas vacinas não sejam completamente protetoras, a resultante redução da viremia de HIV-1, como ocorre com o uso de medicamentos antirretrovirais, pode atenuar a epidemia, promovendo uma diminuição da transmissibilidade do vírus (Wawer et al., 2005; Johnston \& Fauci, 2007; Tonks, 2007).

Vacinas baseadas em antígenos inativados (Sheppard, 2005) ou vacinas recombinantes que utilizam vetores das mais diferentes origens (Duerr et al., 2006), têm sido testadas com eficácias questionáveis para aplicação na população (Watkins et al., 2008). Uma vacina eficaz contra o HIV-1 deveria ser capaz de induzir uma ampla resposta imunológica protetora, através da indução de resposta imune humoral com produção de anticorpos neutralizantes e/ou indução de resposta imune celular mediada por linfócitos T CD8+. Diferentemente da resposta imunológica humoral, a imunidade celular obtida seria capaz de destruir células infectadas com diversas variantes virais (Amanna \& Slifka, 2009).

A resposta imunológica celular mediada por linfócitos T CD8+ tem sido associada ao controle temporal da carga viral plasmática detectada na fase aguda da infecção (Borrow et al, 1994; Koup et al., 1994). A ausência de resposta imune mediada por estas células implica em persistência da carga viral plasmática e prolongamento da fase sintomática observada na infecção aguda, além da baixa 
contagem de linfócitos T CD4+, parâmetro este utilizado para monitoramento do estado imunológico dos pacientes infectados pelo HIV (Walker et al., 1986).

Este tipo de associação entre o controle da replicação viral e a resposta imune celular mediada por linfócitos T CD8+ também foi descrito para modelos de infecção em animais, em que se observou um rápido aumento da carga viral plasmática na fase crônica da doença, como conseqüência da depleção desta população celular em macacos resos infectados com o SIV (simian immunodeficiency virus). A carga viral plasmática somente era controlada e retornava aos níveis baixos quando a contagem dos linfócitos T CD8+ específicos contra o vírus voltou a subir (Jin et al., 1999; Schmitz et al., 1999; Friedrich et al., 2007). Ainda, fortes respostas imunológicas mediadas pelos linfócitos T CD8+ observadas em pacientes, cuja viremia era baixa ou indetectável, foram correlacionadas com a magnitude e a especificidade destas respostas celulares (Rinaldo et al., 1995; Musey et al., 1997; Ogg et al., 1998; Liu J et al., 2009).

Embora estudos demonstrem que as características qualitativas dos linfócitos T CD8+ como o potencial de liberação de perforina, sejam mais importantes que a magnitude da resposta imune celular avaliada pela produção de IFN- $\gamma$, o fato é que em pacientes infectados com HIV-1 conhecidos como controladores de elite, a clínica assintomática de até 15 anos de infecção sem uso de antirretrovirais e a carga viral plasmática inferior a 2.000 cópias $/ \mathrm{mL}$ têm sido atribuídas à resposta mediada por linfócitos T CD8+ e sua especificidade (Migueles et al., 2002; Hesperger et al., 2011; Poropatich \& Sullivan, 2011; Riva et al., 2011). Da mesma forma, redução da viremia de SIV observada em macacos resos foi atribuída à amplitude e magnitude da resposta imune mediada pelos linfócitos $\mathrm{T}$ CD8+ (Liu et al., 2009).

Ainda que alguns poucos autores relatem que não haja diferença de magnitude e especificidade de resposta, bem como frequência de linfócitos T CD8+ entre os pacientes controladores de elite e os demais pacientes, classificados como progressores, estes linfócitos exercem maior controle sobre a replicação viral nos pacientes que controlam espontaneamente a viremia, que além da resposta imune mediada por linfócitos T CD8+, também apresentam forte resposta imunológica mediada por linfócitos T CD4+ (Migueles et al., 2004; Migueles et al., 2006; Migueles et al., 2008). 
A definição de pacientes controladores de elite começou a ser descrita a partir do início da década de 90, quando técnicas laboratoriais mais sensíveis permitiram quantificar o número de cópias de RNA viral circulantes (Vermeulen et al., 2013). Os pacientes infectados com HIV que apresentam valores de linfócitos T CD4+ superiores a 500 células/ $\mu \mathrm{L}$ por mais de 10 anos são chamados de pacientes não-progressores de longo tempo (LTNP - long term non-progressors) (Okulicz \& Lambotte, 2011).

Os pacientes controladores de elite, também chamados de controladores avirêmicos, são caracterizados por manter baixa, ou mesmo indetectável, a carga viral plasmática por mais de 10 anos, sem auxílio de medicamentos antirretrovirais. Desta forma, representam um grupo de interesse para estudos de novos medicamentos e estratégias terapêuticas, e desenvolvimento de vacinas. Isto porque, embora esta lenta evolução clínica possa ser atribuída à infecção por uma variante viral atenuada (Salvi et al., 1998), de modo geral, as pesquisas apontam para fatores associados ao próprio hospedeiro, quem apresenta o sistema imunológico preservado, com pouca depleção de linfócitos T CD4+, resposta imune preservada e clínica assintomática (Autran et al., 2011; Blankson, 2011).

Dentre as características inerentes ao hospedeiro, associadas ao controle espontâneo da carga viral plasmática nos pacientes controladores de elite, podemos apontar os fatores genéticos que favorecem a resposta imunológica celular, tais como a presença de alelo com deleção de 32 pares de bases no gene do co-receptor CCR5 do HIV-1 (ccr5 $\Delta 32$ ), ou de determinados alelos de HLA, (histocompatibility leykocyte antigen), ou moléculas do complexo principal de histocompatibilidade ( $\mathrm{MHC}$ - major histocompatibility complex), considerados protetores, como o HLA-B57, frequentemente encontrado entre os pacientes controladores de elite (Migueles et al., 2000; Migueles et al, 2002; Saez-Cirion et al., 2007a; Pereyra et al., 2010 apud em Autran et al., 2011; Autran et al., 2011).

Os HLA participam do direcionamento da resposta imunológica e da infecção pelo HIV-1, com consequente seleção de variantes virais que possuem menor capacidade de replicação (Lassen et al., 2009 apud em Autran et al., 2011). Isto ocorre porque, para ativação da resposta imunológica mediada por células, os linfócitos $\mathrm{T}$ precisam primeiramente reconhecer a presença do antígeno, que é apresentado por células apresentadoras de antígeno (APCs) via moléculas de MHC 
(Krensky, 1997). Os linfócitos T CD8+ reconhecem peptídeos de oito a 11 aminoácidos, produtos da degradação de proteínas endógenas, acoplados a moléculas de MHC de classe I (MHC-I) presentes na superfície das células infectadas (Yewdell \& Bennink, 1992; Heemels \& Ploegh, 1995).

No HIV-1, nove genes são responsáveis pela codificação de polipeptídeos maduros, derivando 15 proteínas clássicas, entre as quais Env, Gag, Pol, Tat, Nef, Vif e Vpu. Estes peptídeos "ótimos", como também são chamados, têm sido amplamente estudados por vários pesquisadores, inclusive com potencial para vacina (Draenert et al., 2003; Gorse et al., 2008; Priddy et al., 2008).

Durante a síntese proteica, entretanto, outros polipeptídeos podem ser produzidos em consequência de falhas no processo de síntese proteica. Esses polipeptídeos, que podem ser chamados de DRIPs (defective ribossomal peptides), são caracterizados por não apresentarem função conhecida, serem lábeis e, de fácil degradação (Yewdell et al., 1996; Schubert et al., 2000; Qian iet al., 2006). A síntese destes polipeptídeos, por outro lado, não é exclusiva de infecções virais, como vírus influenza A e HIV-1, mas também são encontrados em tumores e situações de estresse celular (Elliott et al., 1996; Wang et al., 1996; Mayrand et al., 1998).

Os DRIPs, também conhecidos como peptídeos crípticos, também podem significar seqüências de leitura não convencional ou transcrição de seqüências "ocultas". Este termo também se aplica aos sítios de corte incomuns, que podem levar às mutações. Esses produtos de sequência alternativa de leitura ou críptica da fase aberta de leitura (ARF - alternative reading frame ou cORF - cryptic open reading frame), têm sido mais investigados desde o final da década de 80, por serem capazes de se ligarem a moléculas de MHC-I e serem apresentados por estas moléculas aos linfócitos T CD8+ (Malarkannan et al., 1995; Mayrand \& Green, 1998; Shastri et al., 2002).

Considerados como fonte alternativa de ligantes de MHC, é possível que os peptídeos crípticos contribuam com a resposta imune celular total, induzindo uma resposta específica mediada por linfócitos T CD8+ (Cardinaud et al., 2004;Ho \& Green, 2006).

Resultantes de leituras alternativas de um gene codificante, os peptídeos crípticos também podem ser derivados de regiões não traduzidas do DNA e introns. Vários mecanismos geradores de peptídeos crípticos têm sido descritos presentes em todo o processo de síntese proteica (Shastri et al., 2005). Dentre os 
mecanismos responsáveis pela geração destes peptídeos, estão 1) tradução de sequência existente após o stop códon, 2) tradução de RNA-m utilizando um códon de iniciação diferente do códon convencional e 3) ausência de um gene promotor relacionado (Bullock \& Eisenlohr, 1996; Bullock et al., 1997). Particularmente importante para este presente trabalho é a ocorrência destes durante o processo de tradução, da iniciaçãoo da leitura do RNA-m em uma sequência AUG localizada posteriormente àquela em que a tradução deveria ter sido iniciada, utilizando uma sequência não convencional, como AUU, UGG, GAU, ACG, CUG e GCG (Macejak \& Sarnow, 1991; Bullock \& Eisenlohr, 1996). O deslize na leitura do RNA-m, como também é conhecido esse processo, e/ou aparecimento de "nós" na sequência que cause interrupção na continuidade da tradução são mecanismos geradores de peptídeos crípticos (Hatfield \& Oroszian, 1990).

Um destes mecanismos de geração de peptídeos crípticos foi observado ao manipular-se o genoma do vírus Influenza A. Com a introdução de mutações nas sequências de iniciação do gene ou RNA-m, os pesquisadores concluíram que os peptídeos crípticos são comumente expressos, e são capazes de induzir imunidade mediada por linfócitos T (Schirmbeck et al., 2005). Em um grupo de macacos resos infectados com a cepa SIVmac239, a resposta imune mediada por linfócitos T CD8+ contra peptídeos crípticos da região do gene env foi associada ao controle espontâneo da replicação viral que se observa nestes animais, além de serem capazes de promover o escape de variantes virais (Maness et al., 2007; Maness et al., 2009; Maness et al., 2010). Em camundongos deficientes de linfócitos T CD8+, a reconstituição com estas células específicas contra peptídeo críptico de um retrovírus tornaram estes animais capazes de eliminar a infecção viral (Mayrard et al., 2000; Ho \& Green, 2006). Já na infecção natural por HIV-1, a presença de resposta de linfócitos T CD8+ contra peptídeos derivados de erros de transcrição na região do gene tat e rev foram associados ao controle da replicação viral entre os pacientes infectados. Esta resposta, não detectada em indivíduos não-infectados por HIV-1, foi maior entre os pacientes controladores espontâneos de viremia e entre aqueles, cujo controle de viremia foi efetivo após introdução de medicamentos antirretrovirais (Garrison et al., 2009).

O estudo de resposta imunológica celular contra outros peptídeos, além dos clássicos, pode contribuir para a eficácia de vacinas candidatas, ao expandir o espectro de alvos da resposta imunológica mediada por linfócitos T CD8+ 
e, consequentemente intensificar o controle de replicação viral. Por conseguinte, este estudo objetivou avaliar a resposta imune contra os peptídeos crípticos em indivíduos controladores da replicação do HIV-1 sem o uso de antirretrovirais com a hipótese de que a resposta imune celular contra epítopos crípticos virais pudesse estar presente. Ainda, tal resposta imune foi comparada àquela de indivíduos também infectados, mas que apresentam viremia mais elevada, não controlada espontaneamente, típica da evolução clínica da infecção pelo HIV-1. 


\section{OBJETIVOS}

\subsection{Objetivo geral}

Avaliar a presença de resposta imunológica celular contra peptídeos crípticos na infecção por HIV-1 em pacientes sem uso de drogas antirretrovirais (ART).

\subsection{Objetivos específicos}

Determinar a frequência, magnitude, amplitude e especificidade da resposta imunológica celular mediada por linfócitos T CD8+ contra peptídeos crípticos, utilizando o método de ELISPOT para Interferon $\gamma$ (IFN- $\gamma$ ), em pacientes infectados com HIV-1 em fase aguda da infecção, com análise complementar em amostras de seguimento. 


\section{CASUÍSTICA E METODOLOGIA}

\subsection{Casuística}

As amostras avaliadas neste estudo foram selecionadas de uma coorte de indivíduos infectados pelo HIV-1, acompanhados desde o início da infecção. Detalhes da seleção e seguimento dos participantes desta coorte de infecção recente, previamente estabelecida no Ambulatório de Doenças Infecciosas da Universidade Federal de São Paulo ${ }^{1}$, e posteriormente transferida para o Hospital das Clínicas da Faculdade de Medicina da Universidade de São Paulo ${ }^{2}$, foram publicados por Kallas e cols (2004).

Resumidamente, o tempo de infecção foi estimado na primeira visita dos voluntários, pelo método Serologic Testing Algorithn for Recent HIV Seroconversion ou STARHS, que se baseia na desensibilização de ensaio imunoenzimático para diagnóstico da infecção pelo HIV-1 (Vironostika HIV-1 microELISA system - BioMérieux, Durham, NC, EUA). Todos os pacientes, cujas amostras apresentaram reatividade negativa no STARHS após a obtenção de resultados positivos utilizando testes padrões de ELISA e Western Blot, segundo o algoritmo do Ministério da Saúde do Brasil (Brasil, 2004), foram considerados recém-infectados com tempo estimado de até 170 dias (Kallas et al., 2004). Os participantes foram então convidados a realizar visitas clínicas regulares, quando foram obtidas amostras para avaliação laboratorial e isolamento de células mononucleares do sangue periférico (CMN).

Neste estudo, foram selecionadas amostras provenientes de 46 pacientes, todos com idade superior a 18 anos, que não estavam grávidas nem sob suspeita, e tempo de acompanhamento na coorte de até 15 meses.

\footnotetext{
${ }^{1}$ (projeto intitulado "Avaliação da resposta imunológica em pacientes recentemente infectados pelo HIV-1, identificados pela técnica sorológica de ensaio imunoenzimático com estratégia de testagem dupla (detuned) - projeto no Comitê de Ética em Pesquisa da UNIFESP oㅜ 919/01)

${ }^{2}$ projeto de pesquisa intitulado "Decifrando a genética e a função KIR na infecção recente pelo HIV-1 pela bio-informática", protocolo no 0458/08 da CAPPesq da Diretoria Clínica do Hospital das Clínicas e da Faculdade de Medicina da Universidade de São Paulo, aprovado em 16 de julho de 2008
} 


\subsection{Peptídeos crípticos}

Os peptídeos crípticos foram definidos utilizando como base a sequência genômica da variante HXB2 do HIV-1, a mesma utilizada como referência em vários estudos de vacina, em especial aqueles realizados nos Estados Unidos e na Europa (Zhang $\mathrm{H}$ et al., 2009).

As leituras alternativas de sequências aberta (alternative open reading frame - ARF) que não iniciam com o códon AUG, para o aminoácido metionina foram determinadas com auxílio do programa Geneious Pro (Biomatters, Auckland, Nova Zelândia). Todos os peptídeos possíveis traduzidos do gene no sentido 5'-3' (leitura senso) e 3'-5' (leitura antisenso) foram então identificados. Todos os peptídeos que faziam parte, total ou parcial, de proteínas funcionais foram excluídos com auxílio do programa BLAST (www.ncbi.nlm.nih.gov/blast). Os genes codificadores destas proteínas estão representados em azul na Figura 1.

As leituras alternativas das sequências abertas ou epítopos crípticos (criptic open reading frame - cORF) do genoma que codificam no total de 47 regiões estão representadas na Figura 1 em lilás. Estas cORFs correspondem a 13 regiões codificadas no sentido 5'-3' e 34 regiões de sequências lidas no sentido 3'-5' (Champiat et al., 2011).

Um total de 197 peptídeos derivados das 47 regiões de ARF e com capacidade de ligação às moléculas $H L A-A^{*} 02,-B^{*} 07$ ou $-B^{\star} 58$, foi selecionado com auxílio do programa NetCTL (http://www.cbs.dtu.dk/services/NetCTL/) (Champiat et al., 2012). Outros dois peptídeos, correspondentes a duas variantes splicing ("corte") dos genes transcritos tat e rev, foram incluídos. Essas variantes são resultados do sítio alternativo de "corte" no RNA-m, durante seu "amadurecimento", quando os introns são removidos e duas regiões exons são unidas. Esses sítios alternativos de "corte" resultariam na adição de outros aminoácidos ao RNA-m. Desta forma, um total de 199 peptídeos crípticos foi obtido e, então agrupados em pools de 2 a 11 peptídeos cada (Anexo 1). 


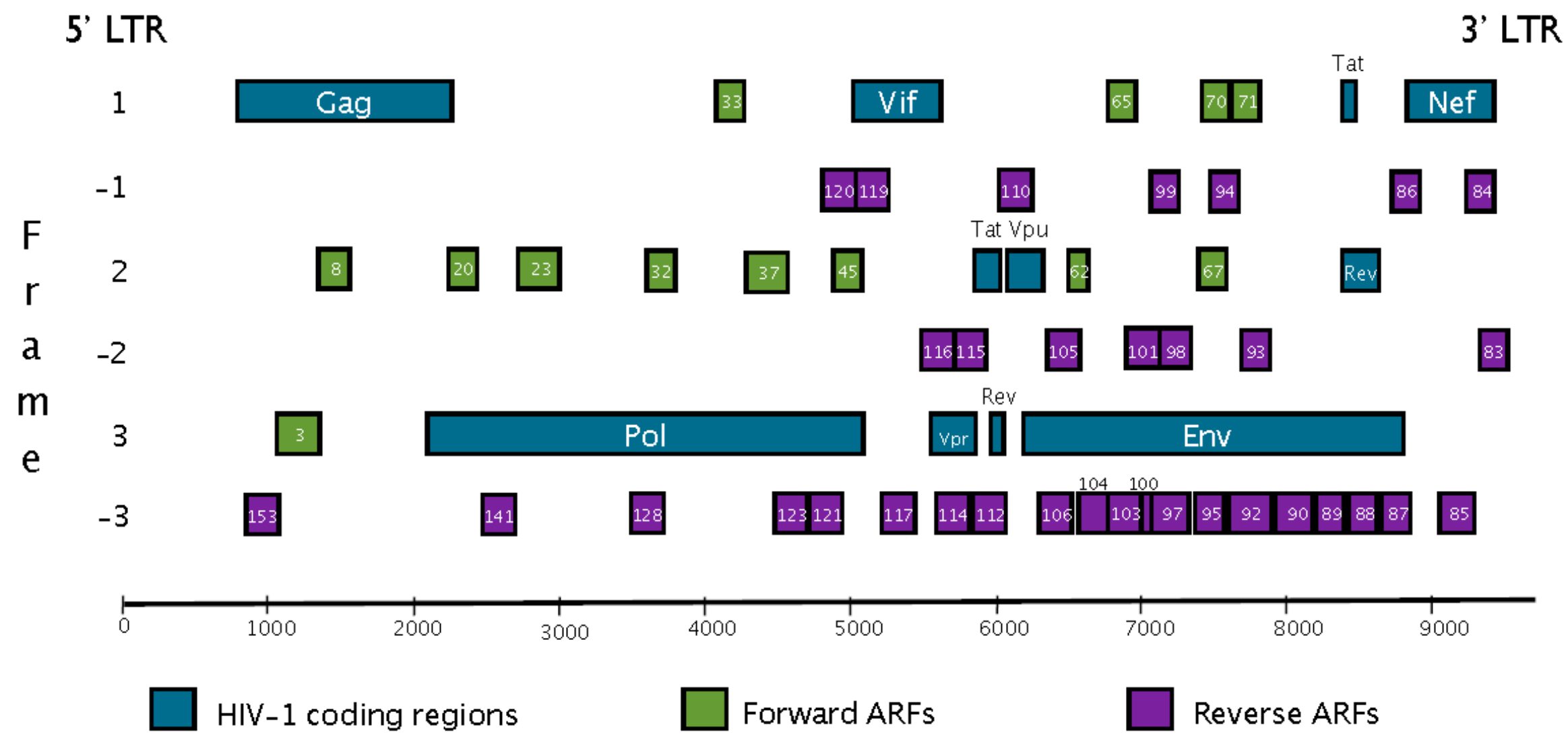

Figura 1 - Genoma da HXB2 do HIV-1. As três leituras alternativas possíveis da sequência do gene da cepa HXB2 do HIV-1, no sentido senso (5'-3') e antisenso (3'-5'). Em azul, estão representadas as sequências codificadoras de proteínas conhecidas do HIV-1, em verde, as sequências de leitura senso e em lilás, as sequências de leitura antisenso que originaram os peptídeos crípticos avaliados neste estudo. (Figura gentilmente cedida por Champiat S. e cols) 


\subsection{Ensaios de ELISPOT (Enzyme-linked Immunospot Assay)}

O ensaio de ELISPOT (Enzyme-linked Immunospot Assay) para IFN- $\gamma$ foi executado conforme previamente descrito (Meiklejohn et al., 2004). Placas de 96 poços de fundo chato contendo membrana de nitrocelulose 0,45 $\mu \mathrm{m}$ (Multiscreen, Millipore, Bedford, MA, EUA) foram sensibilizadas com 10 $\mu \mathrm{g} /$ poço de anticorpo monoclonal (mAb) anti-IFN- $\gamma$ humano (MabTech, Nacka, Suécia), incubado por 1 hora a temperatura ambiente. O excesso de anticorpo foi retirado em duas lavagens utilizando tampão salina-fosfato (PBS phosphate buffer saline). Os sítios livres da membrana de nitrocelulose foram bloqueados com $50 \mu \mathrm{L}$ de R-10 (meio de cultura RPMI-1640 (GIBCO Invitrogen, Grand Island, NY, EUA), suplementado com penicilina, estreptomicina e $10 \%$ de soro bovino fetal, durante 1 hora a $37^{\circ} \mathrm{C}$ com $5 \%$ de $\mathrm{CO}_{2}$.

Células mononucleares do sangue periférico $(\mathrm{CMN})$, isolada em gradiente de densidade Ficol-Hypaque e criopreservadas foram descongeladas, lavadas três vezes com $50 \mathrm{~mL}$ de R-10, a $1.200 \mathrm{rpm}$ por 10 minutos, para retirada de solução de criopreservação e contadas em câmara de Neubauer utilizando o corante vital Azul de Tripan a 0,4\% (Sigma Aldrich, St. Louis, MA, EUA). A suspensão de células teve a concentração ajustada para $2 \times 10^{6}$ células $/ \mathrm{mL}$. Desta suspensão final foram utilizados $50 \mu \mathrm{L}$ em cada poço da placa.

Foram adicionados $50 \mu \mathrm{L}$ do pool de peptídeos por poço (na concentração de $10 \mu \mathrm{g} / \mathrm{mL}$ de cada peptídeo por poço), em duplicata e $50 \mu \mathrm{L}$ de solução de $5 \mu \mathrm{g} / \mathrm{mL}$ de fitohemaglutinina (PHA) ou Gag, para controle positivo e, R-10, para controle negativo da reação.

Após 16 a 18 horas de incubação a $37^{\circ} \mathrm{C}$ com $5 \%$ de $\mathrm{CO}_{2}$, as placas foram lavadas duas vezes com PBS e duas vezes com PBS-T (PBS contendo $1 \%$ de Tween-20, Fischer Scientific, Fair Lawn, NJ, EUA). Após a lavagem, as placas foram incubadas com $50 \mu \mathrm{L}$ de solução de anticorpo antiIFN $\gamma$ humano conjugado com biotina (MabTech, Nacka, Suécia) diluído em PBS-TB (PBS-T com 1\% de albumina bovina sérica (Sigma Aldrich, St. Louis, 
MA, EUA), durante 30 minutos a temperatura ambiente. $O$ excesso de anticorpo anti-IFN $\gamma$ humano biotinilado foi retirado com duas lavagens utilizando PBS-T.

A presença de $\mathrm{CMN}$ produtoras de IFN- $\gamma$ foi detectada por meio da incubação de estreptoavidina conjugada com fosfatase alcalina (Jackson Immuno Research Lab), por 1 hora a temperatura ambiente. Após esta incubação, a placa foi lavada duas vezes com PBS-T e mergulhada nesta solução por 1 a 2 horas. Após este tempo, a solução de PBS-T foi descartada e $100 \mu \mathrm{L}$ de solução de Vector Stain ${ }^{\mathrm{TM}}$ (Vector Laboratories, Burlingane, CA, EUA) foram adicionados por 15 minutos ou até o aparecimento de pontos (spots) azuis nos poços de controle positivo, representando reação positiva.

O número de $\mathrm{CMN}$ produtoras de IFN- $\gamma$ (células formadoras de pontos ou spots - CFS) por poço foi determinado com auxílio do equipamento AID reader (AID, Oberkochem, Alemanha). Os resultados foram expressos em número de células formadoras de spots por um milhão de células mononucleares (CFS $/ 10^{6} \mathrm{CMN}$ ), e os poços foram considerados positivos, quando a média de CFS da duplicata foi de no mínimo cinco spots a mais e duas vezes o número de spots médio observado nos poços de controle negativo.

\subsection{Análise estatística}

Os resultados obtidos com amostras de diferentes grupos de participantes foram comparados utilizando métodos não paramétricos, considerando diferença com significância estatística quando valor crítico de $p$ foi inferior a 0,05 . 


\section{RESULTADOS}

\subsection{População estudada}

Neste estudo, foram avaliados 46 pacientes com idade variando entre 20 e 58 anos, sendo três do sexo feminino e 43 do sexo masculino.

As amostras utilizadas neste estudo foram coletadas nas visitas 1 $(n=3), 2$ ( $n=21), 3(n=8), 4 \quad(n=13)$ e $5(n=1)$ e criopreservadas em nitrogênio líquido até o momento do ensaio. A primeira visita ocorreu três meses após o teste STAHRS ser positivo, e as demais visitas, ocorreram a cada três meses após a visita anterior.

De acordo com os resultados do STAHRS, obtidos a partir do banco de dados dos voluntários no projeto original, o tempo de infecção pósSTAHRS (170 dias) dos pacientes no momento da coleta da amostra utilizada neste estudo variou entre 14 e 496 dias, com tempo médio de infecção de 54, 125, 224, 343 e 496 dias, nas visitas 1, 2, 3, 4 e 5, respectivamente.

Dos 46 pacientes 33 não apresentavam sintomas compatíveis com o quadro de infecção aguda $(71,7 \%)$ e o valor médio à primeira determinação da contagem de linfócitos T CD4+ e T CD8+, obtidos do banco de dados do laboratório, foi de $596 \pm 224$ células $/ \mu \mathrm{L}$ e $922 \pm 522$ células $/ \mu \mathrm{L}$, respectivamente. A carga viral plasmática de HIV-1 variou entre 49 (1,69log) e 437.000 (5,64 log) cópias/mL.

Dos 46 pacientes estudados, a deleção de 32 pares de base no gene CCR5 (ccr5 $\Delta 32$ ) foi observada em sete pacientes (17\%) dentre aqueles que possuíam esta informação $(n=41)$.

Ao avaliar o tratamento destes pacientes ao longo do tempo de acompanhamento, até agosto de 2011, observou-se que nove dos 46 pacientes faziam uso de algum esquema terapêutico com medicamentos antiretrovirais (ART), representando assim 19\% do total.

A progressão da infecção pelo HIV-1 foi avaliada considerando-se o parâmetro de carga viral plasmática ao longo do tempo de acompanhamento 
(com exceção de quatro pacientes, que foram acompanhados até a visita 4), em média de 23 visitas para cada paciente, correspondendo ao total aproximado de 67 meses, até agosto de 2011.

Baseado na quantificação de carga viral plasmática, os pacientes foram então, agrupados em: (1) controladores avirêmicos, os pacientes que possuíam carga viral indetectável, inferior ao limite mínimo de detecção do teste à epoca, (2) controladores virêmicos, os pacientes que apresentavam carga viral de até 2.000 cópias $/ \mathrm{mL}$, e (3) progressores virêmicos, os pacientes que possuíam carga viral acima de 2.000 cópias $/ \mathrm{mL}$, todos eles sem tratamento antiretroviral. (Casado et al., 2010; Saag \& Deeks, 2010; Okulicz \& Lambotte, 2011).

Na Tabela 1, estão apresentadas as características dos pacientes classificados de acordo com a progressão da infecção pelo HIV-1 baseado na carga viral plasmática. Características de cada paciente podem ser obtidas no Anexo 2.

Diferenças entre os grupos não foram observadas quanto à idade, sexo, etnia, contagem de linfócitos T CD4+ e T CD8+, e freqüência de alelo ccr5 $\Delta 32$. A carga viral plasmática, como esperado, foi significativamente diferente entre os três grupos, conforme avaliado utilizando o Teste de KruskalWallis $(p<0,0001)$. 
Tabela 1 - Características da população estudada após agrupamento baseado no controle da carga viral plasmática ao longo do acompanhamento clínico.

\begin{tabular}{|c|c|c|c|c|}
\hline & \multicolumn{4}{|c|}{ Grupo } \\
\hline & $\begin{array}{c}\text { Controlador } \\
\text { avirêmico (CA) } \\
\end{array}$ & $\begin{array}{c}\text { Controlador } \\
\text { virêmico (CV) }\end{array}$ & $\begin{array}{c}\text { Virêmico } \\
\text { (Vir) }\end{array}$ & $\mathbf{p}$ \\
\hline $\mathbf{N}$ & 13 & 6 & 27 & \\
\hline \multicolumn{5}{|l|}{ Idade (anos) } \\
\hline Mediana & 35 & 34 & 30 & 0,2637 \\
\hline Percentil (25-75\%) & $27,5-39,5$ & $28,5-37,5$ & $25-35$ & \\
\hline \multicolumn{5}{|l|}{ Sexo } \\
\hline Feminino & 0 & 1 & 2 & \\
\hline Masculino & 13 & 5 & 25 & \\
\hline \multicolumn{5}{|l|}{ Etnia } \\
\hline Branco & 6 & 1 & 17 & \\
\hline Mulato / Negro & 5 & 5 & 8 & \\
\hline Outro / Não informado & 2 & --- & 2 & \\
\hline \multicolumn{5}{|l|}{ Sintomas } \\
\hline Assintomáticos & 8 & 5 & 19 & \\
\hline Sintomáticos & 3 & 1 & 8 & \\
\hline Não informado & 2 & --- & --- & \\
\hline \multicolumn{5}{|l|}{ CD4 (células $/ \mu L$ ) } \\
\hline Mediana & 621 & 608 & 513 & 0,4792 \\
\hline Percentil (25-75\%) & $503,5-863$ & $457-669$ & $415,5-712$ & \\
\hline \multicolumn{5}{|l|}{ CD8 (células $/ \mu L$ ) } \\
\hline Mediana & 793 & 806,5 & 921 & 0,2251 \\
\hline Percentil (25-75\%) & $408-949,5$ & $482-1023$ & $646-1213$ & \\
\hline \multicolumn{5}{|l|}{ Viremia (cópias/mL)* } \\
\hline Mediana & 399 & 1120 & 22.900 & $<0,0001$ \\
\hline Percentil (25-75\%) & $399-399$ & $547,5-1635$ & $7145-77.850$ & \\
\hline \multicolumn{5}{|l|}{ Alelos de HLA ligante dos ARFs } \\
\hline HLA-A*02 & 4 & 2 & 14 & \\
\hline HLA-B*07 & 2 & --- & 7 & \\
\hline HLA-B*57 & 8 & 1 & 3 & \\
\hline HLA-B*58 & 1 & --- & 2 & \\
\hline \multicolumn{5}{|l|}{ CCR5 } \\
\hline$(+/+)$ & $9(69,2 \%)$ & $4(66,7 \%)$ & $20(74,1 \%)$ & \\
\hline$(+/ \Delta-32)$ & $2(15,4 \%)$ & --- & $5(18,5 \%)$ & \\
\hline Não informado & 2 & 2 & 2 & \\
\hline \multicolumn{5}{|l|}{ Uso de antiretrovirais (ART) } \\
\hline Sim & $1(7,7 \%)$ & $1(16,7 \%)^{*}$ & $7(25,9 \%)^{*}$ & \\
\hline Não & $12(92,3 \%)$ & $5(83,7 \%)$ & $20(74,1 \%)$ & \\
\hline
\end{tabular}

$\mathrm{n}=$ número de amostras. $\mathrm{p}=$ obtido pelo Teste de Kruskal-Wallis, ARFs= refere-se aos peptídeos crípticos selecionados para este estudo. *ART foi introduzido em momento posterior a data da amostra utilizada no estudo. 


\subsection{Frequência de resposta imunológica celular específica contra peptídeos crípticos}

Todos os 46 pacientes foram avaliados quanto à resposta contra os 22 pools de peptídeos crípticos, utilizando o ensaio de ELISPOT para IFN $\gamma$.

A porcentagem de indivíduos que responderam contra pelo menos um pool de peptídeo críptico, os quais serão referidos neste trabalho como pacientes respondedores, foi de $39,1 \%$, isto é, 18 dos 46 pacientes.

Quanto às subpopulações de células, a contagem de linfócitos $T$ CD4+ nos pacientes respondedores (média \pm desvio padrão $=703 \pm 262$ células $/ \mu \mathrm{L}$ ) foi significativamente maior que a contagem observada nos pacientes não-respondedores (média \pm desvio padrão $=528 \pm 166$ células $/ \mu \mathrm{L}$ ) $(p=0,0179$, teste $t$-Student), como demonstrados na Figura 2A. Por outro lado, a contagem de linfócitos T CD8+ observada nos pacientes respondedores (média \pm desvio padrão= $1.050 \pm 591$ células $/ \mu \mathrm{L}$ ) não foi diferente daquela observada em pacientes não-respondedores (média \pm desvio padrão $=839 \pm$ 466 células $/ \mu \mathrm{L})(\mathrm{p}=0,2112$ - teste $t$-Student), como demonstrada na Figura 2B.

A carga viral plasmática dos pacientes respondedores (média \pm desvio padrão $=30.550 \pm 93.828$ cópias $/ \mathrm{mL}$ ) não foi diferente daquela observada entre os pacientes não-respondedores (média \pm desvio padrão= $56.547 \pm 52.031$ cópias $/ \mathrm{mL})(p=0,3999$, teste $t$-Student), como demonstrado na Figura 2C. 
(A) Linfócitos T CD4+

$p=0,0179$

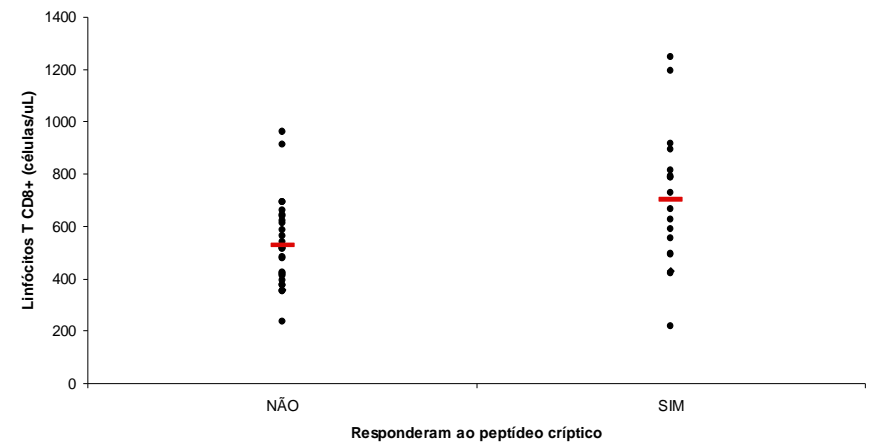

(B) Linfócitos T CD8+

$p=0,2112$

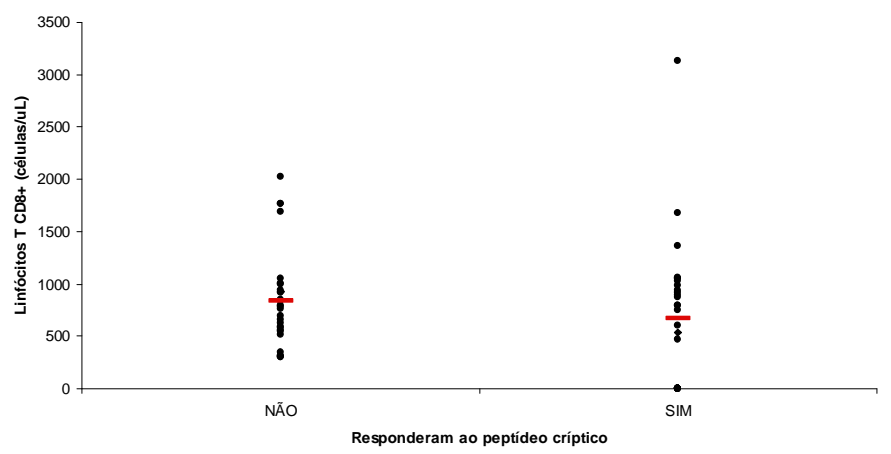

(C) Carga viral plasmática

$\mathrm{p}=0,3999$

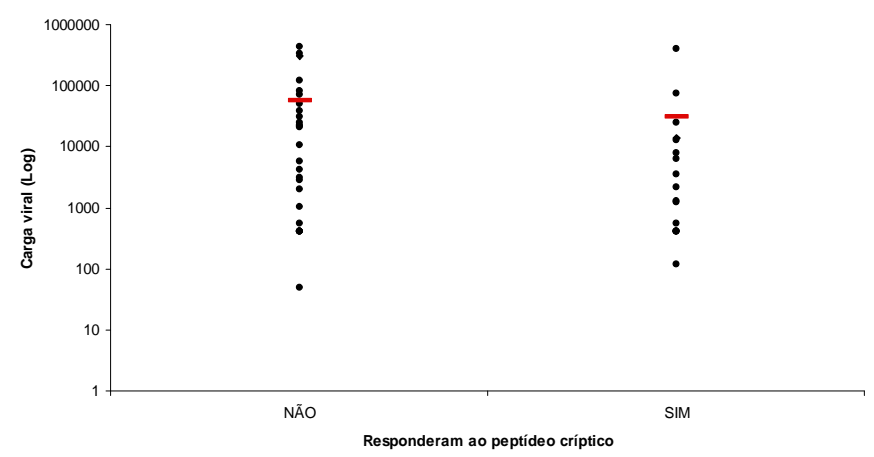

Figura 2 - Determinação da contagem de linfócitos T CD4+ e T CD8+ e carga viral plasmática de HIV-1 nos pacientes respondedores e nãorespondedores aos peptídeos crípticos. (A) contagem de linfócitos T CD4+, (B) contagem de linfócitos T CD8+, e (C) Carga viral plasmática, nos pacientes respondedores e não-respondedores contra algum pool de peptídeos crípticos. Análise estatística foi realizada utilizando teste $t$-Student. 
Agrupando os pacientes de acordo com a progressão da infecção, baseado no controle da carga viral plasmática, nós avaliamos 19 pacientes classificados como controladores, que por sua vez compreende os controladores avirêmicos ou de elite $(n=13)$ e os controladores virêmicos $(n=6)$ e, 27 pacientes progressores virêmicos, cujas características foram descritas anteriormente na Tabela 1.

A resposta imune contra pelo menos um pool de peptídeos crípticos foi observada em $33,3 \%$ dos pacientes progressores e em $47,3 \%$ dos pacientes controladores. Esta diferença significativa ( $p=0,031$, teste $t$-Student) na freqüência de resposta contra pools de peptídeos crípticos entre os grupos está demonstrada na Figura 3.

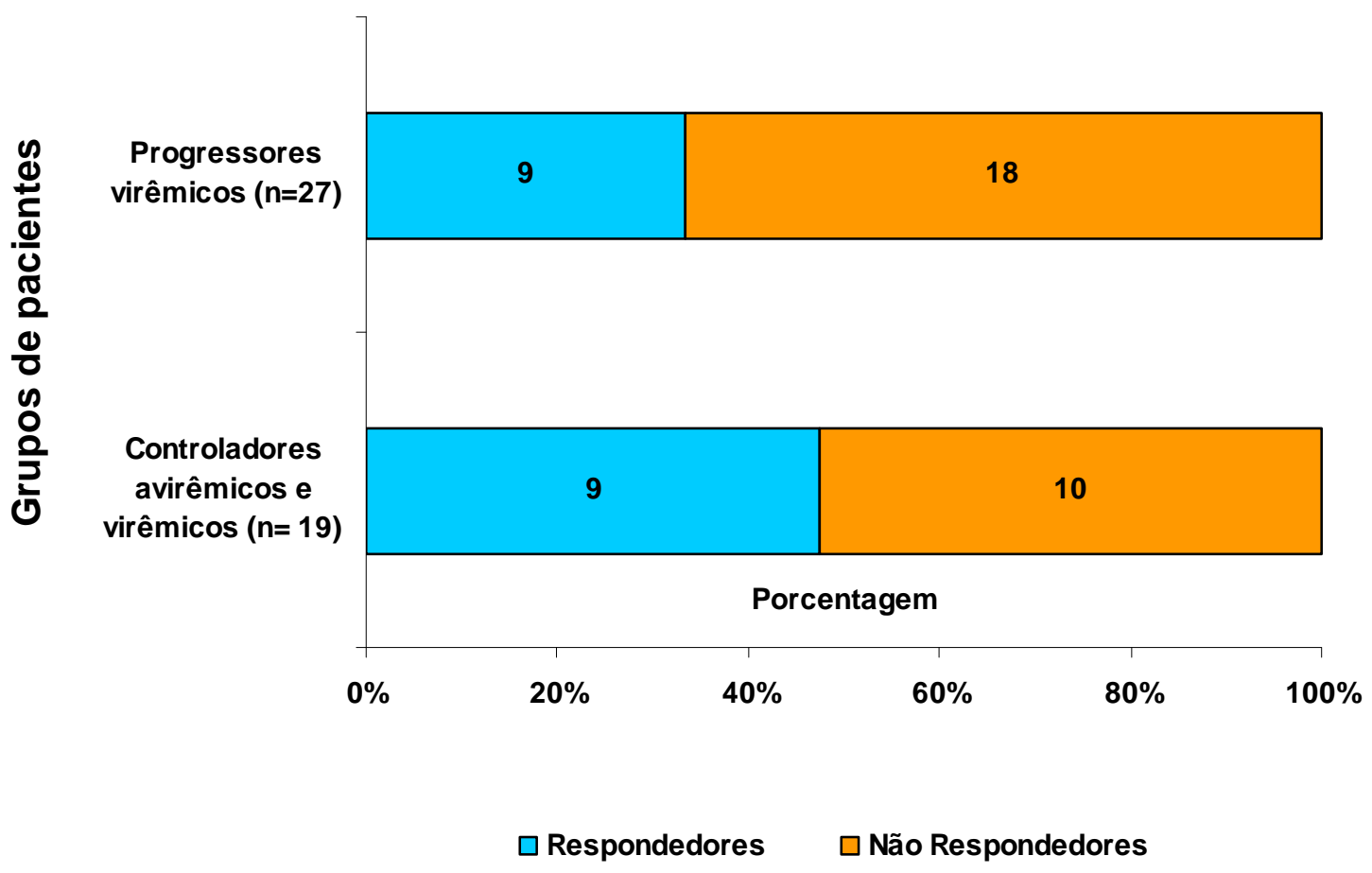

Figura 3 - Porcentagem de resposta imune contra peptídeos crípticos na população estudada. Número de amostras provenientes de pacientes de cada grupo que responderam ou não a pelo menos um pool de peptídeos crípticos. Análise estatística foi realizada utilizando teste $t$-Student, $\mathrm{p}=0,031$. 
A frequência de alelos de HLA- $A^{*} 02$, $-B^{*} 07$ e $-B^{*} 58$, alelos aos quais se ligam os peptídeos crípticos avaliados, nos pacientes respondedores e não-respondedores, dos grupos de pacientes controladores e progressores está representada na Figura 4.

Diferente do que esperávamos, observamos que não houve maior presença de alelos HLA ligantes dos peptídeos crípticos estudados comparando-se os pacientes respondedores e não-respondedores.

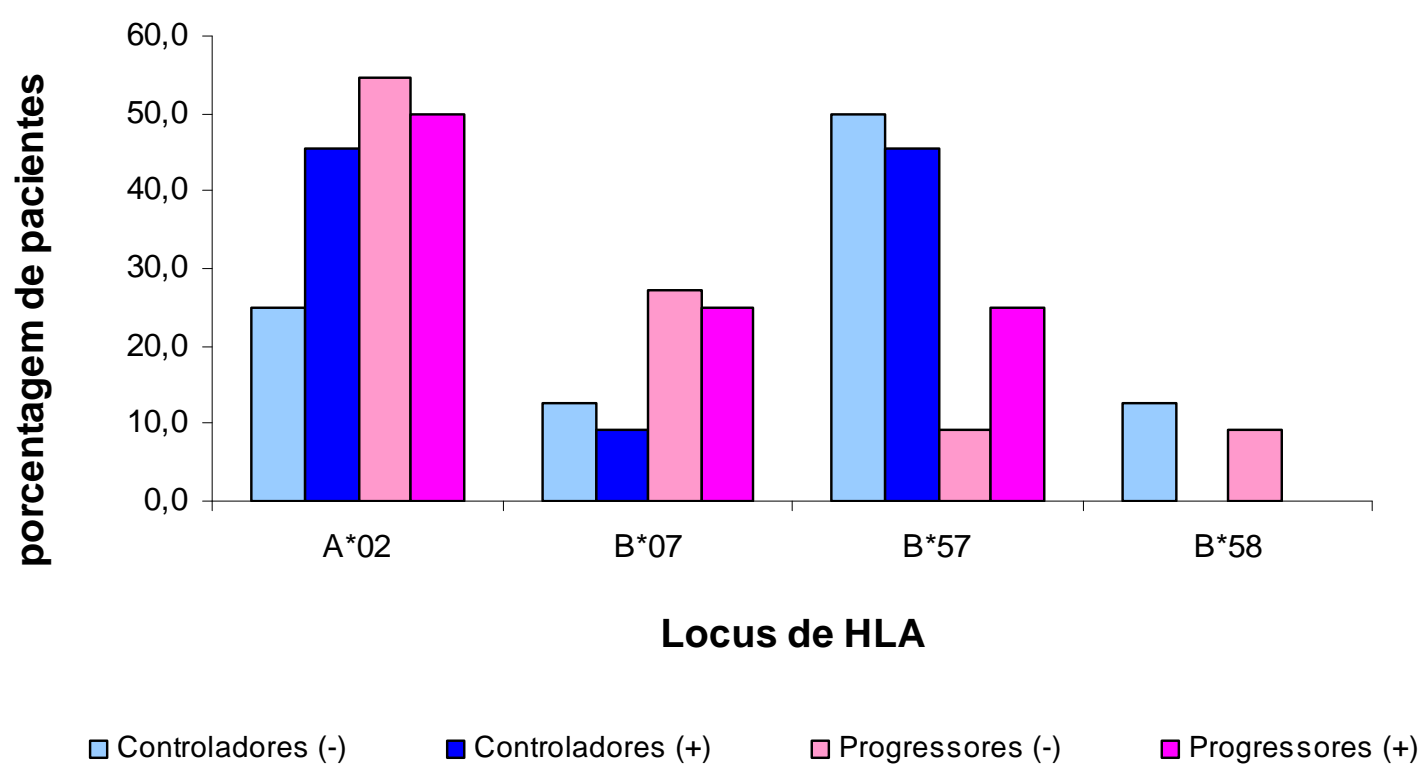

Figura 4 - Porcentagem de pacientes que expressam alelos de HLA ligantes dos peptídeos crípticos avaliados. Os peptídeos crípticos avaliados neste estudo são apresentados por um dos quatro alelos: HLA-A*02, - $B^{*} 07$, $B^{\star} 57$ e $-B^{\star} 58$. Não foi levado em consideração se o alelo estava presente em hetero ou homozigose. Nesta figura os pacientes estão representados conforme o grupo (controladores e progressores) e a resposta a pelo menos 1 pool de peptídeos crípticos $((-)=$ não-respondedores e $(+)=$ respondedores $)$. 
Quando avaliamos o número de pacientes que responderam para os pools de peptídeos crípticos avaliados, observamos que o pool de peptídeos crípticos número 15 (ARF\# 15) foi capaz de induzir resposta imune em sete pacientes, sendo cinco do grupo de controladores e dois do grupo de progressores. Seguido dos pools ARF\# 2 e 11, que foram capazes de induzir resposta imune em seis pacientes, de igual distribuição entre os grupos e, dos pools ARF\# 14 e 21, os quais induziram resposta imune em cinco pacientes, sendo três do grupo de controladores e dois do grupo de progressores para o pool ARF\# 14 e quatro do grupo de controladores e um do grupo de progressores para o pool ARF\# 21, como demonstrado na Figura 5.

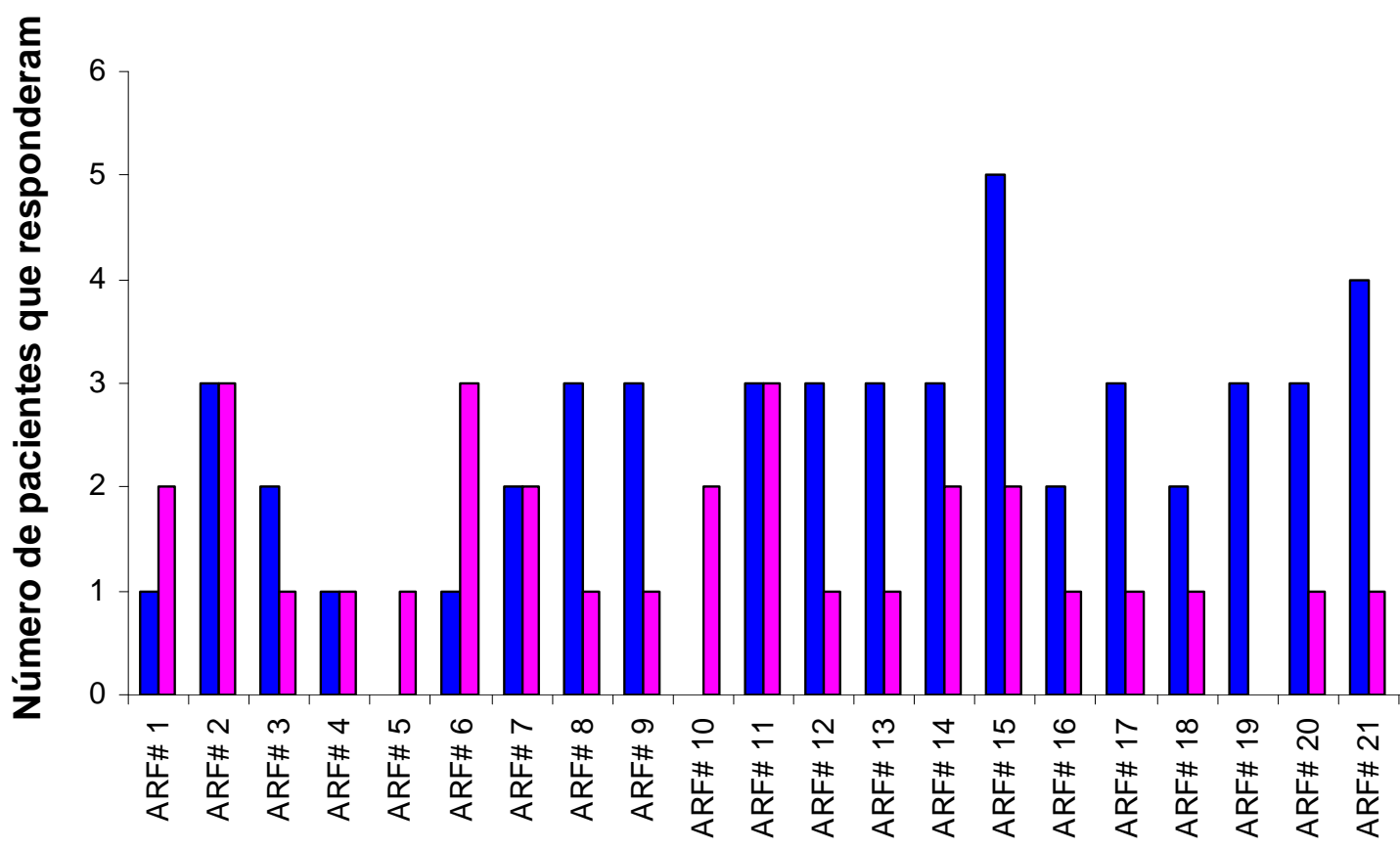

Pool de peptídeos crípticos (ARF\#)

Figura 5 - Número de pacientes que responderam a cada pool de peptídeo críptico avaliado neste estudo. ARF\# é o número de pool de peptídeos crípticos estudado. Os resultados representam o número de pacientes do grupo de controladores (barra azul) e do grupo de progressores (barra rosa) que responderam a determinado pool. Um total de nove pacientes de cada grupo responderam a pelo menos um pool de peptídeos crípticos. 
Os dois grupos de pacientes responderam cada um contra 20 pools de peptídeos crípticos do total de 22 avaliados, sendo que dois pools (ARF\# 19 e 22) induziram resposta apenas nos pacientes do grupo de controladores e dois pools (ARF\# 5 e 10), apenas nos pacientes do grupo de progressores.

\subsection{Amplitude e magnitude da resposta imunológica celular específica contra peptídeo críptico}

Para determinar a amplitude da resposta imune mediada por linfócitos T contra peptídeos crípticos, nós consideramos o número de pools de peptídeos crípticos contra os quais cada paciente respondeu. Para avaliar a magnitude, levamos em consideração a média de $\mathrm{CFS} / 10^{6} \mathrm{CMN}$ dos pacientes respondedores de cada grupo, para cada pool de peptídeos crípticos.

O número de pools de peptídeos crípticos contra os quais os pacientes responderam variou entre um e 16 pools no grupo de controladores e de um a 14 pools no grupo de progressores.

A amplitude de resposta observada no grupo de pacientes controladores (média \pm desvio padrão $=5,6 \pm 5,7$ ) foi maior do que a observada no grupo de pacientes progressores (média \pm desvio padrão= $3,4 \pm 4,3$ ). Enquanto que no grupo de controladores três de nove pacientes $(66,7 \%)$ responderam contra mais de um pool de peptídeos crípticos, entre os progressores foi observado em cinco dos nove pacientes respondedores (44,4\%), como demonstrado na Figura 6. 


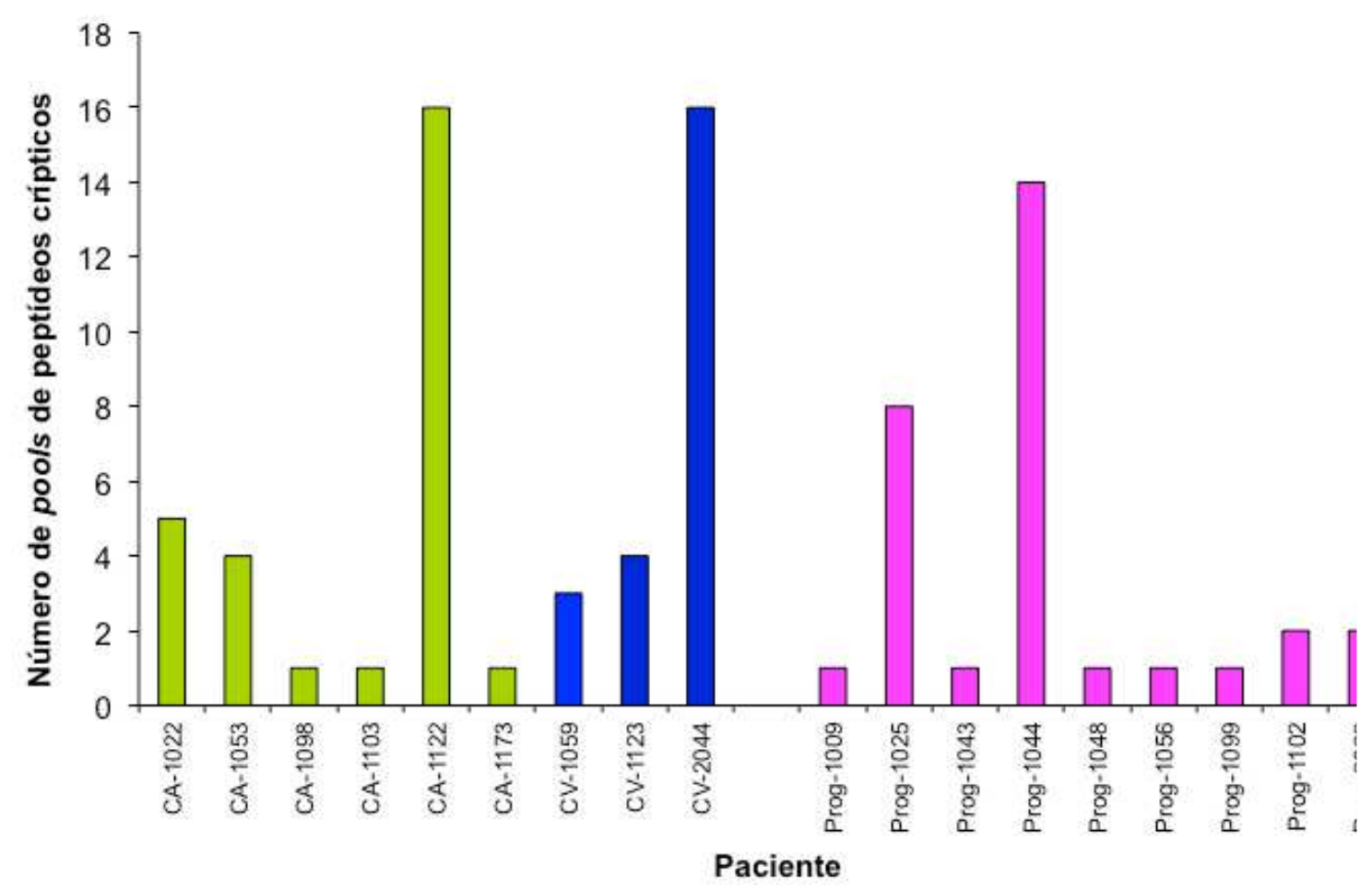

Figura 6 - Número de pools de peptídeos crípticos contra os quais cada paciente dos grupos de controladores e progressores respondeu. CA e $\mathrm{CV}=$ pacientes do grupo de controladores, respectivamente avirêmicos e virêmicos, e Prog= pacientes do grupo de progressores, seguidos da identificação do pacientes codificado.

A magnitude de resposta imunológica específica contra pools de peptídeos crípticos, determinada pela média ( \pm desvio padrão) do número de células formadoras de pontos (spot) por milhão de células mononucleares (CFS $/ 10^{6} \mathrm{CMN}$ ) de todos os pacientes que responderam para determinado pool foi de $237 \pm 144 \mathrm{CFS} / 10^{6} \mathrm{CMN}$.

Quando analisamos os grupos de pacientes, observamos que a média ( \pm desvio padrão) de resposta imunológica do grupo de controladores $\left(290 \pm 115 \mathrm{CFS} / 10^{6} \mathrm{CMN}\right)$ foi significativamente maior que a média apresentada pelos pacientes do grupo de progressores $\left(147 \pm 150 \mathrm{CFS} / 10^{6}\right.$ CMN) ( $p=0,00003$, teste $t$-Student). A média de resposta, em CFS $/ 10^{6} \mathrm{CMN}$, de cada grupo de pacientes, para cada pool está demonstrada na Figura 7. 


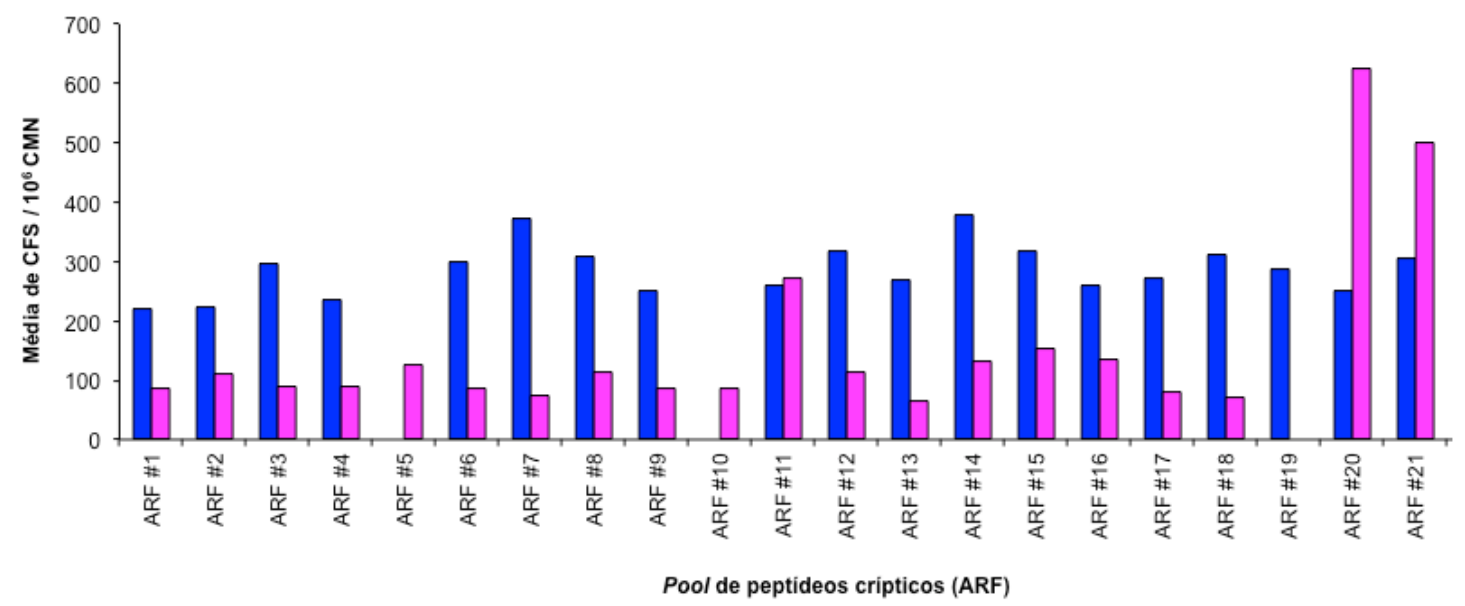

Figura 7 - Magnitude de resposta imunológica celular específica contra pools de peptídeos crípticos. Os resultados estão representados pela média de $\mathrm{CFS} / 10^{6} \mathrm{CMN}$ de cada grupo de pacientes para cada pool. A média do resultado do grupo de pacientes controladores foi de $290 \pm 115 \mathrm{CFS} / 10^{6} \mathrm{CMN}$ e do grupo de pacientes progressores, de $147 \pm 150 \mathrm{CFS} / 10^{6} \mathrm{CMN}$. ARF= número do pool de peptídeos crípticos. A diferença entre os grupos foi significativa, com $\mathrm{p}=0,00003$, pelo teste $t$-Student.

Três pacientes do grupo de controladores e cinco pacientes do grupo de progressores responderam somente contra um pool. A magnitude de resposta de cada um destes pacientes está representada na Figura 8.

Dentre os demais pacientes respondedores, observamos que dois pacientes controladores (Figura 9) e um paciente progressor (Figura 10) responderam contra mais de $50 \%$ dos pools testados. 


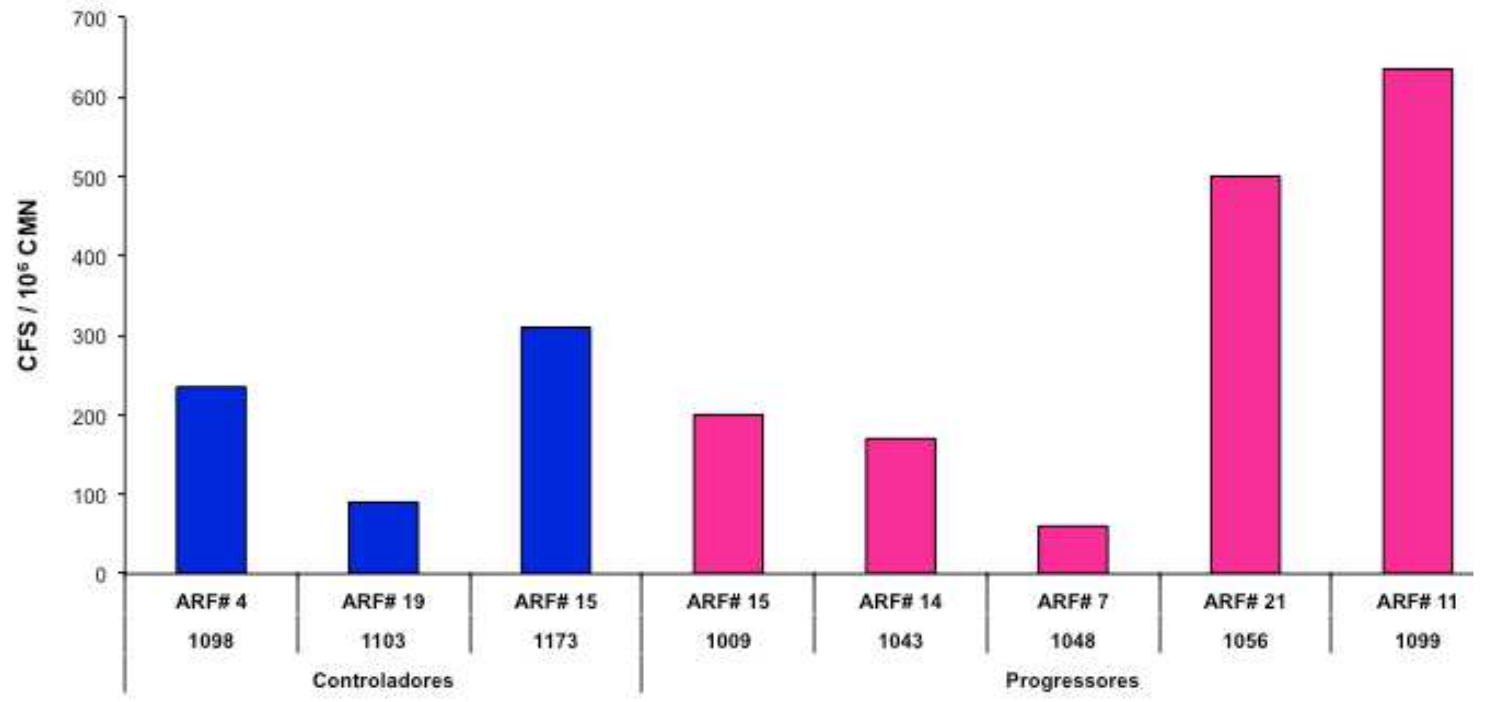

Paciente

Figura 8 - Magnitude de resposta imunológica apresentada por células mononucleares de pacientes que responderam contra apenas um pool de peptídeos crípticos. Pacientes do grupo de controladores (representado em azul) e de progressores (representado em rosa) que responderam contra apenas um pool de peptídeos crípticos. ARF= número do pool de peptídeos crípticos contra o qual o paciente respondeu. 

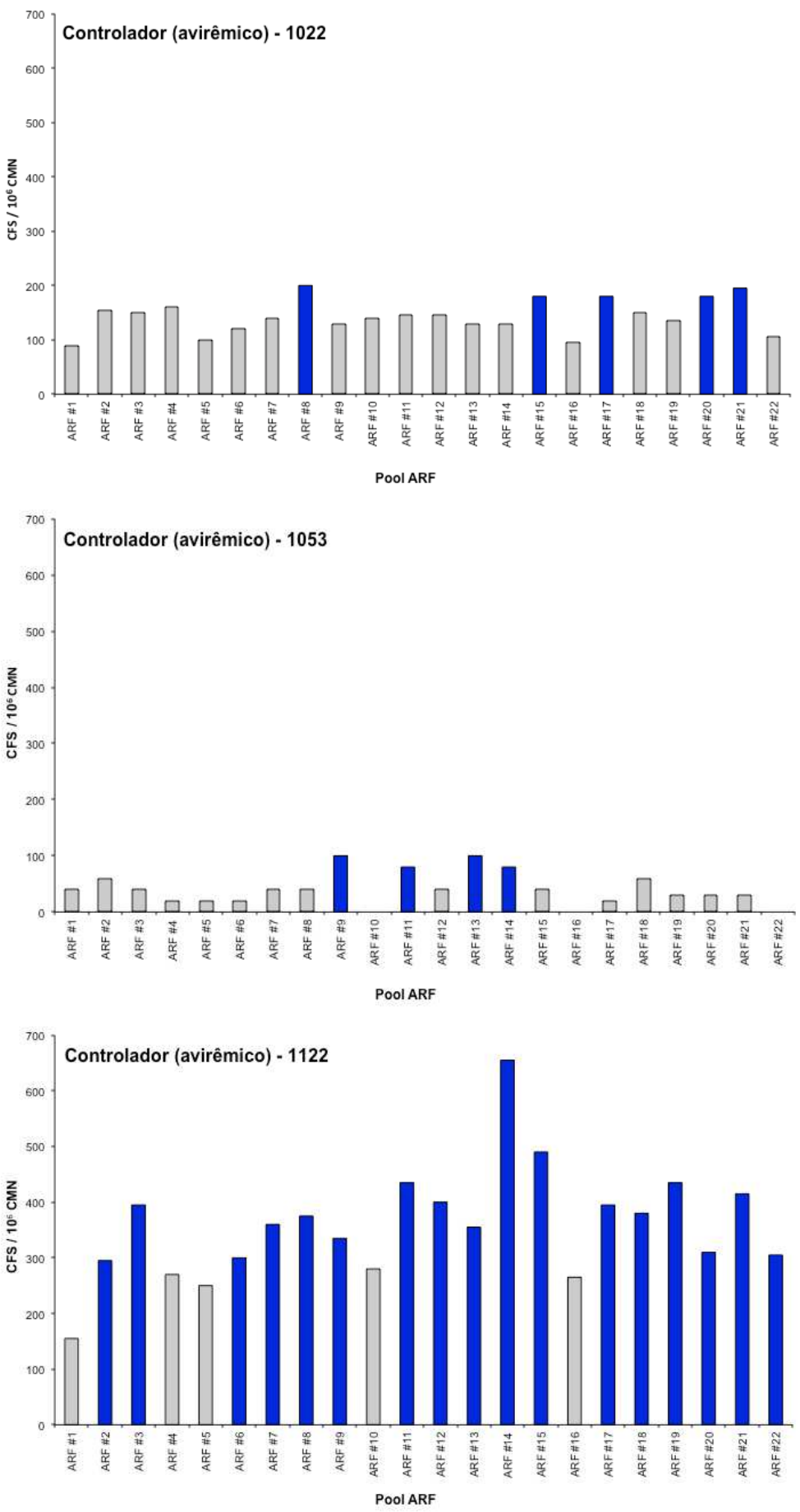

Figura 9 - Magnitude de resposta imune apresentada por células mononucleares provenientes de pacientes controladores que responderam contra mais de um pool de peptídeos crípticos. Colunas em azul representam resultados positivos e colunas em cinza representam magnitude de resultados negativos de cada paciente. 

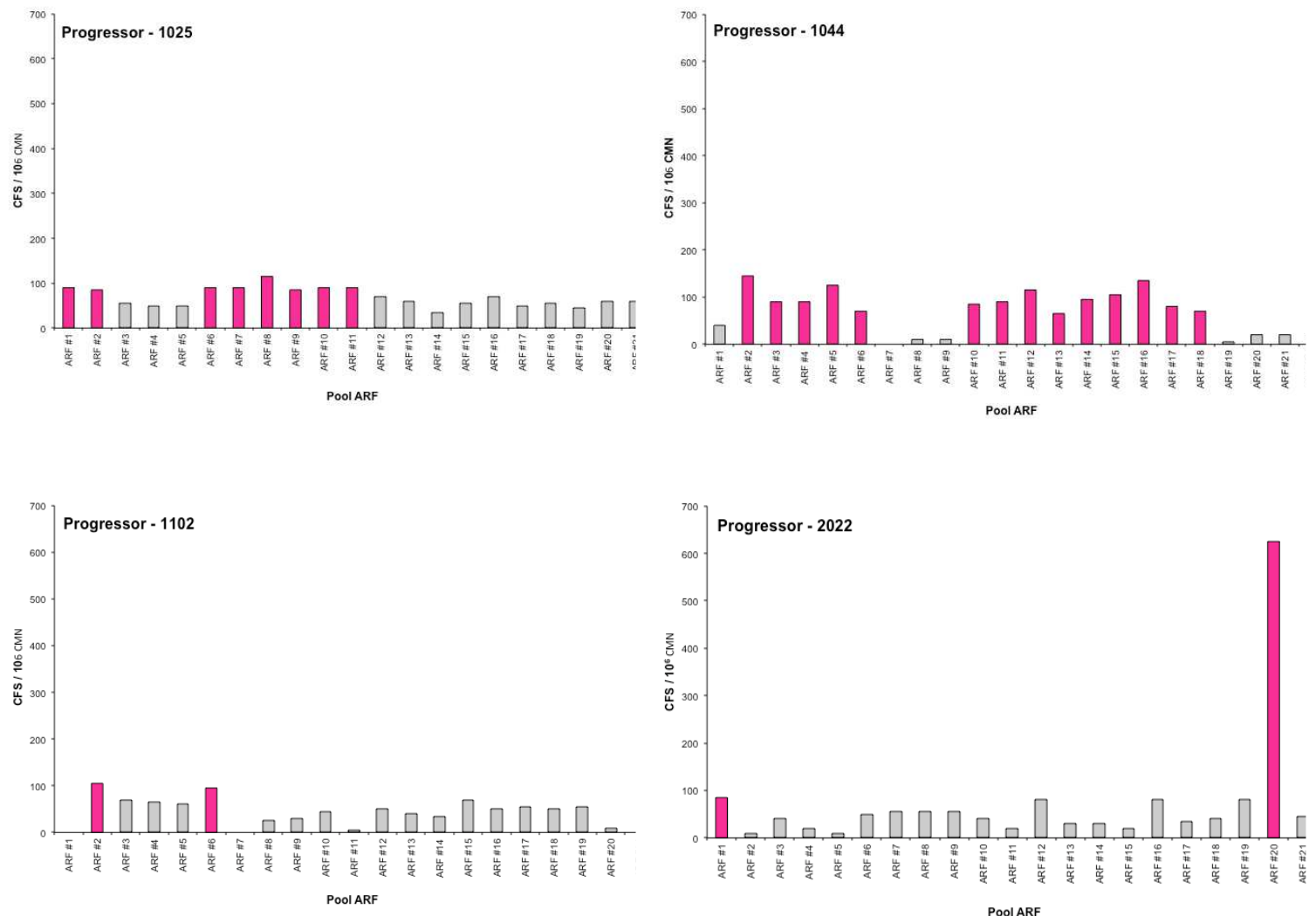

Figura 10 - Magnitude de resposta imune apresentada por células mononucleares provenientes de pacientes progressores que responderam contra mais de um pool de peptídeos crípticos. Colunas em rosa representam resultados positivos e colunas em cinza representam magnitude de resultados negativos de cada paciente. 


\subsection{Correlação da resposta imune celular contra peptídeos crípticos e contagem de linfócitos TCD4+, TCD8+e viremia plasmática}

Para avaliarmos a possível correlação de resposta imune contra peptídeos crípticos com os parâmetros laboratoriais de monitoramento dos pacientes infectados com HIV, isto é, contagem de linfócitos T CD4+, T CD8+e viremia plasmática ou carga viral, consideramos a somatória da resposta obtida contra cada pool expressa em $\mathrm{CFS} / 10^{6} \mathrm{CMN}$.

Ao contrário do que foi observado quando comparamos respondedores e não respondedores, onde valores de linfócitos T CD4+ eram maiores entre os pacientes respondedores, conforme apresentado anteriormente no item 4.2, nesta análise não observamos correlação entre resposta imune contra peptídeos crípticos e os parâmetros de monitoramento, como demonstrado na Figura 11. 
Controladores

Progressores

(A) Linfócitos T CD4+
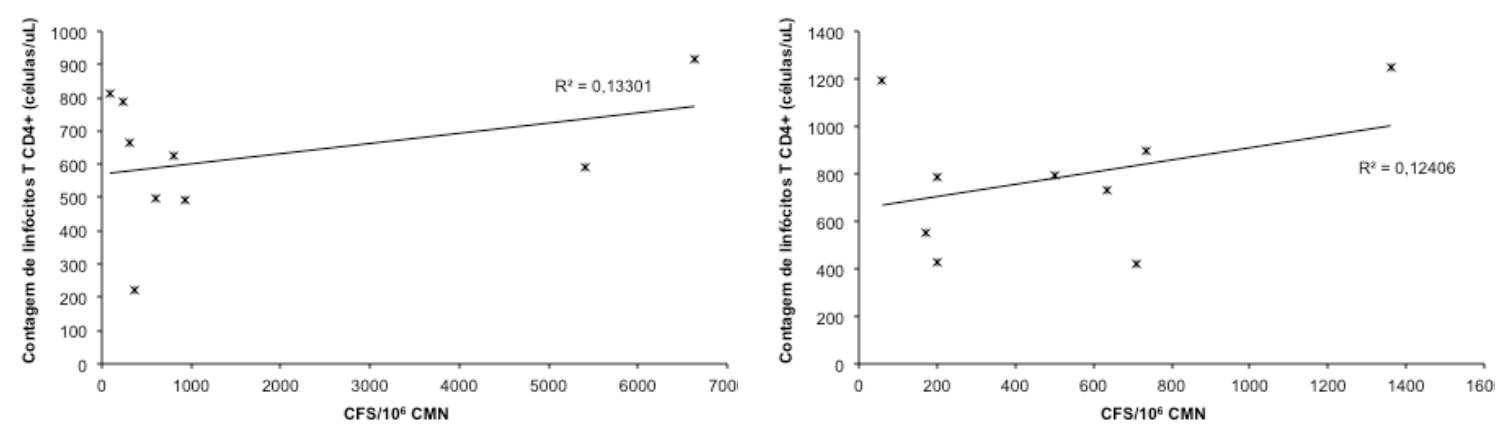

(B) Linfócitos T CD8+
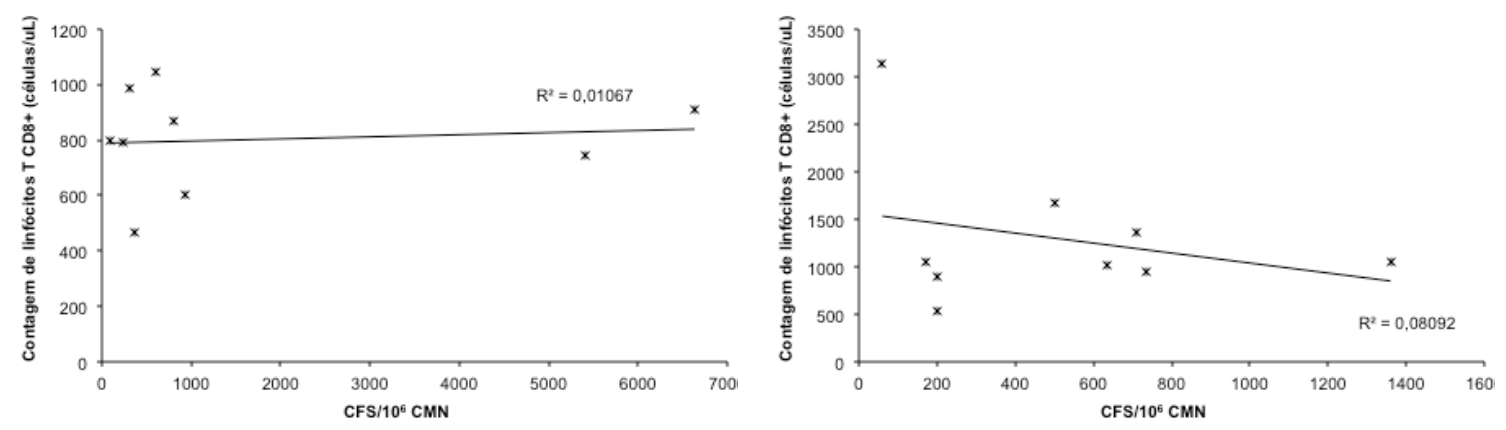

(C) Carga viral plasmática
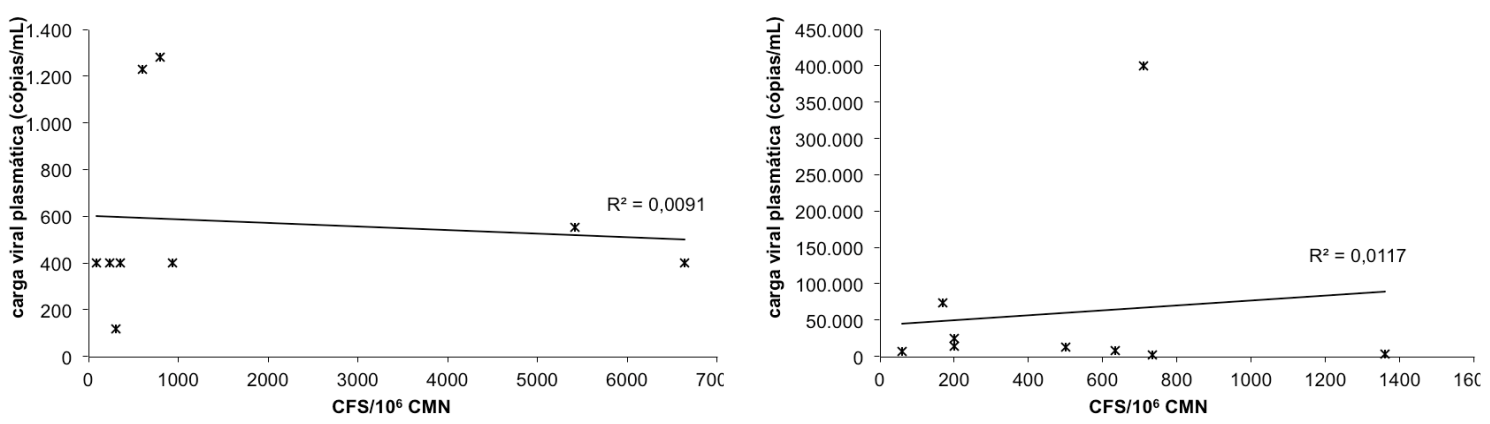

Figura 11 - Correlação da magnitude de resposta imunológica contra peptídeos crípticos e contagem de linfócitos T CD4+ (A) e T CD8+ (B) e carga viral plasmática de HIV-1 (C) nos pacientes dos grupos controladores e progressores. Análise estatística apresentou $p>0,05$ para todas as comparações apresentadas. 


\subsection{Especificidade da resposta imune celular específica contra peptídeo críptico}

Para avaliarmos a especificidade da resposta imunológica celular contra peptídeos crípticos, avaliamos a reatividade das CMN de quatro dos 18 pacientes que responderam contra a pelo menos um pool de peptídeos crípticos.

Para esta avaliação, os peptídeos crípticos que compunham o pool contra o qual as $\mathrm{CMN}$ dos pacientes reagiram, foram testados individualmente em duas concentrações finais, de 10 e $100 \mu \mathrm{g} / \mathrm{mL}$.

Dos quatro pacientes avaliados, três são do grupo de pacientes controladores (avirêmicos: 1098 e 1173, e virêmico: 1099) e um do grupo de pacientes progressores (1102).

Dos quatro pacientes testados, foi possível determinar especificidade de resposta apenas para o paciente 1098, que respondeu contra o pool ARF\# 4. Dentre os peptídeos crípticos que compõe o pool ARF\# 4, os de \# 422 e 429 foram capazes de induzir resposta, mas somente o peptídeo \# 429 foi capaz de induzir resposta na concentração de $10 \mu \mathrm{g} / \mathrm{mL}$. Desta forma, atribuímos a especificidade da resposta imunológica contra o pool ARF\# 4 ao peptídeo \# 429. Todos os resultados estão demonstrados na Figura 12. 
(A)

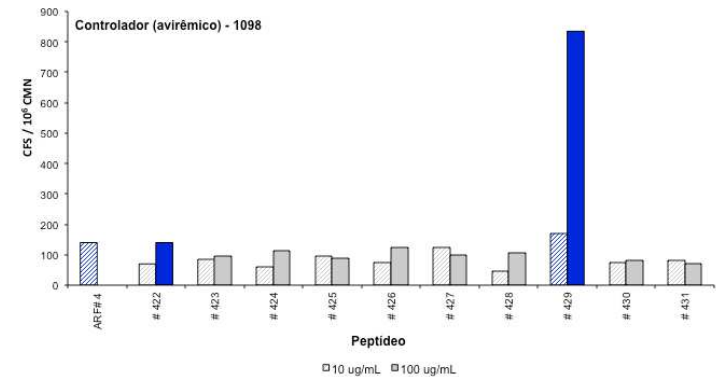

(C)

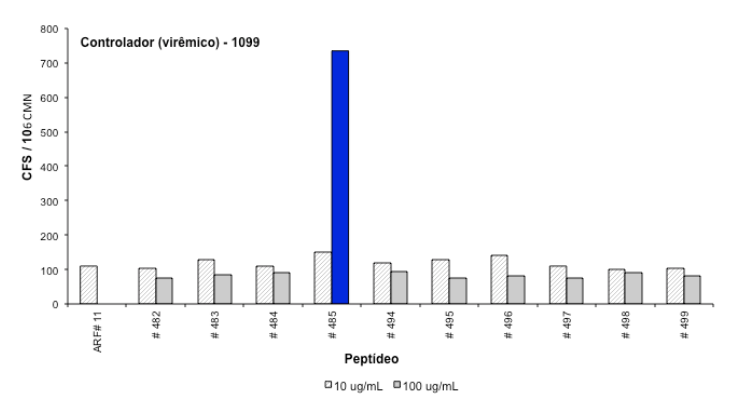

(D)

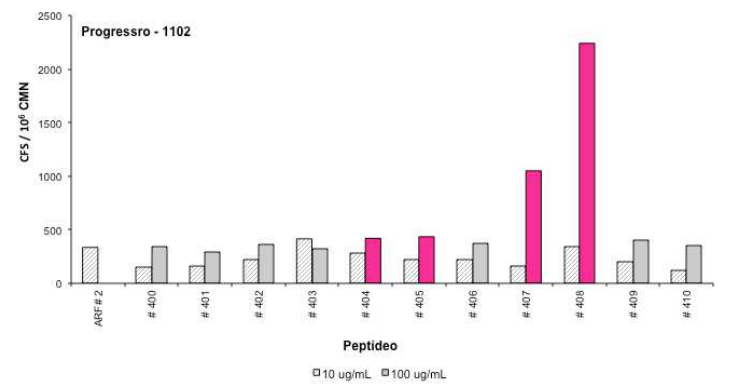

(B)

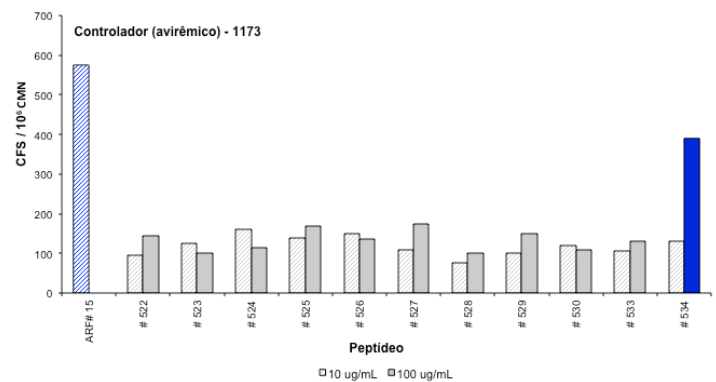

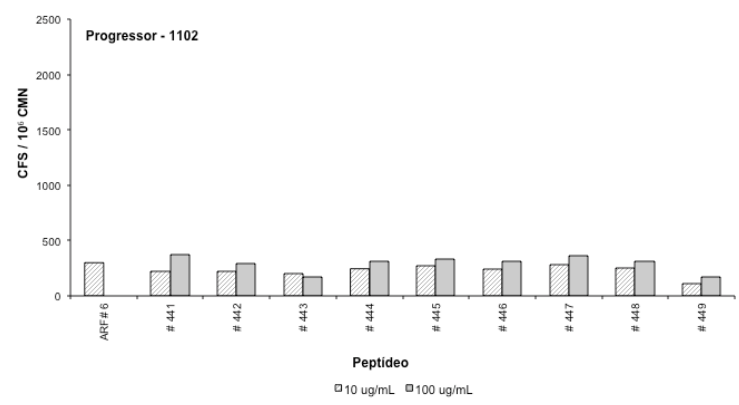

Figura 12 - Magnitude da resposta imunológica específica contra peptídeos crípticos que compõem os pools testados. Resposta de CMN proveniente dos pacientes controladores 1098 (A), 1173 (B) e 1099 (C) e, paciente progressor $(C)$, este testadas contra peptídeos componentes de dois pools (ARF\# 2 e 6). Todos os peptídeos crípticos foram avaliados nas concentrações de 10 e $100 \mu \mathrm{g} / \mathrm{mL}$. Os resultados positivos estão representados em azul (paciente controlador) ou rosa (paciente progressor). Colunas rajadas representam a concentração de $10 \mu \mathrm{g} / \mathrm{mL}$ de peptídeo críptico testado e colunas sólidas, concentração de $100 \mu \mathrm{g} / \mathrm{mL}$. 


\subsection{Resposta imune celular contra peptídeo críptico na fase tardia da infecção}

Com o intuito de verificar a possível manutenção da resposta imune celular contra peptídeos crípticos ao longo da infecção, foi avaliada amostra coletada em uma fase posterior da infecção. Essa amostra coletada aproximadamente cinco anos após o início da infecção (entre 5,3 e 6,7 anos, média \pm desvio padrão $=6 \pm 0,4$ anos), que chamaremos de amostra de fase tardia, foi obtida de 15 dos 18 pacientes que responderam na fase aguda contra algum dos pools de peptídeos crípticos.

Dos 15 pacientes testados, sete eram do grupo de controladores e oito, do grupo de progressores. Enquanto neste último grupo, cinco pacientes mantiveram a resposta, no grupo de controladores somente um paciente manteve resposta contra peptídeos crípticos na fase tardia.

Considerando-se a resposta de todos os pacientes, observa-se que a magnitude de resposta na fase tardia diminuiu comparada a observada na fase aguda. Entretanto, quando os pacientes são analisados individualmente, observamos que dentre os seis pacientes respondedores na fase tardia, apenas um deles teve diminuição no total de resposta contra peptídeos crípticos (paciente progressor 1056: aguda $=500 \mathrm{CFS} / 10^{6} \mathrm{CMN}$ e tardia $=315 \mathrm{CFS} / 10^{6} \mathrm{CMN}$ ), embora tenha mantido sua capacidade de resposta, como demonstrado na Figura 13. 


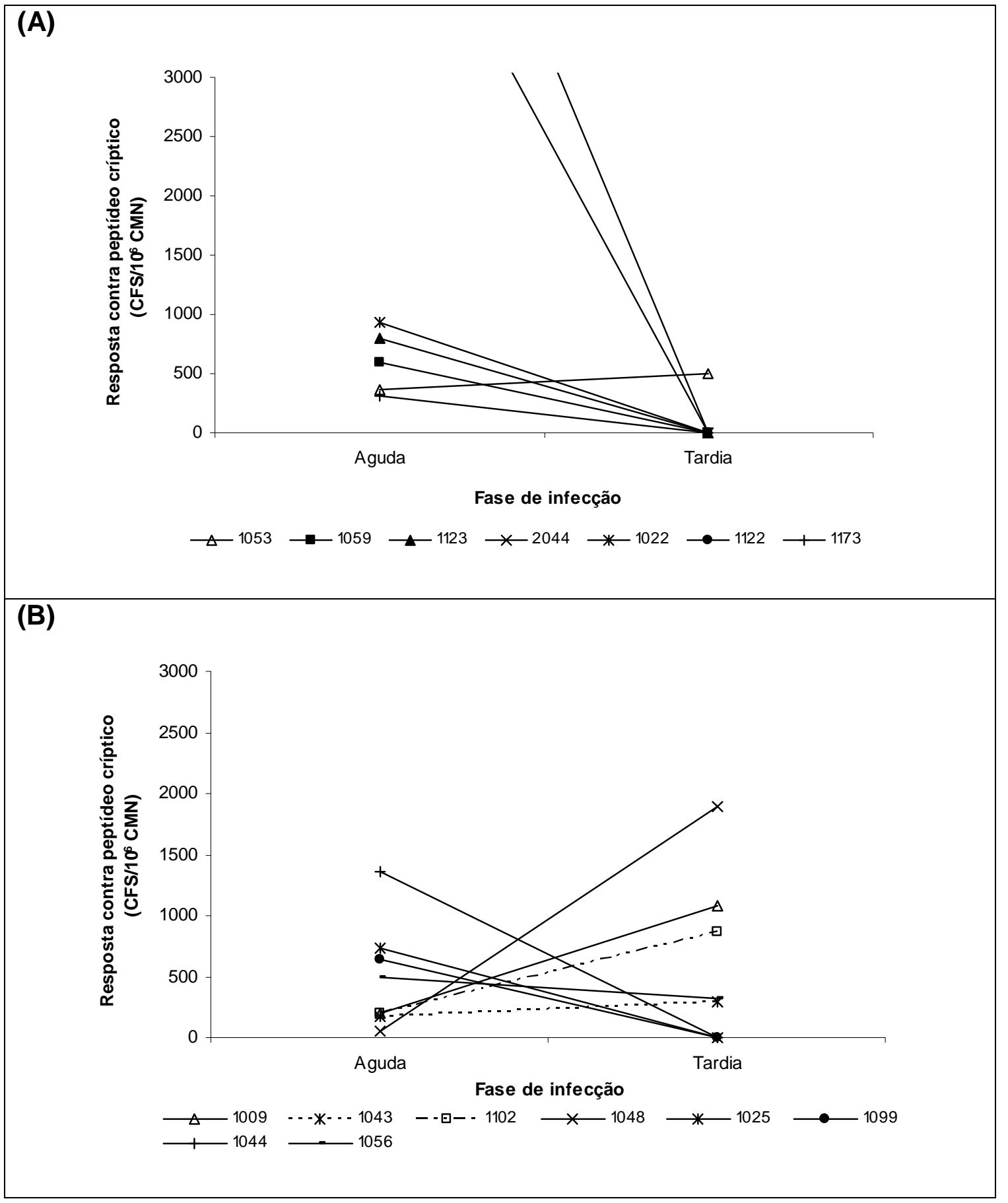

Figura 13 - Magnitude da resposta imunológica específica contra peptídeos crípticos na fase aguda e tardia da infecção pelo HIV. Resposta de CMN proveniente dos pacientes controladores (A) pacientes progressores (B). Os resultados estão expressos pela somatória de resposta de cada paciente contra os peptídeos crípticos estudados, em CFS $/ 10^{6} \mathrm{CMN}$. No gráfico (A) dois pacientes têm suas respostas de fase aguda não-visíveis, devido a grandeza dos valores em relação à escala, sendo eles os pacientes $1122 \mathrm{e}$ 2044, cuja resposta na fase aguda foi de 6.635 e $5.100 \mathrm{CFS} / 10^{6} \mathrm{CMN}$, respectivamente. 
Diferentemente do que se observou na fase aguda da infecção, a magnitude da resposta imune contra peptídeos crípticos foi significativamente $(\mathrm{p}=0,02)$ maior nos pacientes progressores (média \pm desvio padrão: $296 \pm 193$ $\mathrm{CFS} / 10^{6} \mathrm{CMN}$ ) comparado com o grupo de controladores (média \pm desvio padrão: $165 \pm 11 \mathrm{CFS} / 10^{6} \mathrm{CMN}$ ).

Os testes com amostras da fase aguda e fase tardia foram realizados em tempos diferentes, e para certificar de que a capacidade das CMN de responder contra qualquer estímulo não foi perdida, comparamos os resultados de resposta contra um antígeno utilizado como controle. A resposta contra Gag foi mantida, apresentando média ( \pm desvio padrão) na fase aguda de $1.449 \pm 859 \mathrm{CFS} / 10^{6} \mathrm{CMN}$ e na fase tardia de $1.282 \pm 989 \mathrm{CFS} / 10^{6} \mathrm{CMN}$. As respostas contra Gag de cada paciente na fase aguda e tardia estão representadas na Figura 14.

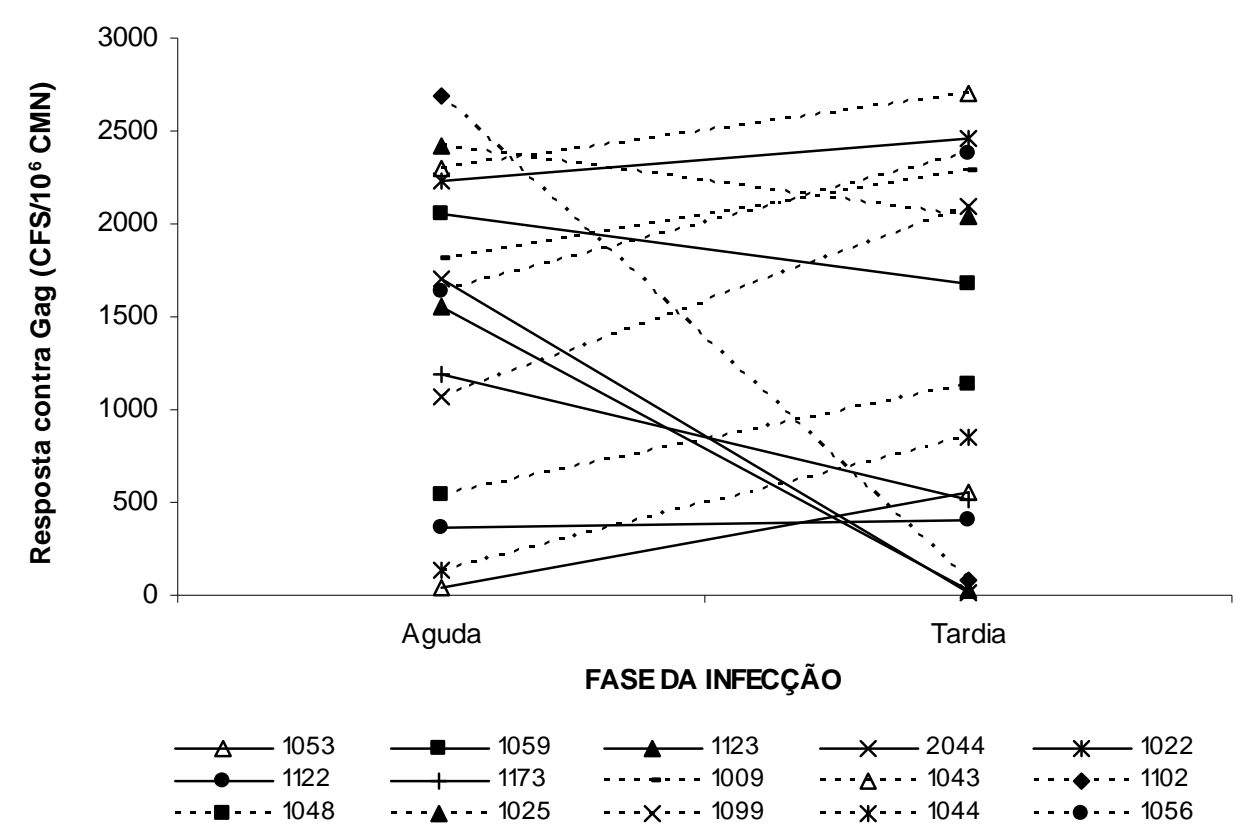

Figura 14 - Magnitude da resposta imunológica específica contra Gag na fase aguda e tardia da infecção pelo HIV. Resposta de CMN proveniente dos pacientes controladores (A) pacientes progressores (B). Os resultados estão expressos pela somatória de resposta de cada paciente contra os peptídeos crípticos estudados, em $\mathrm{CFS} / 10^{6} \mathrm{CMN}$. No gráfico $(\mathrm{A})$ dois pacientes têm suas respostas de fase aguda não-visíveis, devido a grandeza dos valores em relação à escala, sendo eles os pacientes 1122 e 2044, cuja resposta na fase aguda foi de 6.635 e $5.100 \mathrm{CFS} / 10^{6} \mathrm{CMN}$, respectivamente. 
$\mathrm{Na}$ fase tardia, o paciente controlador (1053) respondeu contra os pools ARF\# 13, 18 e 22, mantendo resposta apenas contra o pool ARF\# 13, com magnitudes muito semelhantes (fase aguda: $100 \mathrm{CFS} / 10^{6} \mathrm{CMN} \times$ tardia: $\left.150 \mathrm{CFS} / 10^{6} \mathrm{CMN}\right)$. No grupo de progressores, por sua vez foi observada que os pools ARF\# 17 e 14 foram os que mais induziram resposta entre os pacientes, três e dois respondedores, respectivamente. Para os demais pools de peptídeos crípticos observou-se apenas um paciente respondedor. Esse resultado demonstra, portanto, que os pacientes dos dois grupos responderam contra pools diferentes comparando-se as duas fases, como demonstrado na Figura 15.

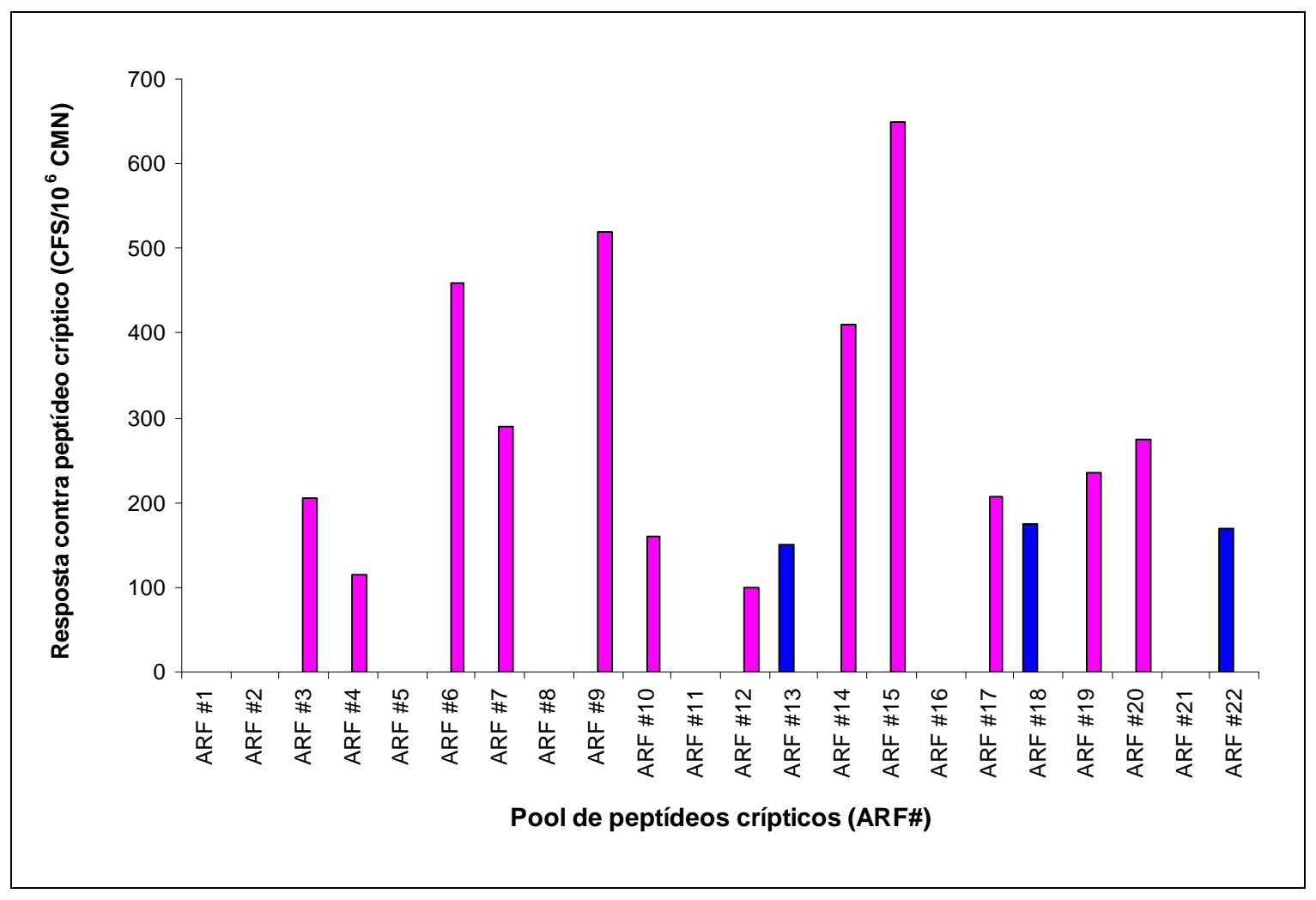

Figura 15 - Magnitude da resposta imunológica específica contra Gag na fase aguda e tardia da infecção pelo HIV. Resposta de CMN proveniente dos pacientes controladores (A) pacientes progressores (B). Os resultados estão expressos pela somatória de resposta de cada paciente contra os peptídeos crípticos estudados, em CFS $/ 10^{6} \mathrm{CMN}$. No gráfico $(\mathrm{A})$ dois pacientes têm suas respostas de fase aguda não-visíveis, devido a grandeza dos valores em relação à escala, sendo eles os pacientes 1122 e 2044, cuja resposta na fase aguda foi de 6.635 e $5.100 \mathrm{CFS} / 10^{6} \mathrm{CMN}$, respectivamente. 


\section{DISCUSSÃo}

Neste trabalho, avaliamos a presença de resposta imunológica contra peptídeos crípticos do HIV-1 mediada por linfócitos do sangue periférico provenientes de pacientes recém-infectados utilizando o ensaio de ELISPOT para IFN- $\gamma$.

Os mecanismos de geração de peptídeos virais crípticos podem ser diversos e incluem as várias leituras alternativas possíveis da sequência do genoma (ARF - alternative reading frame) do vírus, seja no sentido senso ou antisenso. São assim, produtos de erros que ocorre durante a síntese proteica, desde a transcrição do DNA em RNA mensageiro (RNA-m) até a tradução deste em polipeptídeos, quando o processo de leitura se inicia a partir de um códon diferente do códon clássico AUG. Embora sejam rapidamente degradados no citoplasma e não tenham função conhecida para a biologia viral, estes então chamados peptídeos crípticos são considerados ligantes potenciais das moléculas do MHC de classe I (Mayrand et al., 1998). Desta forma, os peptídeos crípticos são apresentados a linfócitos T CD8+ podendo então, ativar resposta imunológica antiviral específica contra eles e citotóxica contra as células infectadas que os sintetizam e apresentam (Garrison et al., 2009). Abre-se aqui, assim, uma importante janela de oportunidade adicional para o desenvolvimento de vacinas contra HIV-1, sejam elas com finalidade preventiva ou terapêutica.

Uma vez que os linfócitos T CD8+ têm sido associados ao controle temporal da replicação viral observada na infecção aguda pelo HIV-1 (Borrow et al., 1994; Koup et al., 1994), avaliamos, neste trabalho, a presença de resposta imune contra peptídeos crípticos do HIV-1 mediada por linfócitos do sangue periférico em 46 pacientes recém-infectados utilizando o ensaio de ELISPOT para IFN- $\gamma$. Utilizamos amostras de CMN provenientes de pacientes acompanhados numa coorte de indivíduos recém-infectados, cujos detalhes foram publicados por Kallas e cols. (2004). As amostras selecionadas foram coletadas entre 14 e 496 dias após a data estimada de infecção por STAHRS 
(170 dias) e, portanto, provenientes da fase inicial da infecção (média \pm desvio padrão: $375 \pm 284$ dias).

Dentre os 46 pacientes recém-infectados com HIV-1 avaliados neste estudo, 18 (39,1\%) deles apresentaram resposta imunológica específica mediada por células contra os peptídeos crípticos testados, com magnitude média de $208 \mathrm{CFS} / 10^{6} \mathrm{CMN}$, sugerindo que os peptídeos crípticos possuem propriedade antigênica. Os peptídeos crípticos são sintetizados in vivo, processados, ligados a moléculas de MHC classe I e apresentados in vivo (provavelmente por linfócitos T CD8+). Este conjunto por sua vez pode então, induzir resposta específica por linfócitos T CD8+, a tal nível que foi possível detectar no ensaio de ELISPOT que realizamos, utilizando 100.000 CMN.

A antigenicidade de peptídeos crípticos foi demonstrada anteriormente por Cardinaud e cols (2004), que observaram a capacidade destes peptídeos crípticos em se ligarem a moléculas de HLA e de imunizar camundongos. Por exemplo, o peptídeo críptico Q9VF, gerado durante a infecção pelo HIV-1 por leitura alternativa do gene gag e apresentado pela molécula HLA-B*07, foi capaz de induzir reconhecimento e resposta específica de linfócitos T CD8+, com subsequente eliminação das células infectadas.

Dentre os nossos pacientes, aqueles que responderam a pelo menos um pool de peptídeos crípticos, chamados então de respondedores, não apresentaram diferenças quanto aos níveis de carga viral plasmática e contagem de linfócitos T CD8+, quando comparados com os pacientes nãorespondedores. Por outro lado, a contagem de linfócitos T CD4+ nos pacientes respondedores foi maior que a observada entre os pacientes nãorespondedores. Esta observação sugere que a presença de resposta imune celular específica contra peptídeos crípticos, assim como observada nos estudos utilizando os peptídeos "ótimos", não está associada à quantidade de partículas virais ou ao número de linfócitos T CD8+ circulantes, mas sim a uma contagem de linfócitos T CD4+ em faixas de valores próximo do normal, isto é em torno de 500 células/ $\mu \mathrm{L}$, que tem sido descritos como abundantes e necessários para a manutenção da resposta imune mediada pelos linfócitos $T$ CD8+ (Deeks et al., 2007). 
Apesar de não observarmos diferença na carga viral plasmática dos pacientes respondedores (30.550 cópias $/ \mathrm{mL}, 3,42 \mathrm{log}$ ) em relação aos pacientes não-respondedores (56.550 cópias $/ \mathrm{mL}, 3,83 \mathrm{log}$ ), este parâmetro tem sido associado a transmissibilidade do vírus e progressão da infecção (Vermeulen et al., 2013). Desta forma, utilizamos os valores de carga viral plasmática para classificar os pacientes quanto a evolução ou progressão da infecção e assim tentar avaliar o possível papel deste tipo de resposta imunológica na infecção pelo HIV-1 (Wawer et al., 2005).

Assim, baseados nos níveis de carga viral plasmática durante o tempo de acompanhamento aproximado de cinco anos, os pacientes foram classificados em dois grupos: controladores e progressores.

A frequência de resposta imune celular contra os peptídeos crípticos observada entre os pacientes controladores foi maior $(47,4 \%$ - nove de 19 pacientes) do que a observada entre os pacientes do grupo progressores, cuja frequência foi de 33,3\% (nove de 27 pacientes), com $\mathrm{p}=0,031$ (teste $t$-Student). Essa diferença no percentual de resposta entre os dois grupos de pacientes sugere que os peptídeos crípticos são capazes de induzir uma resposta imunológica específica que pode ser responsável, ou ao menos contribuir, para o controle da progressão da infecção pelo HIV, mesmo não tendo sido observada correlação com carga viral.

A diferença de carga viral plasmática entre os pacientes do grupo agudo e controladores de elite não pode ser atribuída à presença de alelo $c c r 5 \Delta 32$, uma vez que a frequência deste alelo nos dois grupos de pacientes foi semelhante.

$\mathrm{Na}$ caracterização dos dois grupos de pacientes classificados conforme a progressão da infecção, ao contrário do que observamos quando comparamos os pacientes respondedores e não-respondedores, a média das contagens de linfócitos T CD4+, assim como de linfócitos T CD8+, não foi diferente. Esta observação sugere que a resposta imune celular específica contra peptídeos crípticos envolvida no controle da replicação do HIV-1, ocorre independentemente do quantitativo destas células circulantes.

Sabendo-se que os alelos de HLA podem influenciar positiva ou negativamente para a progressão da infecção pelo HIV-1 (Deeks \& Walker, 
2007) e que os peptídeos crípticos selecionados para este estudo são ligantes potenciais das moléculas $H_{L A}-A^{\star} 02,-B^{\star} 07$ e $-B^{\star} 58$, nós verificamos a frequência destes alelos entre os pacientes respondedores dos dois grupos. Ao contrário do que esperávamos, isto é, que a presença destes alelos fosse semelhante entre os pacientes respondedores dos dois grupos, nós observamos que o alelo HLA-A*02 não foi presente em nenhum dos pacientes do grupo agudo que responderam aos peptídeos crípticos.

É possível que a apresentação de peptídeos crípticos pelas moléculas do MHC classe I não seja fator fundamental na geração da resposta imunológica mediada por linfócitos $\mathrm{T}$ CD8+ in vitro. De fato, alguns pesquisadores observaram que a restrição na apresentação de antígenos pelas moléculas do MHC não era suficiente para o controle da replicação de HIV-1 em pacientes controladores de elite, uma vez que metade destes pacientes não apresentava os HLAs que são protetores (Emu et al., 2008; Pereyra et al., 2008). Por outro lado, pacientes que apresentavam alelos de HLAs protetores progrediam na doença (Miguele et al., 2000). Outros autores acreditam que o papel dos alelos de HLA no controle da replicação viral deva ser avaliado em conjunto com a imunidade inata mediada por células NK, o que também explicaria a baixa viremia observada na fase aguda da infecção nos pacientes controladores de elite (Goujard et al., 2009).

A presença de resposta imune mediada por linfócitos T CD8+ contra peptídeos crípticos também foi observada em modelo animal experimental. Macacos resos infectados com SIV-mac139 capazes de espontaneamente controlar a replicação viral apresentavam forte resposta imune mediada por linfócitos T CD8+ contra um epitopo críptico, cRW9, derivado da leitura alternativa do gene env do SIV (Maness et al., 2007).

Embora a amplitude média de resposta imune celular contra peptídeos crípticos, isto é o número de pools de peptídeos crípticos contra os quais se tem resposta positiva, não tenha sido diferente entre os pacientes do grupo de controladores e progressores, observamos que 66,7\% dos pacientes controladores responderam contra mais de um pool, enquanto que no grupo de pacientes progressores $44,4 \%$ respondeu contra mais de um pool de peptídeo críptico. 
No estudo de Maness et al. (2010), os linfócitos T CD8+ de macacos resos infectados com SIV reconheceram em torno de $25 \%$ dos peptídeos crípticos das regiões codificadoras de pol, tat/vpr, env e env/rev.

Maior amplitude de resposta imune mediada por células, observada nos pacientes controladores de elite, pode significar que os peptídeos crípticos poderiam participar como componentes de vacinas e melhorar a eficácia das mesmas. Embora não tenha sido avaliado neste estudo, a título de comparação, sabe-se que indivíduos não infectados não apresentam resposta imune celular contra peptídeos crípticos do HIV (Garrison et al., 2009).

A magnitude de resposta celular dos pacientes controladores contra peptídeos crípticos foi duas vezes maior que a resposta das $\mathrm{CMN}$ dos pacientes do grupo de progressores. Este fato reforça a hipótese de que a resposta imune mediada por linfócitos T CD8+ contra peptídeos crípticos pode ter papel importante no controle espontâneo da replicação viral nos pacientes do grupo controladores. De fato, estes pacientes possuem resposta imune mediada por linfócitos T CD8+ mais forte do que os demais pacientes também contra os peptídeos clássicos da proteína Gag do HIV-1, com produção de várias citocinas e grânulos citolíticos (Migueles et al., 2008).

A especificidade da resposta imune celular contra peptídeos crípticos foi avaliada apenas em alguns pacientes, sendo três que responderam somente contra um pool de peptídeos crípticos e um paciente que respondeu contra dois pools. Dos pacientes avaliados, foi possível definir a especificidade de resposta em apenas um paciente (1098), pois além de reproduzir a positividade contra o pool de peptídeos crípticos, respondeu a algum peptídeo críptico que compunha o pool, nas duas concentrações avaliadas, 10 e 100 $\mu \mathrm{g} / \mathrm{mL}$. Este paciente (1098) foi classificado como sendo controlador virêmico, permanecendo com níveis inferiores a 2.000 cópias $/ \mathrm{mL}$ mesmo após 44 meses de infecção.

Análises complementares, testando individualmente os peptídeos crípticos em mais pacientes, talvez pudesse implementar esta discussão sobre a especificidade da resposta imune celular contra os peptídeos crípticos na infecção por HIV-1, porém não foram possíveis por motivos técnicos. 
O paciente (1173), que também reproduziu a positividade contra o pool, mas não contra peptídeos crípticos testados individualmente, exceto para o peptídeo \# 534 na concentração de $100 \mu \mathrm{g} / \mathrm{mL}$, também é um controlador virêmico. É possível que a avaliação de alguma amostra de seguimento deste paciente, a partir do momento que este controle de viremia foi efetivo demonstre uma resposta semelhante à que foi observada no paciente 1098.

Portanto, a avaliação longitudinal da resposta imune mediada por células contra peptídeos crípticos nos dois grupos de pacientes nos permite entender melhor o desenvolvimento da resposta imune e seu papel no controle da replicação viral, auxiliando no desenvolvimento de vacinas que permitam diminuir a transmissão do HIV-1 e/ou retardar a progressão da doença (Walker et al., 2007; Pereyra et al., 2008). E embora a resposta em fase tardia tenha demonstrado magnitude semelhante ao observado na fase aguda, nota-se que os pools de peptídeos crípticos são diferentes, além de que pacientes controladores em geral tiveram perda desta resposta, enquanto que os progressores a desenvolveram, contradizendo Champiat (2012), que sugeria maior resposta imune contra peptídeos crípticos na fase crônica. É possível que estes peptídeos crípticos tenham induzido uma resposta protetora entre os pacientes controladores na fase aguda, que a medida que controlaram a replicação viral, surgiram menos variantes, e portanto, menos processos que levassem a transcrição e/ou tradução de peptídeos crípticos, e consequentemente, menos estímulo das células imunológicas, particularmente dos linfócitos T CD8+ pelos antígenos, de forma que na fase tardia, a magnitude de resposta desta células seja menor em função da falta de antígenos presente.

Considerando que a magnitude de resposta imune contra peptídeos crípticos foi menor que a resposta contra Gag, podemos sugerir que a resposta contra peptídes crípticos é parte do total de resposta imune, como esperado.

Com os dados que obtivemos, podemos sugerir a incorporação de peptídeos crípticos a produtos vacinais com intuito de aumentar a eficácia dos mesmos, aumentando o espectro de resposta imune celular específica e a magnitude destas, seja afetando a expressão de proteínas crucias para o HIV, 
seja gerando vírus defeituosos e/ou não infectantes, seja aumentando a capacidade direta dos linfócitos $\mathrm{T}$ de reconhecerem e controlarem a replicação viral. 


\section{CONCLUSÕES}

- Resposta imune mediada por células contra peptídeos crípticos foi presente em $39,1 \%$ dos pacientes infectados com HIV-1 na fase aguda;

- A frequência de resposta imune celular contra peptídeos crípticos foi maior entre pacientes que controlam espontaneamente a viremia ao longo dos anos (controladores, 47,4\%), comparando-os aos pacientes progressores $(33,3 \%)$;

- A magnitude de resposta imune celular contra peptídeos crípticos na fase aguda foi duas vezes maior no grupo de pacientes controladores comparado ao grupo de pacientes progressores;

- Apesar dos pacientes respondedores na fase aguda apresentarem maior contagem de linfócitos T CD4+ em relação aos pacientes não respondedores, não houve correlação de magnitude de resposta contra peptídeos crípticos e as contagens de linfócitos T CD4+ e T CD8+, e viremia de HIV-1;

- A resposta imune celular dos pacientes controladores contra peptídeos crípticos na fase tardia diminuiu, por outro lado, a resposta das células provenientes dos pacientes progressores contra peptídeos crípticos aumentou na fase tardia;

- Os pools de peptídeos crípticos que induziram resposta imune celular na fase aguda e na fase tardia eram diferentes, tanto no grupo de pacientes controladores quanto de progressores. 


\section{ANEXOS}

Anexo 1 - Detalhes sobre os pools de peptídeos crípticos: composição e média da magnitude de resposta obtida para cada pool.

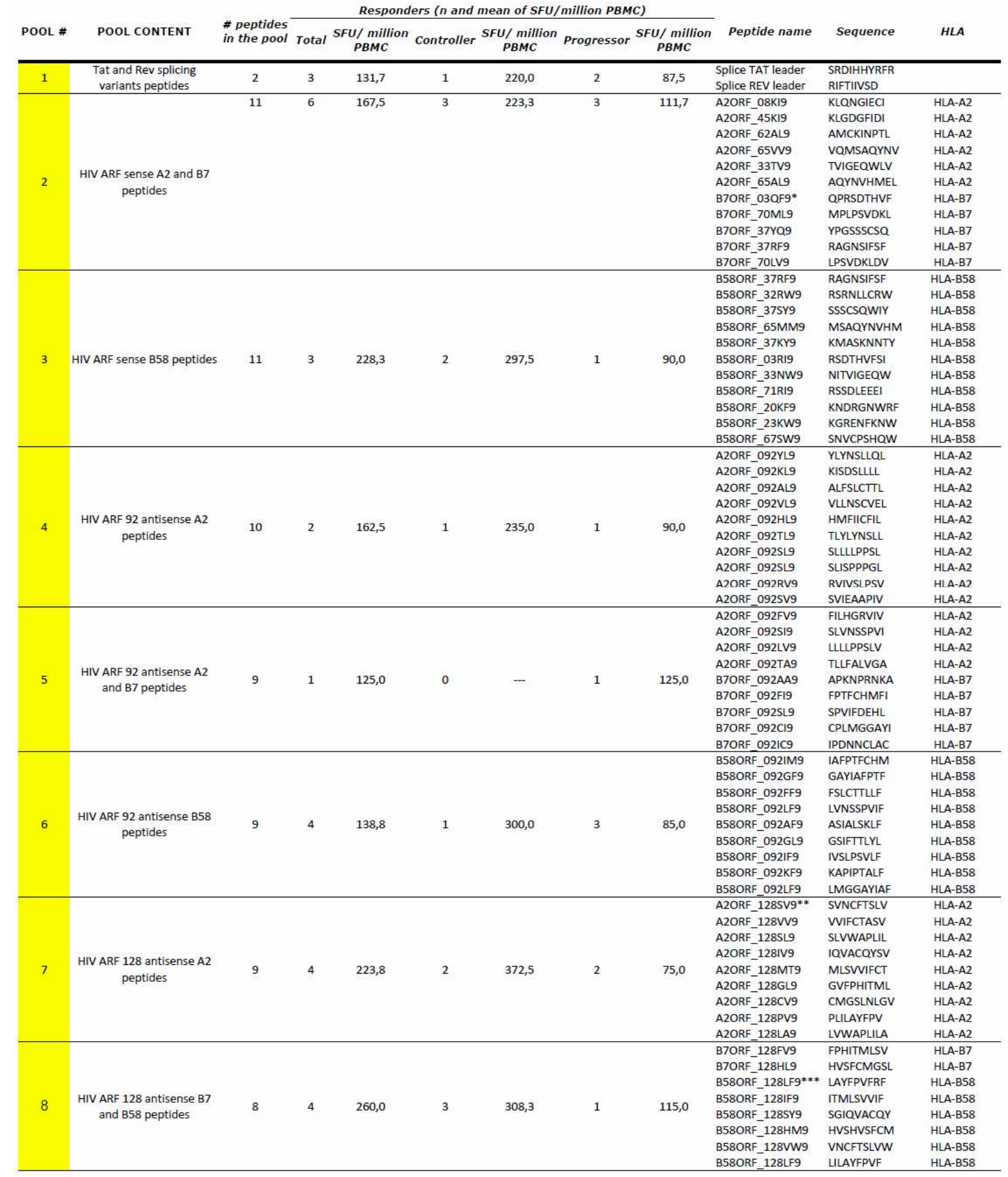




\begin{tabular}{|c|c|c|c|c|c|c|c|c|c|c|c|}
\hline \multirow{10}{*}{9} & & & & & & & & & A2ORF_141VI9 & VLYGFSGPI & HLA-A2 \\
\hline & & & & & & & & & A2ORF_141FL9 & FTGTVSIGL & HLA-A2 \\
\hline & & & & & & & & & B7ORF_141SF9 & SVOISTNAF & HLA-B7 \\
\hline & & & & & & & & & B7ORF_141GF9 & GPSIPGFNF & HLA-B7 \\
\hline & HIV ARF 141 antisense $A 2$, & 10 & 4 & 2088 & 3 & 2500 & 1 & 850 & B7ORF_141FQ9 & FPSFSISVQ & HLA-B7 \\
\hline & B7 and B58 peptides & 10 & 4 & 200,0 & 3 & 250,0 & 1 & $\infty, 0$ & B580RF_141FF9 & FSGPIFEIF & HLA-B58 \\
\hline & & & & & & & & & B58ORF_141SF9 & SVNGHCLTF & HLA-B58 \\
\hline & & & & & & & & & B580RF_141VF9 & VSIGLMGKF & HLA-B58 \\
\hline & & & & & & & & & B580RF_141QF9 & QISTNAFIF & HLA-B58 \\
\hline & & & & & & & & & B580RF_141FL9 & FSSVNGHCL & HLA-B58 \\
\hline & & & & & & & & & A2ORF_153FL9 & FVYSLLMFL & HLA-A2 \\
\hline & & & & & & & & & A2ORF_153MV9 & MVVAVPVFV & HLA-A2 \\
\hline 10 & B7 and B58 peptides & 5 & 2 & 87,5 & 0 & - & 2 & 87,5 & A2ORF_153AL9 & AVPVFVYSL & HLA-A2 \\
\hline & & & & & & & & & B7ORF_153VL9 & VPVFVYSLL & HLA-B7 \\
\hline & & & & & & & & & B580RF_153VY9 & VVAVPVFVY & HLA-B58 \\
\hline & & & & & & & & & B70RF_083SL9 & SPVPPRPRL & HLA-B7 \\
\hline & & & & & & & & & B7ORF_083RP9 & RPRLPGKSP & HLA-B7 \\
\hline & & & & & & & & & B7ORF_083RP9 & RARHSPVPP & HLA-B7 \\
\hline & & & & & & & & & B7ORF_084RM9 & RMOLSGHVM & HLA-B7 \\
\hline 11 & antisense A2 B7 and B58 & 10 & 6 & 2650 & 3 & 258.3 & 3 & 2717 & B580RF_086LY9 & LSSSHSFPY & HLA-B58 \\
\hline 11 & peptides & 10 & ${ }^{\circ}$ & 2003,0 & 3 & 258,3 & 3 & 27,7 & B580RF_086CW9 & CCSHPICCW & HLA-B58 \\
\hline & & & & & & & & & A2ORF_087ML9 & MLLPPYLLL & HLA-A2 \\
\hline & & & & & & & & & A2ORF_087LA9 & LLPPYLLLA & HLA-A2 \\
\hline & & & & & & & & & A2ORF_087AL9 & AQLVSFFPL & HLA-A2 \\
\hline & & & & & & & & & B7ORF_087PL9 & PPYLLLAQL & HLA-B7 \\
\hline & & & & & & & & & A2ORF_085LV9 & LLSYLAQLV & HLA-A2 \\
\hline & & & & & & & & & A2ORF_085PL9 & PLLSYLAQL & HLA-A2 \\
\hline & & & & & & & & & A2ORF_085GL9 & GVTSWCSLL & HLA-A2 \\
\hline & & & & & & & & & B580RF_085TW9 & TSWCSLLYW & HLA-B58 \\
\hline 12 & and B58 peptides & 9 & 4 & 266,3 & 3 & 316,7 & 1 & 115,0 & B58ORF_085LL9 & LSYLAQLVL & HLA-B58 \\
\hline & & & & & & & & & B58ORF_085VY9 & vTSWCSLLY & HLA-B58 \\
\hline & & & & & & & & & B580RF_085AW9 & AGSQGVTSW & HLA-B58 \\
\hline & & & & & & & & & B580RF_085LY9 & LLYWPLLSY & HLA-B58 \\
\hline & & & & & & & & & A2ORF_095VV9 & VLQVLLNQV & HLA-A2 \\
\hline & & & & & & & & & A2ORF_088AL9 & AMAVALSKL & HLA-A2 \\
\hline & & & & & & & & & A2ORF_088CV9 & CTTSITLSV & HLA-A2 \\
\hline & & & & & & & & & A2ORF_088LI9 & LQAPCTTSI & HLA-A2 \\
\hline & & & & & & & & & A2ORF_088KS9 & KLTALFFSS & HLA-A2 \\
\hline 13 & HIV ARF 88 antisense A2, & 10 & 4 & & 3 & & 1 & & B7ORF_088AL9 & APCTTSITL & HLA-B7 \\
\hline 10 & B7 and B58 peptides & 10 & 4 & 218,8 & 3 & $2 / 0,0$ & 1 & 65,0 & B7ORF_088VV9 & VPSATAMAV & HLA-B7 \\
\hline & & & & & & & & & B7ORF_088SL9 & SATAMAVAL & HLA-B7 \\
\hline & & & & & & & & & B7ORF_088VL9 & VALSKLTAL & HLA-B7 \\
\hline & & & & & & & & & B58ORF_088LM9 & LSVPSATAM & HLA-B58 \\
\hline & & & & & & & & & B580RF_088LF9 & LSKLTALFF & HLA-B58 \\
\hline & & & & & & & & & A2ORF_089S19 & SLSPPSSSI & HLA-A2 \\
\hline & & & & & & & & & B7ORF_0891L9 & IPSGLSGPL & HLA-B7 \\
\hline & & & & & & & & & B7ORF_089S59 & SPPSSSIPS & HLA-B7 \\
\hline & & & & & & & & & A2ORF_090VL9 & VMLNOFHKL & HLA-A2 \\
\hline & HIV ARF $89,90,93,94$ & & & & & & & & A2B580RF_090FM9 & FIYHSOFVM & HLA-A2/HLA-B58 \\
\hline 14 & antisense $\mathrm{A} 2, \mathrm{~B} 7$ and $\mathrm{B} 58$ & 11 & 5 & 280,0 & 3 & 378,3 & 2 & 132,5 & B580RF_090NW9 & NSCSFFSCW & HLA-B58 \\
\hline & & & & & & & & & B7ORF_093SL9 & SPQQIVLLL & HLA-B7 \\
\hline & & & & & & & & & A2ORF_094FI9 & FLLLYIYII & HLA-A2 \\
\hline & & & & & & & & & A2ORF_094MI9 & MVQFLLLYI & HLA-A2 \\
\hline & & & & & & & & & B7ORF_094CV9 & CPSYLLLQV & HLA-B7 \\
\hline & & & & & & & & & B580RF_094LF9 & LLYIYIIHF & HLA-B58 \\
\hline & & & & & & & & & A2ORF_097LV9 & LIFPIFPIV & HLA-A2 \\
\hline & & & & & & & & & A2ORF_097C19 & CLIFPIFPI & HLA-A2 \\
\hline & & & & & & & & & A2ORF_097LI9 & LLLGLVQU & HLA-A2 \\
\hline & & & & & & & & & A2ORF_097TV9 & TIMVLALSV & HLA-A2 \\
\hline & & & & & & & & & A2ORF_097FV9 & FLVLLLGLV & HLA-A2 \\
\hline 15 & HIV ARF 92 antisense A2 & 11 & 7 & 270,7 & 5 & 318,0 & 2 & 152,5 & A2ORF_097RL9 & RILFLVLLL & HLA-A2 \\
\hline & & & & & & & & & A2ORF_097VL9 & VLLLGLVQL & HLA-A2 \\
\hline & & & & & & & & & A2ORF_097KS9 & KLTDLITTS & HLA-A2 \\
\hline & & & & & & & & & A2ORF_097AL9 & ALSVKLTDL & HLA-A2 \\
\hline & & & & & & & & & B580RF_097TF9 & TSSSARLPF & HLA-B58 \\
\hline & & & & & & & & & B580RF_097IL9 & ITTSSSARL & HLA-B58 \\
\hline & & & & & & & & & B7ORF_097GF9 & GPLWIRILF & HLA-B7 \\
\hline & & & & & & & & & B7ORF_097WL9 & WIRILFLVL & HLA-B7 \\
\hline & & & & & & & & & A2ORF_098Q19 & QLYYYGFSI & HLA-A2 \\
\hline & HIV ARF $97,98,99$ & & & & & & & & B58ORF_098LY9 & LSHISYFSY & HLA-B58 \\
\hline 16 & antisense $\mathrm{A} 2, \mathrm{~B} 7$ and $\mathrm{B} 58$ & 9 & 3 & 218,3 & 2 & 260,0 & 1 & 135,0 & A2ORF_099FL9 & FFLYCCWVL & HLA-A2 \\
\hline & peptides & & & & & & & & A2ORF_099FV9 & FFFLYCCWV & HLA-A2 \\
\hline & & & & & & & & & B580RF_099VF9 & VLSGYGFFF & HLA-B58 \\
\hline & & & & & & & & & B58ORF_099SY9 & SGYGFFFLY & HLA-B58 \\
\hline & & & & & & & & & B580RF_099GW9 & GFFFLYCCW & HLA-B58 \\
\hline & & & & & & & & & A2ORF_100ML9 & MVLALSVKL & HLA-A2 \\
\hline & & & & & & & & & B580RF_101LW9 & LYCADICTW & HLA-B58 \\
\hline & & & & & & & & & A2ORF_103VV9 & VMTEVLQLV & HLA-A2 \\
\hline & & & & & & & & & A2ORF_103GV9 & GQACVMTEV & HLA-A2 \\
\hline 17 & antisense $A 2$ and $B 58$ & 10 & 4 & 223,8 & 3 & 271.7 & 1 & 800 & A2ORF_103CL9 & CVMTEVLQLL & HLA-A2 \\
\hline 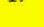 & peptides & & & 220,0 & 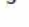 & 27, & 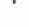 & 80,0 & B58ORF_103MF9 & MGIGSKDTF & HLA-B58 \\
\hline & & & & & & & & & A2ORF_105YI9 & YLCIICFSI & HLA-A2 \\
\hline & & & & & & & & & B58ORF_105HW9 & HIYOYYFLW & HLA-B58 \\
\hline & & & & & & & & & B580RF_105IF9 & IMYLCIICF & HLA-B58 \\
\hline & & & & & & & & & B580RF_105KY9 & KIFCHIYQY & HLA-B58 \\
\hline
\end{tabular}




\begin{tabular}{|c|c|c|c|c|c|c|c|c|c|c|c|}
\hline \multirow{10}{*}{18} & \multirow{10}{*}{$\begin{array}{l}\text { HIV ARF } 104,110 \text { antisense } \\
\text { A2 and B58 peptides }\end{array}$} & \multirow{10}{*}{10} & \multirow{10}{*}{3} & \multirow{10}{*}{230,0} & \multirow{10}{*}{2} & \multirow{10}{*}{310,0} & \multirow{10}{*}{1} & \multirow{10}{*}{70,0} & A2ORF_104FI9 & FISPFSIII & HLA-A2 \\
\hline & & & & & & & & & A2ORF_104IV9 & IILPLLLLVV & HLA-A2 \\
\hline & & & & & & & & & A2ORF_104LI9 & LILKEQFFI & HLA-A2 \\
\hline & & & & & & & & & A2ORF_104VV9 & VLVSFFKSV & HLA-A2 \\
\hline & & & & & & & & & A2B58ORF_104FL9 & FSIIILPLL & HLA-A2/HLA-B58 \\
\hline & & & & & & & & & A2ORF_104IL9 & ILPLLLLVL & HLA-A2 \\
\hline & & & & & & & & & B58ORF_104VF9 & VSFFKSVHF & HLA-B58 \\
\hline & & & & & & & & & B58ORF_104KF9 & KLTQSGVNF & HLA-B58 \\
\hline & & & & & & & & & B58ORF_104SF9 & SGVNFTHGF & HLA-B58 \\
\hline & & & & & & & & & A2ORF_110TI9 & TMDHTTIAI & HLA-A2 \\
\hline \multirow{10}{*}{19} & \multirow{10}{*}{$\begin{array}{c}\text { HIV ARF } 106,112,114 \\
\text { antisense A2, B7 and B58 } \\
\text { peptides }\end{array}$} & \multirow{10}{*}{10} & \multirow{10}{*}{3} & \multirow{10}{*}{288,3} & \multirow{10}{*}{3} & \multirow{10}{*}{288,3} & \multirow{10}{*}{-} & \multirow{10}{*}{-} & B580RF_106MF9 & MSFFHMLKF & HLA-B58 \\
\hline & & & & & & & & & B580RF_106HF9 & HMLKFSVTF & HLA-B58 \\
\hline & & & & & & & & & A2ORF_112S19 & SLSPLLPAI & HLA-A2 \\
\hline & & & & & & & & & B7ORF_112TL9 & TVLMSSSSL & HLA-B7 \\
\hline & & & & & & & & & B58ORF_112SL9 & SSSSLSPLL & HLA-B58 \\
\hline & & & & & & & & & A2B58ORF_114LL9 & LTSWMLPGL & HLA-A2/HLA-B58 \\
\hline & & & & & & & & & A2ORF_114AL9 & AIGTSSFRL & HLA-A2 \\
\hline & & & & & & & & & B7ORF_114KI9 & KATLFTIAI & HLA-B7 \\
\hline & & & & & & & & & B7ORF_114TF9 & TIAIGTSSF & HLA-B7 \\
\hline & & & & & & & & & B580RF_114TW9 & TSSFRLTSW & HLA-B58 \\
\hline \multirow{7}{*}{20} & \multirow{7}{*}{$\begin{array}{l}\text { HIV ARF } 115,116,117,119, \\
120 \text { antisense A2, B7 and } \\
\text { B58 peptides }\end{array}$} & \multirow{7}{*}{7} & & & & & & & B7ORF_115IL9 & IPISFIDML & HLA-B7 \\
\hline & & & & & & & & & B7ORF_116NF9 & NPRKMSNSF & HLA-B7 \\
\hline & & & & & & & & & B580RF_116ML9 & MSNSFILKL & HLA-B58 \\
\hline & & & 4 & 345,0 & 3 & 251,7 & 1 & 625,0 & A2ORF_117LI9 & LLVPSIVEI & HLA-A2 \\
\hline & & & & & & & & & B7ORF_117LI9 & LPCYVLLDI & HLA-B7 \\
\hline & & & & & & & & & B7ORF_119MQ9 & MPVSFSCMQ & HLA-B7 \\
\hline & & & & & & & & & B58ORF_120MF9 & MSIKPSPSF & HLA-B58 \\
\hline & & & & & & & & & A2ORF_121FL9 & FQSGFLLSL & HLA-A2 \\
\hline & & & & & & & & & A2ORF_121SA9 & SLLSCITTA & HLA-A2 \\
\hline & & & & & & & & & A2ORF_121LL9 & LLGTTFMSL & HLA-A2 \\
\hline & & & & & & & & & A2ORF_121MT9 & MIFAFLLGT & HLA-A2 \\
\hline & & & & & & & & & A2ORF_121FS9 & FLLGTTFMS & HLA-A2 \\
\hline 21 & HIV ARF 121 antisense A2, & 11 & 5 & 344,0 & 4 & 305,0 & 1 & 500,0 & B7ORF_121AF9 & APSPFQRSF & HLA-B7 \\
\hline & & & & & & & & & B7ORF_121GL9 & GPFQSGFLL & HLA-B7 \\
\hline & & & & & & & & & B7ORF_121SG9 & SPFQRSFAG & HLA-B7 \\
\hline & & & & & & & & & B58ORF_121FF9 & FAFLLGTTF & HLA-B58 \\
\hline & & & & & & & & & B58ORF_121FF9 & FAGPFQSGF & HLA-B58 \\
\hline & & & & & & & & & B580RF_121RS9 & RSFAGPFQS & HLA-B58 \\
\hline & & & & & & & & & A2ORF_123IA9 & IMSTILSPA & HLA-A2 \\
\hline & & & & & & & & & A2ORF_123WA9 & WMNTAICTA & HLA-A2 \\
\hline & & & & & & & & & A2ORF_123FT9 & FLLKLWMNT & HLA-A2 \\
\hline 22 & HIV ARF 123 antisense A2, & 7 & 2 & 285,0 & 2 & 285,0 & - & -- & B7ORF_123SL9 & SVAIMSTIL & HLA-B7 \\
\hline & & & & & & & & & B7ORF_123YL9 & YPPIPPFLL & HLA-B7 \\
\hline & & & & & & & & & B58ORF_123SY9 & STILSPALY & HLA-B58 \\
\hline & & & & & & & & & B580RF_123AF9 & ALYPPIPPF & HLA-B58 \\
\hline
\end{tabular}

*Cardineau et al., 2004. J. Exp. Med.

**Bansai et al., 2010, J. Exp. Med.

***Peptide close to AYFPVFRFL, Bansai et al., 2010, J. Exp. Med. 
Anexo 2 - Características dos pacientes estudados.

\begin{tabular}{|c|c|c|c|c|c|c|c|c|c|c|c|c|c|c|c|c|c|c|c|c|}
\hline ID & Grupo & Sexo & Idade & Etnia & \multicolumn{4}{|c|}{ HLA } & \multirow{2}{*}{\begin{tabular}{|c|c|} 
CCR5- \\
DELTA 32 \\
NEG \\
\end{tabular}} & \begin{tabular}{|c|}
$\begin{array}{c}\text { Subtipo } \\
\text { HIV-1 }\end{array}$ \\
\end{tabular} & Sint & $\begin{array}{l}\text { Trat. } \\
\text { S/N }\end{array}$ & $\begin{array}{c}\text { Sample } \\
\text { Date }\end{array}$ & \multirow{2}{*}{\begin{tabular}{|c|}
$\begin{array}{c}\text { post STARHS } \\
\text { (days) }\end{array}$ \\
97
\end{tabular}} & \multirow{2}{*}{$\begin{array}{c}\mathrm{CD} 4 \\
360\end{array}$} & \multirow{2}{*}{\begin{tabular}{l|} 
CD8 \\
927
\end{tabular}} & \multirow{2}{*}{$\frac{\text { CV }}{300.000}$} & ELISPOT & $\begin{array}{c}\# \\
\text { pools } \\
\end{array}$ & $\begin{array}{c}\text { Last visit } \\
\text { Date }\end{array}$ \\
\hline 1001 & Prog & $M$ & 34 & mulato & \begin{tabular}{|l|}
$* 30$ \\
\end{tabular} & $\mathrm{~A}^{*} 33$ & $B^{*} 42$ & $\mathrm{~B}^{*} 42$ & & & & SIM (out-99) & $10-$ set -98 & & & & & & & $19-a b r-02$ \\
\hline 1002 & Prog & $M$ & 39 & branco & $A^{*} 02$ & $A^{*} 11$ & $\mathrm{~B}^{*} 27$ & $\mathrm{~B}^{*} 35$ & NEG & B & Sim & $\operatorname{SIM}($ jul-02) & $26-\mathrm{fev}-99$ & 256 & 377 & 697 & 21.100 & Neg & & 12 -ago-13 \\
\hline 1006 & Prog & $\mathrm{F}$ & 25 & branco & $A^{*} 33$ & $A^{*} 68$ & $B^{*} 07$ & $\mathrm{~B}^{*} 15$ & NEG & & & SIM $($ set -04$)$ & 16-dez-98 & 96 & 662 & 563 & 10.600 & Neg & & 2 -set-13 \\
\hline 1009 & Prog & $M$ & 25 & outro & $A^{*} 31$ & $A^{*} 68$ & $B^{*} 39$ & $\mathrm{~B}^{*} 57$ & POS & & Sim & NÄO & 05-jan-99 & 123 & 429 & 539 & 14.000 & Pos & 1 & 13 -jul-10 \\
\hline 1013 & Prog & $\mathrm{M}$ & 20 & branco & \begin{tabular}{|l|}
$A^{*} 02$ \\
\end{tabular} & $A^{*} 26$ & $\mathrm{~B}^{*} 27$ & $\mathrm{~B}^{*} 35$ & NEG & B & & NÄO & $25-$ nov-98 & 14 & 585 & 1772 & 2.870 & Neg & & 10 -jun-04 \\
\hline 1019 & Prog & M & 27 & branco & \begin{tabular}{|l|}
$A^{*} 02$ \\
\end{tabular} & $\mathrm{~A}^{*} 03$ & $B^{*} 39$ & $\mathrm{~B}^{*} 35$ & NEG & & & NÄO & 21-mai-99 & 119 & 564 & 921 & 24.800 & Neg & & $04-m a i-04$ \\
\hline 1021 & Prog & $\mathrm{M}$ & 29 & mulato & \begin{tabular}{|l|}
$A^{*} 24$ \\
\end{tabular} & $A^{*} 68$ & $B^{*} 35$ & $\mathrm{~B}^{*} 58$ & NEG & & Sim & SIM (jun-01) & 15 -jun-99 & 116 & 354 & 1054 & 38.400 & Neg & & $07-j u l-04$ \\
\hline 1022 & CA & $M$ & 24 & branco & $A^{*} 02$ & $A^{*} 02$ & $B^{*} 14$ & $\mathrm{~B}^{*} 52$ & NEG & B & Sim & NÄO & $22-$ jun -99 & 109 & 491 & 603 & 399 & Pos & 5 & 01 -ago-13 \\
\hline 1024 & Prog & $M$ & 57 & branco & $A^{*} 02$ & $\mathrm{~A}^{*} 02$ & $B^{*} 27$ & $\mathrm{~B}^{*} 44$ & & & Sim & NÄO & $07-$ set-99 & 146 & 426 & 587 & 69.400 & Neg & & 15-dez-99 \\
\hline 1025 & Prog & $M$ & 25 & mulato & \begin{tabular}{|l|}
$A^{*} 11$ \\
\end{tabular} & $\mathrm{~A}^{*} 74$ & $\mathrm{~B}^{*} 35$ & $\mathrm{~B}^{*} 40$ & pos & & & NÄO & $21-$ set-99 & 181 & 894 & 940 & 2.210 & Pos & 8 & 04-Mai-09 \\
\hline 1034 & CA & $M$ & 25 & mulato & $A^{*} 02$ & $A^{*} 03$ & $B^{*} 15$ & $\mathrm{~B}^{*} 57$ & NEG & & & NÄO & 25 -ago-00 & 373 & 516 & 302 & 399 & Neg & & $27-a b r-04$ \\
\hline 1036 & Prog & $M$ & 30 & mulato & $A^{*} 11$ & $A^{*} 32$ & $\mathrm{~B}^{*} 07$ & $\mathrm{~B}^{*} 40$ & NEG & & & NÄO & $04-a b r-00$ & 244 & 513 & 942 & 4.150 & Neg & & 22 -jan-03 \\
\hline 1041 & CA & $M$ & 39 & mulato & $A^{*} 30$ & $A^{*} 31$ & $B^{*} 14$ & $\mathrm{~B}^{*} 14$ & NEG & & & NÄO & $23-\mathrm{mai}-00$ & 216 & 621 & 1691 & 402 & Neg & & 29 -ago-00 \\
\hline 1042 & Prog & $M$ & 29 & mulato & $A^{*} 03$ & $A^{*} 11$ & $\mathrm{~B}^{*} 07$ & $\mathrm{~B}^{*} 35$ & NEG & & & NÄO & 30 -ago-00 & 315 & 482 & 318 & 3.070 & Neg & & $05-m a i-04$ \\
\hline 1043 & Prog & $M$ & 36 & branco & \begin{tabular}{|l|}
$A^{*} 01$ \\
\end{tabular} & $\mathrm{~A}^{*} 32$ & $\mathrm{~B}^{*} 27$ & $\mathrm{~B}^{*} 37$ & NEG & $\mathrm{B}$ & Sim & SIM (fev-02) & 15 -fev-00 & 97 & 553 & 1059 & 73.200 & Pos & 1 & 17 -jun-04 \\
\hline 1044 & Prog & $\mathrm{M}$ & 22 & outro & \begin{tabular}{|l|}
$* 24$ \\
\end{tabular} & $\mathrm{~A}^{*} 30$ & $B^{* 14}$ & $\mathrm{~B}^{*} 35$ & POS & B & & SIM & $04-a b r-00$ & 139 & 1249 & 1047 & 3.520 & Pos & 14 & 21 -out-13 \\
\hline 1048 & Prog & $M$ & 34 & branco & $A^{*} 02$ & $A^{*} 32$ & $B^{*} 14$ & $\mathrm{~B}^{*} 44$ & NEG & B & & SIM & $02-\mathrm{mai}-00$ & 111 & 1194 & 3134 & 6.340 & Pos & 1 & $18-\mathrm{fev}-13$ \\
\hline 1053 & CA (Trat) & $M$ & 35 & branco & \begin{tabular}{|l|}
$A^{*} 01$ \\
\end{tabular} & $A^{*} 68$ & $\mathrm{~B}^{*} 07$ & $\mathrm{~B}^{*} 57$ & POS & $\mathrm{B}$ & & SIM $(a b r-00)$ & 06 -jun-00 & 118 & 221 & 469 & 399 & Pos & 4 & 24-mar-04 \\
\hline 1056 & Prog & $\mathrm{M}$ & 25 & branco & \begin{tabular}{|l|}
$A^{*} 01$ \\
\end{tabular} & $A^{*} 66$ & $\mathrm{~B}^{*} 08$ & $\mathrm{~B}^{*} 39$ & NEG & & & NAOO & 12-jan-01 & 422 & 790 & 1672 & 12.500 & Pos & 1 & 13 -ago-04 \\
\hline 1057 & Prog & $M$ & 31 & mulato & $A^{*} 02$ & $A^{*} 29$ & $B^{*} 07$ & $B^{*} 49$ & NEG & B & & NÄO & $11-\mathrm{jul}-00$ & 118 & 693 & 2027 & 334.000 & Neg & & $02-j u n-04$ \\
\hline 1059 & $\mathrm{CV}$ & $M$ & 26 & neqro & \begin{tabular}{|l|}
$A^{*} 01$ \\
\end{tabular} & $A^{*} 02$ & $\mathrm{~B}^{*} 18$ & $\mathrm{~B}^{*} 42$ & NEG & & & NÄO & 21-mar-01 & 350 & 497 & 1047 & 1.230 & Pos & 3 & $30-$ set -13 \\
\hline 1060 & CA & $M$ & 40 & mulato & $A^{*} 30$ & $A^{*} 32$ & $B^{*} 14$ & $\mathrm{~B}^{*} 57$ & NEG & B & & NẪO & $11-a b r-01$ & 357 & 913 & 1004 & 399 & Neq & & 08 -out- 02 \\
\hline 1062 & Proq & $\mathrm{F}$ & 40 & branco & \begin{tabular}{|l|}
$A^{*} 02$ \\
\end{tabular} & $\mathrm{~A}^{*} 30$ & $B^{*} 44$ & $\mathrm{~B}^{*} 45$ & NEG & & & NẪO & 21-mar-01 & 308 & 480 & 544 & 5.630 & Neq & & $01-$ set -04 \\
\hline 1065 & Prog & $M$ & 22 & branco & $A^{*} 02$ & $\mathrm{~A}^{*} 68$ & $B^{*} 39$ & $\mathrm{~B}^{*} 58$ & NEG & & & NÅO & $07-$ nov- 00 & 125 & 615 & 855 & 20.300 & Neq & & 16 -iun-04 \\
\hline 1068 & CA & M & 47 & branco & $A^{*} 03$ & $A^{*} 29$ & $\mathrm{~B}^{*} 07$ & $\mathrm{~B}^{*} 58$ & POS & $B$ & Sim & NÅ̃O & $01-\operatorname{dez}-00$ & 120 & 962 & 841 & 399 & Neq & & 10 -set -04 \\
\hline 1069 & Prog & $M$ & 32 & mulato & $A^{*} 02$ & $A^{*} 66$ & $\mathrm{~B}^{*} 38$ & $\mathrm{~B}^{*} 57$ & pos & & & NÄO & 31 -out -01 & 496 & 355 & 779 & 22.900 & Neq & & 29-mai-03 \\
\hline 1073 & CA & M & 37 & branco & \begin{tabular}{|l|l|}
$A^{*} 01$ \\
\end{tabular} & $\mathrm{~A}^{*} 34$ & $\mathrm{~B}^{*} 35$ & $\mathrm{~B}^{*} 57$ & NEG & & & NÄO & 19-out-01 & 394 & 541 & 309 & 399 & Neg & & 25 -ago-04 \\
\hline 1088 & CV & $M$ & 36 & negro & $A^{*} 26$ & $A^{*} 30$ & $B^{*} 14$ & $\mathrm{~B}^{*} 42$ & NEG & & & NÄO & $08-j a n-02$ & 223 & 417 & 300 & 1.010 & Neg & & $07-$ set -03 \\
\hline 1089 & CV & $M$ & 39 & mulato & \begin{tabular}{|l|}
$A^{*} 11$ \\
\end{tabular} & $A^{*} 32$ & $\mathrm{~B}^{*} 08$ & $\mathrm{~B}^{*} 53$ & NEG & $B$ & & NÄO & 18-jan-02 & 247 & 695 & 664 & 1.990 & $\mathrm{Neg}$ & & $28-\mathrm{fev}-03$ \\
\hline 1090 & Prog & $\mathrm{M}$ & 20 & branco & \begin{tabular}{|l|}
$A^{*} 02$ \\
\end{tabular} & $\mathrm{~A}^{*} 30$ & $\mathrm{~B}^{* 18}$ & $\mathrm{~B}^{*} 45$ & NEG & $\mathrm{B}$ & & NÄO & 05 -out- 01 & 170 & 395 & 763 & 30.400 & Neg & & 18 -fev-04 \\
\hline 1096 & Prog & $M$ & 32 & branco & $A^{*} 02$ & $\mathrm{~A}^{*} 30$ & $\mathrm{~B}^{*} 07$ & $\mathrm{~B}^{*} 44$ & NEG & & Sim & NÄO & $06-$ nov-01 & 116 & 410 & 1772 & 49.200 & Neg & & $26-\mathrm{mar}-02$ \\
\hline 1098 & CA & M & 31 & mulato & $A^{*} 03$ & $A^{*} 26$ & $\mathrm{~B}^{*} 27$ & $\mathrm{~B}^{*} 57$ & NEG & B & & SIM (mar-11) & 14-ago-02 & 364 & 787 & 793 & 399 & Pos & 1 & 18 -nov-13 \\
\hline 1099 & Prog & $M$ & 32 & branco & $A^{*} 02$ & $A^{*} 29$ & $B^{*} 39$ & $\mathrm{~B}^{*} 44$ & NEG & & Sim & NÄO & $04-\operatorname{dez}-01$ & 90 & 731 & 1024 & 7.950 & Pos & 1 & 13 -ago-04 \\
\hline 1102 & Prog (Trat) & M & 45 & branco & $A^{*} 01$ & $A^{*} 03$ & $\mathrm{~B}^{*} 07$ & $\mathrm{~B}^{*} 27$ & pos & & & SIM & 16 -jan-02 & 126 & 788 & 899 & 25.000 & Pos & 2 & 15 -ago-04 \\
\hline 1103 & CA & M & 26 & & $A^{*} 01$ & $A^{*} 02$ & $B^{*} 35$ & $\mathrm{~B}^{*} 57$ & NEG & B & & NÄO & $12-\operatorname{set}^{-}-01$ & 21 & 813 & 796 & 399 & Pos & 1 & $02-$ set -04 \\
\hline 1104 & Prog & $M$ & 33 & mulato & $A^{*} 01$ & $A^{*} 02$ & $B^{*} 49$ & $\mathrm{~B}^{*} 57$ & NEG & $B$ & Sim & NÄO & $08-j a n-02$ & 111 & 421 & 793 & 437.000 & Neg & & 10 -ago-04 \\
\hline 1122 & CA & $M$ & 32 & branco & $A^{*} 02$ & $A^{*} 26$ & $B^{*} 51$ & 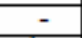 & NEG & & & NÄO & 06 -ago-02 & 181 & 918 & 913 & 399 & Pos & 16 & $10-$ nov-09 \\
\hline 1123 & CV & $M$ & 32 & mulato & $A^{*} 01$ & $A^{*} 30$ & $B^{* 14}$ & $\mathrm{~B}^{*} 57$ & NEG & & & NÄO & $03-$ set -02 & 223 & 625 & 868 & 1.280 & Pos & 4 & 25 -ago-04 \\
\hline 1138 & CV & $\mathrm{M}$ & 36 & branco & \begin{tabular}{|l|}
$A^{*} 11$ \\
\end{tabular} & $A^{*}=24$ & $\mathrm{~B}^{* 35}$ & $\mathrm{~B}^{*} 44$ & & & Sim & NÄO & 01 -jul-03 & 349 & 643 & 998 & 543 & Neg & & 25 -ago-04 \\
\hline 1143 & Prog & M & 57 & branco & $A^{*} 02$ & $A^{*} 24$ & $\mathrm{~B}^{*} 07$ & $\mathrm{~B}^{*} 18$ & & & & SIM (nov-05) & 28 -jan-03 & 97 & 641 & 595 & 82.500 & Neg & & $01-j u l-04$ \\
\hline 1173 & CA & $M$ & 38 & outro & $A^{*} 26$ & $A^{*} 68$ & $B^{*} 15$ & $\mathrm{~B}^{*} 57$ & & & & NÄO & 10 -ago-04 & 320 & 665 & 986 & 117 & Pos & 1 & 13 -jul-10 \\
\hline 1174 & CA & $M$ & 29 & mulato & $A^{*} 23$ & $A^{*} 24$ & $B^{*} 44$ & $\mathrm{~B}^{*} 57$ & & & & NÄO & $06-m a i-04$ & 246 & 239 & 347 & 49 & Neg & & 20 -ago-04 \\
\hline 2017 & CA & $M$ & 41 & branco & $A^{*} 02$ & $A^{*} 11$ & $\mathrm{~B}^{*} 35$ & $B^{*} 39$ & NEG & & Sim & NÁO & 10 -ago-00 & 365 & 518 & 622 & 399 & Neg & & $09-a b r-03$ \\
\hline 2022 & Prog & M & 21 & branco & & & & & NEG & $\mathrm{C}$ & & NÁO & $27-j a n-00$ & 127 & 421 & 1367 & 400.000 & Pos & 2 & 27 -jan-00 \\
\hline 2025 & Prog & $M$ & 27 & branco & $A^{*} 29$ & $A^{*} 32$ & $B^{*} 40$ & $B^{*} 49$ & NEG & B & & NÄO & 14-dez-00 & 281 & 377 & 517 & 121.000 & Neg & & 27 -ago-04 \\
\hline 2044 & $\mathrm{CV}$ & $\mathrm{F}$ & 31 & mulato & $A^{*} 02$ & $A^{*} 30$ & $B^{*} 15$ & $\mathrm{~B}^{*} 18$ & & & & SIM (jul-04) & $10-\operatorname{dez}-02$ & 209 & 591 & 745 & 552 & Pos & 16 & 30 -jun-04 \\
\hline
\end{tabular}




\section{REFERÊNCIAS}

Adlakha A, Pavlou M, Walker DA, Copas AJ, Dufty N, Batson S, Edwards SG, Singer M, Miller RF. Survival of HIV-infected patients admitted to the intensive care unit in the era of highly active antiretroviral therapy. Int J STD AIDS. 2011 Sep;22(9):498-504.

Amanna IJ, Slifka MK. Wanted, dead or alive: new viral vaccines. Antiviral Res. 2009, 84(2):119-130.

Autran B, Descours B, Avettand-Fenoel V, Rouzioux C. Elite controllers as a model of functional cure. Curr Opin HIV Aids. 2011, 6:181-187.

Bansal A, Carlson J, Yan J, Akinsiku OT, Schaefer M; Sabbaj S, Bet A, Levy DN, Heath S, Tang J, Kaslow RA, Walker BD, Ndung'u T, Goulder PJ, Heckerman D, Hunter E, Goepfert PA. CD8 T cell response and evolutionary pressure to HIV-1 cryptic epitopes derived from antisense transcription. J Exp Med. 2010, 207:5159.

Blankson JN. The study of elite controllers: a purê academic exercise or a potential pathway to na HIV-1 vaccine? Curr Opin HIV AIDS. 2011, 6:147-150.

Borrow P, Lewicki H, Hahn BH, Shwa GM, Oldstone MB. Vírus-specific CD8+ cytotoxic $\mathrm{T}$ lymphocyte activity associated with control of viremia in primary human immunodeficiency virus type 1 infection. J Virol. 1994, 68:6103-6110.

Bullock TNJ, Eisenlohr LC. Ribossomal scanning past the primary initiation codon as a mechanism for expression of CTL epitopes encoded in alternative reading frames. J Exp Med. 1996; 184:1319-1329.

Bullock TNJ, Patterson AE, Franlin LL, Notidis E, Eisenlohr LC. Initiation codon scanthrough versus termination codon readthrough demonstrates strong potential for major histocompatibility complex class I-restricted cryptic epitope expression. J Exp Med. 1997; 186(7):1051-1058.

Cardinaud S, Moris A, Février M, Rohrlich P-S, Weiss L, Langlade-demoyen P, Lemonnier FA, Schwartz O, Habel A. Identification of cryptic MHC I-restricted epitopes encoded by HIV-1 alternative reading frame. J Exp Med. 2004; 199(8):1053-1063.

Casado C, Colombo S, Rauch A, Martínez R, Günthard HF, Garcia S, Rodrígues C, del Romero J, Telenti A, López-Galíndez C. Host and viral genetic correlates of clinical definitions of HIV-1 disease progression. PLoS ONE. 2010; 5(6):e11079.

Deeks SG, Walker BD. Human immunodeficiency vírus controllers: mechanisms of durable virus control in the absence of antiretroviral therapy. Immunity. 2007, 27:406-416.

Draenert R, Verrill CL, Tang Y, Allen TM, Wurcel AG, Boczanowski M, Lechner A, Kim AY, Suscovich T, Brown NV, Addo MM, Walker BD. Persistent recognition of autologous virus by high-avidity CD8 T cells in chronic, progressive human immunodeficiency virus type 1 infection. J Virol. 2004, 78(2):630-41.

Duerr A, Wasserheit JN, Corey L. HIV vaccines: new frontiers in vaccine development. Clin Infect Dis. 2006, 43(4):500-511.

Elliot $\mathrm{T}$, Bodmer $\mathrm{H}$; Townsend $\mathrm{A}$. Recognition of ouT of-frame major histocompatibility complex class I-restricted epitopes in vivo. Eur $\mathbf{J}$ Immunol. 1996, 26:1175-1179.

Emu B, Sinclair E, Hatano $\mathrm{H}$ et al. HLA class I-restricted T cell responses may 
contribute to the control of human immunodeficiency vírus infection, but such responses are not always necessary for long-term virus control. J Virol. 2008, 82:5398-5407.

Friedrich TC, Valentine LE, Yant LJ, Raksz EG, Piaskowski SM; Furlott JR, Weisgrau KL, Burwitz B, May GE, León EJ, Soma T, Napoe G, Capuano SV 3rd, Wilson NA, Watkins DI. Subdominant CD8+ T cell responses are involved in durable control of AIDS. J Virol. 2007, 81:3465-3476.

Garrison KE, Champiat S, York VA, Agrawal AT, Kallas EG, Martin JN, Hecht FM, Deeks SG, Nixon DF. Transcriptional erros in human immunodeficiency vírus type 1 generate targets for $T$ cell responses. Clin Vacc Immunol. 2009, 16(9):1369-1371.

Gorse GJ, Patel GB, Arbuckle JA, Belshe RB. Binding of antibodies to human immunodeficiency virus type 1 (HIV-1)-infected lymphocytes elicited by vaccines and by natural infection. Vaccine. 2004, 22(3-4):383-97.

Goujard C, Chaix ML, Lambotte $\mathrm{O}$, et al. Spontaneous control of viral replication during primary HIV infection: when is "HIV controller"status established? Clin Infect Dis. 2009, 49-982-986.

Hatfield D \& Oroszian S. The where, what and how of ribossomal frameshifting in retroviral protein synthesis. Trens Biochem Sci. 1990, 15:186-190.

Heemels M-T \& Ploegh H. Generation, translocation, and presentation of MHC class I-restricted peptides. Annu Rev Biochem. 1995, 64:463-491.

Hesperger AR, Migueles AS, Betts MR, Connors M. Qualitative features of the HIVspecific CD8+ T cell response associated with immunologic control. Curr Opin HIV AIDS. 2011; 6:169-173.

Ho O \& Green WR. Alternative translational products and cryptic T cell epitopes: expecting the unexpected. J Immunol. 2006b, 177:8283-8289.

Ho O \& Green WR. Cytolitic CD8+ T cells directed against a cryptic epitope derived from a retroviral alternative reading frame confer disease protection. J Immunol. 2006a, 176:2470-2475.

Jin X, Bauer DE, Tuttleton SE, Lewin S, Gettie A; Blanchard J, Irwin CE, Safrit JT, Mittler J, Weinberger L, Kostrikis LG, Zhang L, Perelson AS, Ho DD. Dramatic rise in plasma viremia after CD8(+) T cell deplpetion in simian immunodeficiency vírus-infected macaques. J Exp Med. 1999, 189:991-998.

Johnston MI, Fauci AS. An HIV vaccine--evolving concepts. N Engl J Med. 2007 May 17;356(20):2073-81

Kallas EG, Bassichetto KC, Oliveira SM, Goldenberg I, Bortoloto R, Moreno DMFC, Kanashiro C, Chaves MMS, Sucupira MCA, Diniz A, Mesquita FC. Establishment of the serologic testing algorithm for recent human immunodeficiency virus (HIV) seroconversion (STARHS) strategy in the city of São Paulo, Brazil. Braz J Infect Dis [serial on the internet]. 2004, 8(6):399-406. Available from: http://www.scielo.br/scielo.php?script=sci_arttext\&pid=S1413$86702004000600003 \& \operatorname{lng}=e n$

Kembo J. Social and economic consequences of HIV and AIDS on children: case study of a high-density community in Harare, Zimbabwe. SAHARA J. 2010, 7(4):39-46.

Koup RA, Safrit JT, Cao Y, Andrews CA, McLeod G, Borkowsky W, Farthing C, Ho DD. Temporal association of cellular immune responses with the initial control of viremia in primary human immunodeficiency virus type 1 syndrome. $\mathbf{J}$ Virol. 1994; 68(7):4650-4655.

Krensky AM. The HLA system, antigen processing and presentation. Kidney Int 
Suppl. 1997, 58:S2-S7.

Lassen KG, Lobritz MA, Bailey JR et al. Elite suppressor-derived HIV-1 envelope glycoproteins exhibit reduced entry efficiency and kinectis. PLoS Pathog. 2009, 5:e1000377.

Lawn SD, Meinties G. Pathogenesis and prevention of immune reconstitution disease during antiretroviral therapy. Exp Rev Anti-infect Therapy. 2011, $9(4): 415-430$.

Liu J, O'Brien KL, Lynch DM, Simmons NL, La Porte A, Immune control of an SIV challenge by a $T$ cell based vaccine in rhesus monkeys. Nature. 2009, 457:8791.

Macejak DG \& Sarnow P. Internal initiation of translation mediated by the 5' leader of a cellular mRNA. Nature. 1991, 353:90-94.

Malarkannan S, Atkarian M, Shastri N. A rare cryptic translation product is presented by $\mathrm{K}^{\mathrm{b}}$ major histocompatibily complex class I molecule to alloreactive T cells. J Exp Med. 1995, 182:1739-1750.

Maness NJ, Valentine LE, May GE, Reed J, Piaskowski SM, Soma T, Furlott J, Rakasz EG, Friedrich TC, Price DA, Gostick E, Hughes AL, Sidney J, Sette A, Wilson NA, Watkins DI. AIDS virus-specific CD8+ T lymphocytes against an immunodominant cryptic epitope select for viral escape. J Exp Med. 2007, 204(11):2505-2512.

Maness NJ, Wilson RA, Reed JS, Piaskowski SM, Sacha JB, Walsh AD, Thoryk E, Heidecker GJ, Citron MP, Liang X, Bett AJ, Casimiro DR, Watkins D. Robust, vaccine-induced $\mathrm{CD} 8(+) \mathrm{T}$ lymphocyte response against an ouT of-frame epitope. J Immunol. 2010, 184:67-72.

Mayrand SM \& Green WR. Non-traditionally derived CTL epitopes: exceptions that prove the rules? Immunol Today. 1998, 19:551-556.

Mayrand SM, Healy PA, Torbett BE, Green WR. Anti-gag cytolytic T Imphocytes specific for na alternative translational reading frame-derived epitope and resistance versus susceptibility to retrovírus indecued murine Aids in F1 mice. Virology. 2000, 272:438-449.

Mayrand SM, Schwartz DA, Green WR. An alternative translational reading frame encodes na immunodominant retroviral CTL determinant expressed by an immunodeficiency-causing retrovírus. J Immunol. 1998, 160:39.

McGrath CJ, Chung MH, Richardson BA, Benki-Nugent S, Warui D, John-Stewart GC. Younger age at HAART initiation is associated with more rapid growth reconstitution. AIDS. 2011, 25(3):345-55.

Meiklejohn DA, Karlsson RK, Karlsson AC, Chapman JM, Nixon DF, Scheweighart B. ELISPOT cell rescue. J Immunol Methods. 2004, 288(1-2):135-147.

Migueles SA, Laborico AC, Shupert WL; Sabbaghian MS, Rabin R, Hallahan CW, Van Baarle D, Kostense S, Miedema F, McLaughlin M, Ehler L, Metcalf J, Liu S, Connors M.. HIV-specific CD8+ T cell proliferation is coupled to perforin expression and is maintained in nonprogressors. Nat Immunol. 2002; 3:10611068.

Migueles SA, Osborne CM, Royce C; Compton AA, Joshi RP, Weeks KA, Rood JE, Berkley AM, Sacha JB, Cogliano-Shutta NA, Lloyd M, Roby G, Kwan R, McLaughlin M, Stallings S, Rehm C, O'Shea MA, Mican J, Packard BZ, Komoriya A, Palmer S, Wiegand AP, Maldarelli F, Coffin JM, Mellors JW, Hallahan CW, Follman DA, Connors M. Lytic granule loading of CD8+ T cells is required for HIV-infected cell elimantion associated with immune control. Immunity. 2008; 29:1009-1021. 
Migueles SA, Sabbaghian MS, Shupert WL; Bettinotti MP, Marincola FM, Martino L, Hallahan CW, Selig SM, Schwartz D, Sullivan J, Connors M. HLA B*5701 is highly associated with restriction of virus replication in a subgroup of HIVinfected long term nonprogressors. Proc Natl Acad Sci USA. 2000; 97:27092714.

Migueles SA, Tilton JC, Connors M. Advances in understanding immunologic control of HIV infection. Curr HIV/Aids Rep. 2004; 1:12-17.

Migueles SA, Tilton JC, Connors M. Qualitative host factors associated with immunological control of HIV infection by CD8 T cells. Curr Opin HIV Aids. 2006; 1:28-33.

Montaner JS, Wood E, Kerr T, Lima V, Barrios R, Shannon K, Harrigan R, Hogg R. Expanded highly active antiretroviral therapy coverage among HIV-positive drug users to improve individual and public health outcomes. J Acquir Immune Defic Syndr. 2010, 55(Suppl 1):S5-9.

Musey L, Hughes J, Schacker T, Shea T, Corey L, McElrath MJ. Cytotoxic-T cell responses, viral load, and disease progression in early human immunodeficiency virus type 1 infection. N Engl J Med. 1997, 337(18):1267-74.

Ogg GS, Jin X, Bonhoeffer S, Dunbar PR, Nowak MA, Monard S, Segal JP, Cao Y, Rowland-Jones SL, Cerundolo V, Hurley A, Markowitz M, Ho DD, Nixon DF, McMichael AJ. Quantitation of HIV-1-specific cytotoxic T lymphocytes and plasma load of viral RNA. Science. 1998, 279(5359):2103-6.

Okulicz JF, Lambotte O. Epidemiology and clinical characteristics of elite controllers. Curr Opin HIV Aids. 2011; 6:163-168.

Pereya F, Addo MM, Kauffmann DE; Liu Y, Miura T, Rathod A, Baker B, Trocha A, Rosenberg R, Mackey E, Ueda P, Lu Z, Cohen D, Wrin T, Petropoulos CJ, Rosenberg ES, Walker BD. Genetic and immunologic heterogeneity among persons Who control HIV infection in the absence of therapy. J Infect Dis. 2008, 197:563-571.

Pereyra F, Jia X, McLaren PJ et al. The major determinants of HIV-1 control affect HLA class I peptide presentation. Science. 2010: 330:1551-1557.

PN-DST/Aids. Boletim Epidemiológico Aids e DST. 2011. Brasília, DF: Ministério da Saúde. Ano VIII, no.01.

Poropatich K \& Sullivan Jr D.J. Human immunodeficiency virus type 1 long-term non-progressors: the viral, genetic and immunological basis for disease nonprogression. J Gen Virol. 2011, 92:247-268.

Priddy FH, Brown D, Kublin J, Monahan K, Wright DP, Lalezari J, Santiago S, Marmor M, Lally M, Novak RM, Brown SJ, Kulkarni P, Dubey SA, Kierstead LS, Casimiro DR, Mogg R, DiNubile MJ, Shiver JW, Leavitt RY, Robertson MN, Mehrotra DV, Quirk E; Merck V520-016 Study Group. Safety and immunogenicity of a replication-incompetent adenovirus type 5 HIV-1 clade B gag/pol/nef vaccine in healthy adults. Clin Infect Dis. 2008, 46(11):1769-81.

Qian S-B, Princiotta MF, Bennink JR, Yewdell JW. Characterization of rapidly degraded polypeptides in mammalian cells reveals a novel layer of nascent protein quality control. J Biol Chem. 2006, 281:392-400.

Riva A, Vicenzi E, Galli M, Poli G. Strenous Resistance to Natural HIV-1 Disease Progression. Fut Virol. 2011, 6(4):521-533.

Roge BT, Barfod TS, Kirk O, Katzenstein TL, Obel N, Nielsen H, Pedersen C, Mathiesen LR, Lundgren JD, Gerstoft J. Resistance profiles and adherence at primary virological failure in three different highly active antiretroviral therapy regimens: analysis of failure rates in a randomized study. HIV Med. 2004, 
$5(5): 344-51$.

Saag M \& Deeks SG. How do HIV elite controllers do what they do? Clin Infect Dis. 2010; 51(2):239-241.

Saez-Cirion A, Lacabaratz C, Lambotte O, xxx. HIV controllers exhibit potent CD8 T cell capacity to suppress HIV infection ex vivo and peculiar cytotoxic $T$ lymphocyte activation phenotype. Proc Natl Acad Sci USA. 2007; 104:67766781.

Salvi R, Garbuglia AR, Di Caro A, Pulciani S, Montella F, Benedetto A. Grossly defective nef gene sequences in a human immunodeficiency virus type 1seropositive long-term nonprogressor. J Virol. 1998, 72(5):3646-57.

Schirmbeck R, Riedl P, Fissolo N, Lemonnier FA, Bertoletti A, Reimann J. Translation from cryptic readinig frames of DNA vaccines generates an extended repertoire of immunogenic, MHC class I-restricted epitopes. J Immunol. 2005; 174:4647-4656.

Schmitz JE, Kuroda MJ, Santra S, Sasseville VG, Simon MA, Lifton MA, Racz P, Tenner-Racz K, Dalesandro M, Scallon BJ, Ghrayeb J, Forman MA, Montefiori DC, Rieber EP, Letvin NL, Reimann KA. Control of viremia in simian immunodeficiency virus infection by CD8+ lymphocytes. Science. 1999; 283:857-860.

Schubert U, Anton LC, Gibbs J, Norbury CC, Yewdell JW, Bennink JR. Rapid degradation of a large fraction of newly synthesized proteins by proteassomes. Nature. 2000, 404:770-774.

Shastri N, Carinaud S, Schwab SR, Serwals T, Kunisawa J. All the peptides that fit: the beginning, the middle, and the end of the MHC class I antigen-processing pathway. Immunol Rev. 2005, 207:31-41.

Shastri N, Schwab S, Serwold T. Producing nature's gene-chips: the generation of peptides for display by MHC class I molecules. Annu Rev Immunol. 2002, 20:463-XXX.

Sheppard HW. Inactivated- or killed-virus HIV/AIDS vaccines. Curr Drug Targets Infect Disord. 2005, 5(2):131-41.

Thorner A, Rosenberg E. Early versus delayed antiretroviral therapy in patients with HIV infection: a review of the current guidelines from a immunological perspective. Drugs. 2003, 63(13):1325-1337.

Tonks A. Quest for the AIDS vaccine. BMJ. 2007, 334(7608):1346-8.

UNAIDS. Epidemic Update. In: UNAIDS report on the Global Aids Epidemic 2013. 2013, $198 \mathrm{p}$.

Vass J. The relationship between labour market dynamics and HIV/AIDS prevalence: a literature review. 2002.

VERMEULEN M, COLEMAN C, MITCHEL J, REDDY R, van DRIMMELEN H, FICKETT T, BUSCH M, LELIE N. Comparison of human immunodeficiency virus assays in window phase and elite controller samples: viral load distribution and implications for transmission risk. Transfusion. 2013, 53(10):2384-98.

Walker BD. Elite control of HIV Infection: implications for vaccines and treatment. Top HIV Med. 2007, 15(4):134-6.

Walker CM, Moody DJ, Stite DP, Levy JÁ. CD8+ lymphocytes can control HIV infection in vitro by suppressing virus replication. Science. 1986; 234:15631566.

Wang R-F, Parkhurst MR, Kawakami Y, Robbins PF, Rosenberg SA. Utilization of an alternative open reading frame of a normal gene in generation a novel human cancer antigen. J Exp Med. 1996, 183:1131-1140. 
Watkins DI, Burton DR, Kallas EG, Moore JP, Koff WC. Nonhuman primate modelos and the failure of the Merck HIV-1 vaccine in humans. Nat Med. 2008, 14(6):617-621.

Wawer MJ, Gray RH, Sewankambo NK, Serwadda D, Li X, Laeyendecker O, Kiwanuka N, Kigozi G, Kiddugavu M, Lutalo T, Nalugoda F, Wabwire-Mangen F, Meehan MP, Quinn TC. Rates of HIV-1 transmission per coital act, by stage of HIV-1 infection, in Rakai, Uganda. J Infect Dis. 2005, 191(9):1403-9.

Yewdell JW \& Bennink JR. Cell biology of antigen processing and presentation to major histocompatibility complex class I molecule-restricted T lymphocytes. Adv Immunol. 1992, 52:1-23.

Yewdell JW, Anton LC, Bennink JR. Defective ribosomal products (DRiPs): a major source of antigenic peptides for MHC class I molecules? J Immunol. 1996, 157:1823-1826.

Zhang Hm Qiu Z, Jiao Y, Wang A, Li T. HIV-1 specific CD8+ T cell responses to HXB2 Gag and Nef peptide pools in Chinese HIV/AIDS patients. Sci China C life Sci. 2009, 52(9):841-6.

Zuk DM, Hughes CA, Foisy MM, Robinson JL, Singh AE, Houston S. Adverse effects of antiretrovirals in HIV-infected pregnant women. Ann Pharmacother. 2009, 43(6):1028-35. 


\section{APÊNDICES}

1) Cópia do artigo de Champiat S, 2012

2) Artigo submetido ao Journal of AIDS

3) Comprovante de submissão de artigo 


\title{
Influence of HAART on Alternative Reading Frame Immune Responses over the Course of HIV-1 Infection
}

\author{
Stephane Champiat ${ }^{1}$, Rui André Saraiva Raposo ${ }^{1}$, Nicholas J. Maness ${ }^{2}$, John L. Lehman ${ }^{1,8}$, Sean E. Purtell ${ }^{8}$, \\ Aaron M. Hasenkrug ${ }^{1}$, Jacob C. Miller ${ }^{1}$, Hansi Dean ${ }^{3}$, Wayne C. Koff ${ }^{3}$, Marisa Ailin Hong ${ }^{4}$, \\ Jeffrey N. Martin ${ }^{6}$, Steven G. Deeks ${ }^{7}$, Gerald E. Spotts ${ }^{7}$, Christopher D. Pilcher ${ }^{7}$, Fredrick M. Hecht ${ }^{7}$, \\ Esper G. Kallas ${ }^{5}$, Keith E. Garrison ${ }^{89}$, Douglas F. Nixon ${ }^{1 * 9}$
}

1 Division of Experimental Medicine, Department of Medicine, University of California San Francisco, San Francisco, California, United States of America, 2 Department of Pathology and Laboratory Medicine, University of Wisconsin-Madison, Madison, Wisconsin, United States of America, $\mathbf{3}$ International AIDS Vaccine Initiative, New York, New York, United States of America, 4 Division of Clinical Immunology and Allergy, University of São Paulo, São Paulo, Brazil, and Institute Adolfo Lutz, São Paulo, Brazil, 5 University of São Paulo, São Paulo, Brazil, Division of Clinical Immunology and Allergy, University of São Paulo, São Paulo, Brazil, 6 Epidemiology and Prevention Interventions Center, Division of Infectious Diseases, and The Positive Health Program, San Francisco General Hospital, University of California San Francisco, San Francisco, California, United States of America, 7 Positive Health Program, Department of Medicine, San Francisco General Hospital, University of California San Francisco, San Francisco, California, United States of America, 8 Department of Biology, Saint Mary's College of California, Moraga, California, United States of America

\begin{abstract}
Background: Translational errors can result in bypassing of the main viral protein reading frames and the production of alternate reading frame (ARF) or cryptic peptides. Within HIV, there are many such ARFs in both sense and the antisense directions of transcription. These ARFs have the potential to generate immunogenic peptides called cryptic epitopes (CE). Both antiretroviral drug therapy and the immune system exert a mutational pressure on HIV-1. Immune pressure exerted by ARF $C D 8^{+} T$ cells on the virus has already been observed in vitro. HAART has also been described to select HIV- 1 variants for drug escape mutations. Since the mutational pressure exerted on one location of the HIV-1 genome can potentially affect the 3 reading frames, we hypothesized that ARF responses would be affected by this drug pressure in vivo.

Methodology/Principal findings: In this study we identified new ARFs derived from sense and antisense transcription of HIV-1. Many of these ARFs are detectable in circulating viral proteins. They are predominantly found in the HIV-1 env nucleotide region. We measured T cell responses to 199 HIV-1 CE encoded within 13 sense and 34 antisense HIV-1 ARFs. We were able to observe that these ARF responses are more frequent and of greater magnitude in chronically infected individuals compared to acutely infected patients, and in patients on HAART, the breadth of ARF responses increased.
\end{abstract}

Conclusions/Significance: These results have implications for vaccine design and unveil the existence of potential new epitopes that could be included as vaccine targets.

Citation: Champiat S, Raposo RAS, Maness NJ, Lehman JL, Purtell SE, et al. (2012) Influence of HAART on Alternative Reading Frame Immune Responses over the Course of HIV-1 Infection. PLoS ONE 7(6): e39311. doi:10.1371/journal.pone.0039311

Editor: Paul A. Goepfert, University of Alabama, United States of America

Received September 23, 2011; Accepted May 18, 2012; Published June 29, 2012

Copyright: () 2012 Champiat et al. This is an open-access article distributed under the terms of the Creative Commons Attribution License, which permits unrestricted use, distribution, and reproduction in any medium, provided the original author and source are credited.

Funding: The study was funded by the International AIDS Vaccine Initiative (IAVI), a not for profit organization focused on helping facilitate the discovery of an effective AIDS vaccine. Two scientists from IAVI were involved in the design, analysis and writing of the paper and are included as co-authors. The funders had no role in data collection or decision to publish the manuscript.

Competing Interests: The authors have declared that no competing interests exist.

*E-mail: douglas.nixon@ucsf.edu

9 These authors contributed equally to this work.

\section{Introduction}

$\mathrm{CD}^{+} \mathrm{T}$ cell responses are a major component in the immune control of HIV-1 replication [1,2,3,4]. Primate studies suggest that the breadth and magnitude of the vaccine-induced $\mathrm{CD}^{+} \mathrm{T}$ cell response correlates with viral load [5]. In the Step Trial that failed to demonstrate efficacy, the Merck trivalent vaccine induced a low number of $\mathrm{CD}^{+} \mathrm{T}$ cell epitope responses per vaccinee (with a median of three epitopes), suggesting that to be effective, vaccines should induce a greater number of $\mathrm{T}$ cell responses [6].

HIV-1 infected cells are recognized by the $\mathrm{CD}^{+} \mathrm{T}$ cell receptor (TCR) through viral peptides presented on MHC-I molecules. Most of the HIV-1 epitopes described have been identified in
HIV-1 proteins encoded by primary open reading frames (ORFs) of the viral genome $[7,8,9,10,11,12]$. Aside from these "traditional epitopes", a new type of epitopes derived from frame-shifted proteins, called alternative reading frame (ARF) epitopes or cryptic epitopes (CE), have been reported for influenza virus [13,14], malignancies $[15,16,17,18]$, and an autoimmune disease [19]. ARF expression may be explained by several transcriptional and translational mechanisms [20]: ribosomal frame-shifting [21], cryptic promoter activation, internal ribosomal entry sites [22], initiation codon scan-through [23], doublet decoding alternative splicing patterns [24], and initiation from non-AUG codons [25].

These nontraditional Cytotoxic T Lymphocyte (CTL) epitopes are generated during HIV-1 and/or SIV infections 
[26,27,28,29,30,31,32]. However, another source of cryptic epitopes originates from antisense $\left(3^{\prime}\right.$ to $\left.5^{\prime}\right)$ RNA transcription such antisense transcripts have been identified in HIV-1 infections $[33,34,35]$, and CEs derived from these antisense RNA have been previously reported in SIV and HIV-1 infections [26,28,30]. CD8 ${ }^{+}$ specific T cells against HIV-1 CE could potentially contribute to viral control in vivo [36]. In vitro studies show that SIV ARF epitope-specific CTLs are able to select for viral escape variants [30]. These ARF-derived peptides could therefore be an important source of epitopes and could be used in an HIV-1 vaccine to broaden the spectrum of the $\mathrm{CD}^{+} \mathrm{T}$ cell responses.

To date, many studies have shown that immunological pressure exerted by CTL shapes HIV-1 sequences by selecting for CTL escape mutations $[32,37,38,39]$. HAART has also been described to select HIV-1 variants for drug escape mutations $[40,41,42,43,44,45,46,47,48]$. More recently, there has been some evidence that emergence of drug resistance mutations can potentially abolish HIV-1 CTL responses [49].

In this regard, we anticipated that ARFs would be affected by immunological and drug pressure in vivo. Immune pressure exerted by the ARF $\mathrm{CD}^{+} \mathrm{T}$ cells on the virus has already been reported in vitro [30]. Since the mutational pressure exerted on one location of HIV-l's genome can potentially affect each of the 3 reading frames, ARF expression could be affected by HAART. HAART mutational pressure on the virus could therefore be responsible for the mutation or conservation of the genome of certain traditional proteins or could disturb the expression of certain locations on HIV-1's genome, influencing ARF expression and escape from ARF CTL responses.

In this study, we evaluated the influence of HAART on HIV1 ARF $\mathrm{T}$ cell responses over the course of HIV-1 infection. We identified new cryptic epitopes derived from sense and antisense transcription of HIV-1. To evaluate the effect of HAART on the ARF $\mathrm{T}$ cell responses, we tested PBMCs from HIV-1 acutely infected patients enrolled in a HAART interruption program and HIV-1 chronically infected patients before and after HAART introduction. We report that $\mathrm{ARF}$ responses were more frequent and stronger in magnitude in chronically infected individuals compared to acutely infected patients, and importantly that HAART increased the breadth of the ARF responses. Our results indicate that $\mathrm{CE}$ could potentially be used to increase the breadth of an HIV-1 vaccine response.

\section{Materials and Methods}

\section{Subjects}

All subjects were recruited at the University of California, San Francisco (UCSF), and were at least 18 years of age at the time of sample collection. All samples were obtained according to protocols approved by the Institutional Review Board (IRB) at UCSF. Written informed consent was obtained from all subjects, according to the Declaration of Helsinki. In order to study the effect of HAART on ARF responses, IFN- $\gamma$ ELISPOT assays were conducted in 2 different cohorts: the "OPTIONS cohort" with acutely infected individuals, and the "SCOPE cohort" with chronically infected individuals.

The OPTIONS cohort consists of subjects in acute or early HIV-1 infection, with approximately 90\% enrolled within 6 months of acquiring HIV-1 infection. For the purposes of this manuscript, subjects in this cohort as designated as "acute" or "acutely infected" to help distinguish them from chronically infected subjects. Cryopreserved PBMC samples were taken from subjects enrolled in the OPTIONS cohort who had undergone a treatment interruption study. To qualify for the treatment interruption (TI) study, participants must have initiated antiretroviral therapy within 6 months of HIV-1 seroconversion, received treatment for at least 24 weeks, and maintained viral loads (VL) below 75 copies $/ \mathrm{mL}$ for at least 8 weeks prior to entering the protocol. The treatment interruption $(\mathrm{TI})$ protocol was approved by the UCSF IRB, and was designed for patients who initiated antiretroviral therapy in early HIV-1 infection. Under this protocol, treatment would be re-initiated if viral load exceeded certain thresholds $(>200,000$ copies $/ \mathrm{mL}$ at any time or $>50,000$ copies/mL between weeks 4 and 7 of TI). PBMC from each individual was assayed at an early time-point on HAART, with undetectable viral load, and at a later time-point after HAART interruption, with high viral load. Out of 28 acute patients, we tested the 2 time-points (before and after HAART interruption) for 25 patients. We were unable to follow 3 patients at the time-point before HAART interruption.

HIV-1-infected adults were sampled from the Study of the Consequences of the Protease Inhibitor Era (SCOPE), a clinicbased cohort of over 1000 chronically HIV-1-infected individuals at the University of California San Francisco. Chronically infected individuals were tested at an early time-point before HAART treatment with high viral load, and at a later time-point on HAART with undetectable viral load. Out of 21 chronic patients, 18 patients were tested before and after HAART introduction. For 2 patients we only tested the sample before HAART introduction and for 1 patient we only tested the sample after HAART introduction. A description of the cohorts used is depicted in Table 1. Table S1 depicts the viral load, $\mathrm{CD}^{+}$and $\mathrm{CD}^{+} \mathrm{T}$ cell counts for each patient in each group.

HIV-1 negative, healthy blood donors provided PBMC for control assays $(\mathrm{N}=12)$. No positive $\mathrm{CE}$ responses were noted in any healthy blood donor.

\section{In silico Detection of Alternate Reading Frames}

Geneious Pro software was used to identify alternative openreading frames (ORF) starting with an AUG codon in HIV-1 HXB-2 strain. Both forward and reverse ORFs were identified. Forward ORFs with significant similarity to known HIV proteins were eliminated based on batch BLAST searches with manual editing. Out of the 82 forward ORFs identified, 13 did not have significant similarity via BLAST to known HIV proteins. This resulted in the selection of 13 forward ORFs and 70 reverse ORFs for further analysis (Table S2). In the BLAST searches for the 13 selected forward ORFs, 12 generated short hits against small numbers of circulating viral sequence accessions in the NCBI nr protein database (Table S3). These hits did not prompt rejection of the ORF from further consideration, because of low bit scores, and high e-values relative to those ORFs that represented canonical coding sequence for the virus. For these hits, the geographic origin of the sequence, location within the HIV-1 genome, and any data pertinent to the mechanism by which this aberrant sequence may have arisen were recorded. We believe these sequences to be examples of the incorporation of $\mathrm{ARF}$ regions into circulating viral sequences isolated from $\mathrm{HIV}-1$ positive subjects.

\section{In silico Peptide Prediction}

In silico $\mathrm{T}$ cell immunogenicity prediction methods were used to identify 9-mer peptide epitopes with potential to be processed by cells, transported into the ER by TAP and bind to HLA molecules in the HLA-B58, A2, and B7 super-families. Peptides were identified within the 13 selected forward and 70 reverse HIV-1 alternate reading frames with NetCTL 1.2 software (http://www. cbs.dtu.dk/services/NetCTL/). All forward ORFs were batched and submitted together to prioritize the highest scoring peptides 
Table 1. Patients' characteristics.

\begin{tabular}{|c|c|c|c|c|c|c|}
\hline Patient group & $\begin{array}{l}\text { Number of } \\
\text { patients }\end{array}$ & $\begin{array}{l}\text { Number of } \\
\text { additional } \\
\text { patients }\end{array}$ & $\begin{array}{l}\text { Total number of } \\
\text { tested samples }\end{array}$ & $\begin{array}{l}\text { Mean } \mathrm{CD4}^{+} \mathrm{T} \text { cell } \\
\text { count }\left(\text { cells } / \mathrm{mm}^{3}\right)\end{array}$ & $\begin{array}{l}\text { Mean } \mathrm{CDB}^{+} \mathrm{T} \text { cell } \\
\text { count }\left(\text { cells } / \mathrm{mm}^{3}\right)\end{array}$ & $\begin{array}{l}\text { Mean HIV-1 plasma } \\
\text { viral load (copies/mL) }\end{array}$ \\
\hline $\begin{array}{l}\text { Acute On HAART Early } \\
\text { Time-point }\end{array}$ & 25 & 0 & 25 & 771 & 733 & 59 \\
\hline $\begin{array}{l}\text { Acute Off HAART Later } \\
\text { Time-point }\end{array}$ & 25 & 3 & 28 & 625 & 999 & 117,000 \\
\hline $\begin{array}{l}\text { Chronic Before HAART } \\
\text { Early Time-point }\end{array}$ & 18 & 2 & 20 & 328 & 1,439 & 545,000 \\
\hline $\begin{array}{l}\text { Chronic On HAART } \\
\text { Later Time-point }\end{array}$ & 18 & 1 & 19 & 482 & 1,227 & 52 \\
\hline
\end{tabular}

regardless of individual ORF origin. Top-scoring forward ORF epitopes $(\mathrm{N}=22)$ for HLA-B58, A2, and B7 super-types were selected for peptide synthesis.

Reverse ORFs peptides were also submitted for batch scoring and were prioritized by combining the NetCTL score with additional data regarding previous evidence of ORF expression, ORF length, amino acid similarity to ARF epitopes detected in SIV, and proximity to the $3^{\prime}$ LTR.

Following peptide selection, candidate peptides were again searched using BLAST against a custom database consisting of HXB-2 and consensus B HIV-1 protein sequences gathered from the Los Alamos National Lab HIV sequence databases. Peptides from both forward and reverse reading frame ORFs were included in these searches because any similarity that we expected to detect would have resulted from spurious matches of amino acid sequences within peptides. Peptides were classified according to the numbers of amino acids in common with an HXB-2 and/or consensus B amino acid sequence. Peptides with 5 or fewer amino acids in common were classified as not significantly similar for the purposes of $\mathrm{T}$ cell recognition. Peptides with 6 or more amino acids in common are reported.

199 ARF peptides (forward and reverse ORF) were tested: 22 peptides from 13 identified forward ORF (6 predicted HLA-A2, 5 predicted HLA-B7, and 11 predicted HLA-B58 super-type epitopes), the 2 Tat and Rev splice variant peptides previously published [32], and 175 reverse ORF peptides from 34 identified reverse ORF (80 predicted HLA-A2, 38 predicted HLA-B7, and 60 predicted HLA-B58 super-type epitopes) (Figure 1).

\section{Peptide Synthesis}

Peptides were synthesized on NEP array plates (96 wells plates), with $75 \%$ purity average at a $2.5 \mathrm{mmol}$ scale with a mass spectrometry analysis of 5 peptides per plate to ensure successful synthesis and positive identification. To evaluate classic HIV-1 T cell responses, a pool of peptides from HIV-1 Gag p24 full protein was used. Table S4 lists the sequences of the ARF individual peptides used in this study and Table S5 lists the content of each ARF pool tested.

\section{IFN- $\gamma$ ELISPOT Assays}

Immune responses were measured by IFN- $\gamma$ ELISPOT, as previously described [38]. Data represent the average of two replicate wells minus the average of all negative (no peptide) wells, and are reported as spot-forming cells (SFCs) per million PBMCs, with 100,000 cells added per well. Responses were considered positive if the SFG count was greater than 5 spots (50 SFC per million PBMCs) and greater than twice the background. Peptides were tested at $5 \mu \mathrm{M} /$ well.

To minimize variability, the same individual ran all experiments and the two time-points from the same patient ("on" versus "off" HAART) were tested on the same day.

\section{Statistical Analysis}

Statistical comparisons were performed using repeated measures logistic regression models. The fixed effects parameters in the model were indicators of "On" versus "Off HAART", "Acute" versus "Chronic" patients, and the interaction of these two factors. Random effects were used for both study subject and for peptide pool to account for the intra-response correlations. Analyses were performed using Stata 12.

\section{Results}

ARF Sequences are Found in Viruses with Gross Deletions or Originating in Geographic Regions with a High

\section{Prevalence of Recombinants}

We found relatively small numbers of short matches with HIV-1 sequences while eliminating candidate ARF regions for structural and accessory proteins. Matches represented circumstances where ARF amino acid sequences were incorporated into predicted sequences for viral proteins. Alternatively, these sequences may possibly represent sequencing errors, indels erroneously introduced into the reported nucleic acid sequence, resulting in a frameshift mutation downstream. We noted the geographic origin, the region of the HIV-1 genome in which the hit was found, gross deletions, circulating recombinant forms or other major features of the sequence to determine causative factors associated with the inclusion of ARF regions in HIV-1 sequences. No mechanism for the incorporation of the ARF was discernable for the majority of ARF sequences detected (70\%, referenced in Table S2). Amongst sequences with an attributable origin, over half were associated with either a recombination event or the presence of circulating recombinant forms (Figure 2A). ARFs were also associated with gross deletions, truncations, and point mutations (Figure 2A).

\section{ARF Sequences are Skewed in Distribution}

\section{Predominantly in the HIV-1 Env Nucleotide Region}

We investigated the genomic region that served as the source of $\mathrm{ARF}$ sequences. If incorporation of $\mathrm{ARF}$ sequences were a purely random event, the frequency of incorporation would be expected 


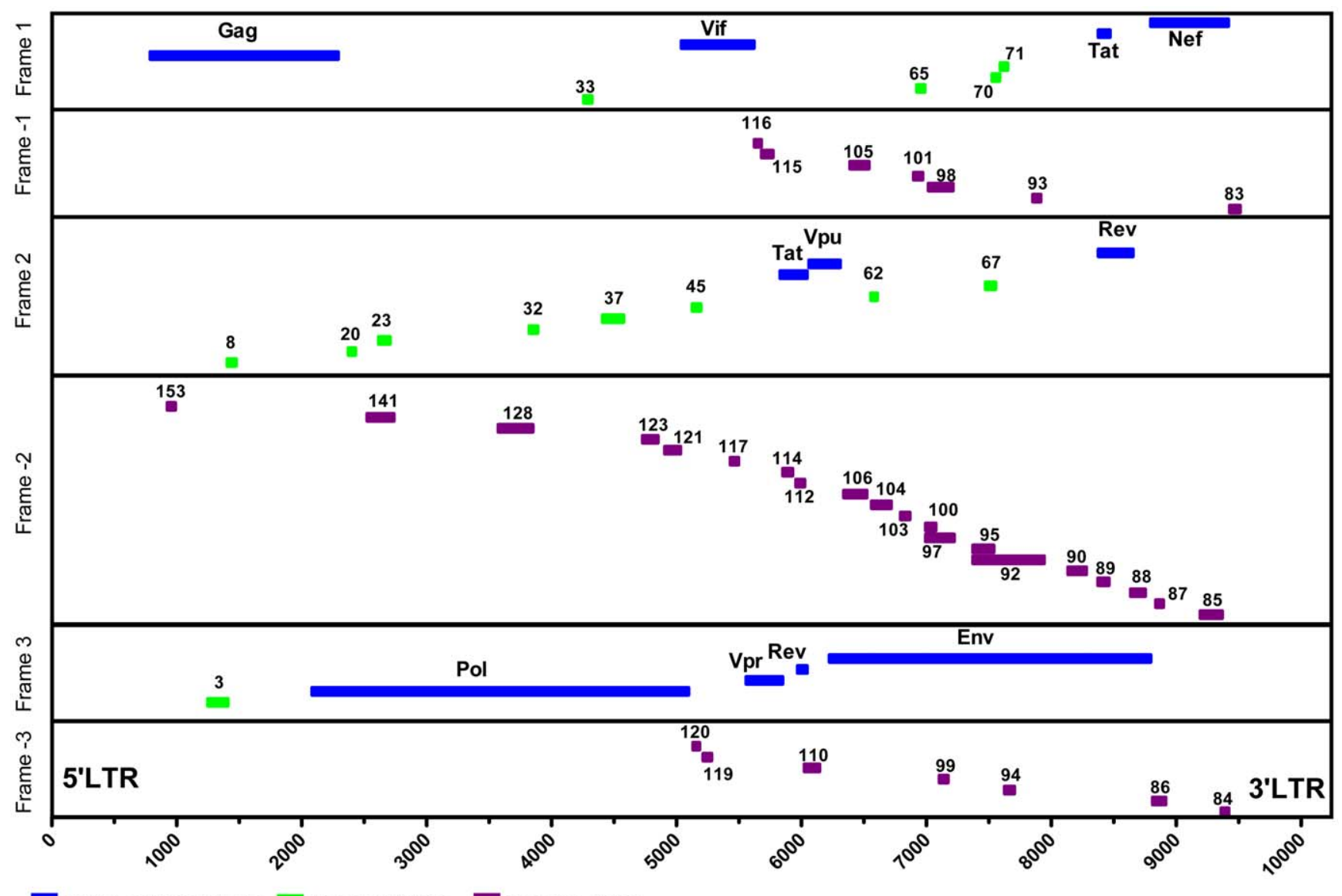

HIV-1 coding regions Forward ARFs $\square$ Reverse ARFs

Figure 1. HIV-1 genome (HXB-2 strain), and localization of the 47 alternative reading frames (ARF). Figure depicts all 199 ARF-tested peptides. These include 13 forward ARF within frames 1, 2 or 3 (in green) and 34 reverse ARF within frames $-1,-2$ or -3 (in purple). HIV-1 classically defined encoding genes are shown in blue.

doi:10.1371/journal.pone.0039311.g001

to be proportional to the contribution of each region to the total coding nucleotide sequence for structural proteins of the virus particle (Figure 2B). We determined that the major contributor of ARF sequences was from the HIV-1 env nucleotide region (Figure 1), despite the fact that the env nucleotide region makes only the second largest contribution to the coding sequence as a percentage of the total of coding bases $(36 \%$ of the coding sequence: 2,751 of 6,878 total coding nucleotides), (Figures 2B and 2C). Interestingly, the HIV-1 pol nucleotide region is responsible for $24 \%$ of the total circulating ARF sequences despite its contribution of $44 \%$ of the coding sequence in the viral genome (Figures 2B and 2C). To examine more precisely the nature of the similarity between the HXB-2 reference, the ARF region and circulating viral sequences, we created amino acid alignments for a subset of matching accessions. We aligned one matching accession from each region of the genome: the envelope region (Figure 2D), the gag region (Figure 2E) and the pol region (Figure 2F). In each region, amino acid alignments showed similarity both to the HXB2 reference sequence and to the alternate reading frame sequence, but within distinct regions of each matching sequence (Figures 2D$2 \mathrm{~F})$. These data indicate that the viral sequences identified in these accessions are likely hybrids or chimaeras of standard and alternate reading frame encoded sequences.
Peptides Originating from ARF Regions are Distinguishable in Amino Acid Sequence from Peptides Derived from HIV-1 Structural and Accessory Proteins

We searched our candidate ARF 9-mer peptides for similarity to HIV-1 structural and accessory proteins. None of the ARF peptides were identical in amino acid sequence to any known structural or accessory protein regions of HIV-1. All ARF-derived peptides differed by two or more amino acids from their closest match in a structural or accessory protein of HIV-1. B7ORF70ML9, the peptide that matched at 7 of 9 amino acids was derived from ORF 70 and was a part of Pool \#2. There were also four peptides that matched at 6 of 9 amino acids (B7ORF70LV9, B7ORF88SL9, A2ORF97LV9 and A2ORF97CI9 were derived from ORF 70, ORF 88 and ORF 97, respectively). ORF 70 is a Forward ORF, ORFs 88 and 97 are Reverse ORFs. The ORF 88 peptides were a part of Pool \#13. The ORF 97 peptides were a part of Pool \#15. As a forward reading frame ARF, ORF 70 was included in our searches of the BLAST databases for ARF incorporation (Table S3). There were 5 hits against this ORF, indicating that ORF 70 is detectably incorporated into circulating viral sequences. The two peptides with BLAST hits within this ARF are similar to Vif amino acids 162-169, which is a previously identified HLA-B7 restricted epitope in the Los Alamos database. However, significant similarity does not extend outside this small region, so it does 

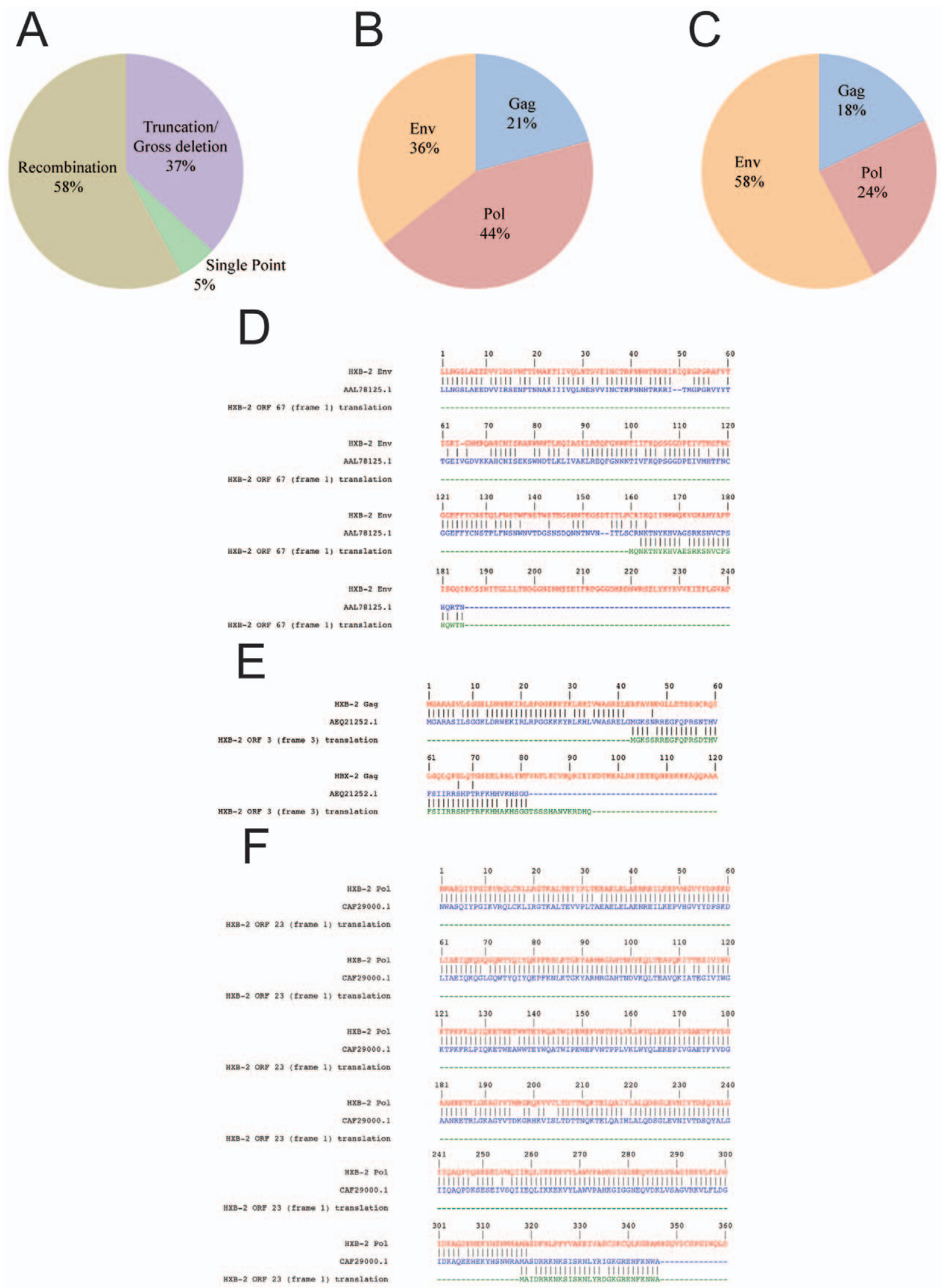

Figure 2. Alternate reading frame-encoded amino acids in circulating viral sequences. A) Distribution of known mutant origins across viral ARF sequences attributable to a particular cause based on information associated with the sequence accession the NCBI nr protein database presented in Table S2. B) Composition of viral coding sequence computed as a percentage assigned to the coding sequence for the Env, Gag, Pol 
poly-proteins based on nucleotide base counts for a particular gene region compared to the total nucleotide count for the structural genes of the virus. Gag comprises 1,503 nt of the total of 6,878 nt of structural gene sequence; Pol comprises 3,139 nt of the total; Env comprises of 2,571 nt of the total. This is the distribution of origins within the genome that would be expected if originating events for the incorporation of ARF and their detection in circulating HIV-1 viral sequences were distributed randomly throughout the genome. C) The distribution of ARF incorporated into circulating viral sequences that was observed in our searches of NCBI nr protein database for ARF sequences in circulating HIV-1 viral sequences. The percentages were computed by dividing the number of BLAST hits with ARF sequence incorporated into a given gene region by the 123 total hits examined. D) A three-way alignment between the HXB-2 reference sequence for the Env region, the accession AAL78125.1 and the alternate reading frame encoded ORF 67. E) A three-way alignment between the HXB-2 reference sequence for the Gag region, the accession AEQ21252.1 and the alternate reading frame encoded ORF 3. F) A three-way alignment between the HXB-2 reference sequence for the Pol region, the accession CAF29000.1 and the alternate reading frame encoded ORF 23. All three-way alignments were generated by combining two pair-wise alignments created in Geneious, followed by manual editing. Note each accession is similar to both the HXB-2 reference sequence for the structural proteins and the alternate reading frame encoded sequence, but not to both sequences simultaneously within the same region of the sequence. doi:10.1371/journal.pone.0039311.g002

not represent a failure to exclude the first exon of Vif from our tests.

\section{HIV-1 Acutely Infected Individuals on HAART Mount Detectable Responses Against ARF Pool Peptides}

To assess if ARF $\mathrm{T}$ cell responses occur early after HIV-1 infection, we tested PBMC from HIV-1 acutely infected individuals with ARF peptides, and detected the production of IFN- $\gamma$ in an ELISPOT assay. In order to show the breadth of the responses, Figure $3 \mathrm{~A}$ depicts the number of detectable responses against the ARF pool peptides tested in patients "On HAART" (blue bars) and "Off HAART" (red bars). For acute subjects, there were a total of 6 responses "On HAART" (1.1\% of all wells) versus 17 responses "Off HAART" $(2.8 \%)(\mathrm{p}=0.06$ by repeated measures logistic regression). We detected 3 independent responses against ARF peptide pools \#2 and \#12, followed by pools \#8, \#14 and \#19. Most peptide pools only elucidated one detectable response. It is not possible to discern whether the responses seen in pools 2, $8,12,14$, and 19 in Figure $3 \mathrm{~A}$ are due to cryptic epitopes or to epitopes with significant homology to the main HIV-1 proteins (peptides P2-407, P2-410; P8-462; P12-490, P12-493; P14-515, P19-569). Figure 3B illustrates the number of ARF peptide pool responses detected in each individual patient tested "On HAART" (blue bars) and "Off HAART" (red bars). Patients \#2, \#7 and \#27 mounted 3 effective ARF responses while off HAART and, in contrast, in patient \#5, we did not detect any responses while off HAART, but detected 3 while on HAART. Out of the 25 patients with undetectable VL and at an early timepoint after infection, 4 mounted a detectable response against ARF peptides (patients \#4, \#5, \#18 and \#25) with an average of 129 SFU (Figure 3). We also determined effective $\mathrm{T}$ cell responses against HIV-1 Gag p24 peptides and found it to be on average $315 \mathrm{SFU}$ on $12 \%$ of responders (3/25) (data not shown).

\section{HAART Interruption is Associated with an Increase in Frequency and Magnitude of ARF Responses}

To evaluate whether HAART could play a role in impacting ARF responses in acutely infected patients, we tested a cohort of 28 patients enrolled in a controlled HAART interruption program. Early time-points before HAART interruption were initially tested in 25 of these patients. Figure 4 illustrates the detectable responses against the different ARF pool peptides in patients while On HAART (blue bars), or Off HAART (red bars). Analysis of responses at later time-points after HAART interruption and with high VL revealed 9 out of 28 patients $(32 \%$ responders) mounted an effective response against the ARF peptide pools with an average of 233 SFU. 14 out of 28 patients (50\% responders) had an effective response against HIV-1 Gag p24 peptides with an average response of 777 SFU (data not shown). The data demonstrate that acutely infected patients mount responses against ARF peptides. Overall, 13 out of 28 patients tested $(46 \%)$ show responses against one or several ARF pools. In this cohort study, patients were enrolled in a controlled HAART interruption program, and responses are rare in patients on HAART $(16 \%)$, but increase after the interruption of therapy $(32 \%)$. In addition, the magnitude of ARF responses increased with the interruption of HAART (128 SFU in patients on HAART to $233 \mathrm{SFU}$ in patients off HAART). Interestingly, the dynamics of ARF responses also changed before and after HAART interruption. In this regard, we report that all responses against ARF peptides in patients on HAART were not maintained after the interruption of the treatment. On the other hand, patients on HAART, but with no effective ARF responses were able to mount ARF $T$ cell responses after treatment interruption.

\section{T Cell Responses Against ARF Pool Peptides are Stronger in HIV-1 Chronically Infected Individuals}

Next, we investigated whether chronically infected patients could still mount effective responses against ARF pool peptides. For this purpose we tested chronically HIV-1 infected subjects at an early time-point before HAART treatment with high viral load and the same patients at a later time-point while on HAART. In order to show the breadth of the measurable responses, Figure $5 \mathrm{~A}$ depicts the number of detectable responses against the ARF pool peptides tested in patients "Before HAART" (grey bars) and "On HAART" (black bars). For chronic subjects, there were a total of 29 responses on HAART $(6.9 \%$ of all wells) versus 8 responses before HAART $(1.6 \%)$ ( $<<0.01$ by repeated measures logistic regression). In parallel, Figure $5 \mathrm{~B}$ shows the number of $\mathrm{ARF}$ responses detected for each individual chronic patient tested. We found that $20 \%$ of the patients tested with high viral load $(4 / 20)$ responded against ARF pool peptides before the introduction of HAART (Figure 5B). Average ARF responses in this group were $2101 \mathrm{SFU}$, compared to $1009 \mathrm{SFU}$ against HIV-1 Gag p24 observed in $45 \%$ of responders (9/20) (data not shown). Overall, chronically HIV-1 infected patients present stronger and more frequent responses against several ARF pools compared to acutely HIV-1 infected. This suggests that ARF responses increase with the duration of infection.

\section{The Introduction of HAART in Chronically HIV-1 Infected Patients Increases the Breadth of ARF Responses}

To investigate if HAART had the same impact on ARF responses in chronically HIV-1 infected individuals as it did in acutely infected, we tested the same patients at a later time-point on HAART and with undetectable viral load. We detected effective responses in $26 \%$ of the patients tested (5/19) against ARF pool peptides at the later time-point while on HAART with undetectable VL (Figure 6). Although the frequency of responses was higher in patients on HAART, the average magnitude of the responses is lower (978 SFU), compared to the responses against 
A
On HAART
Off HAART

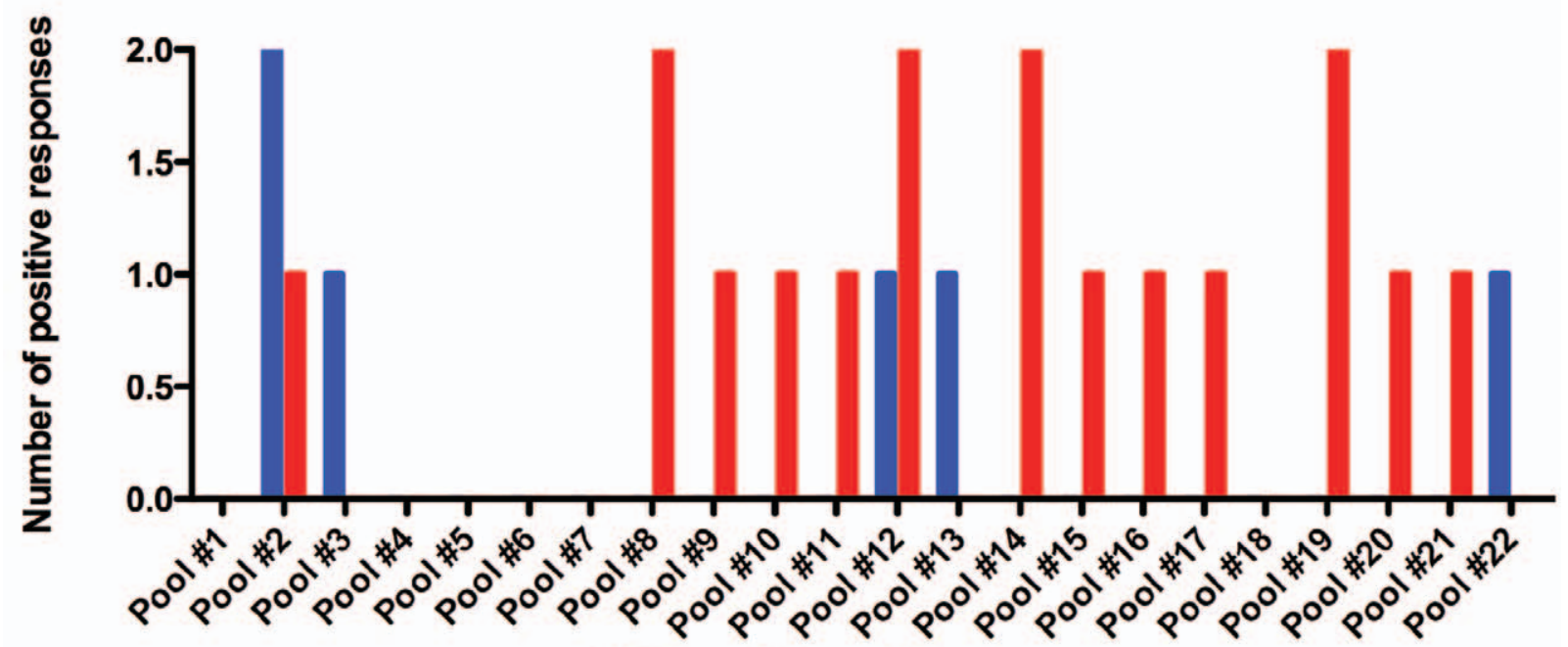

ARF peptide pool Number

B

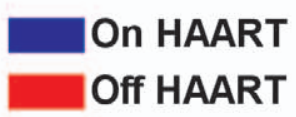

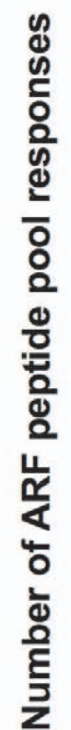

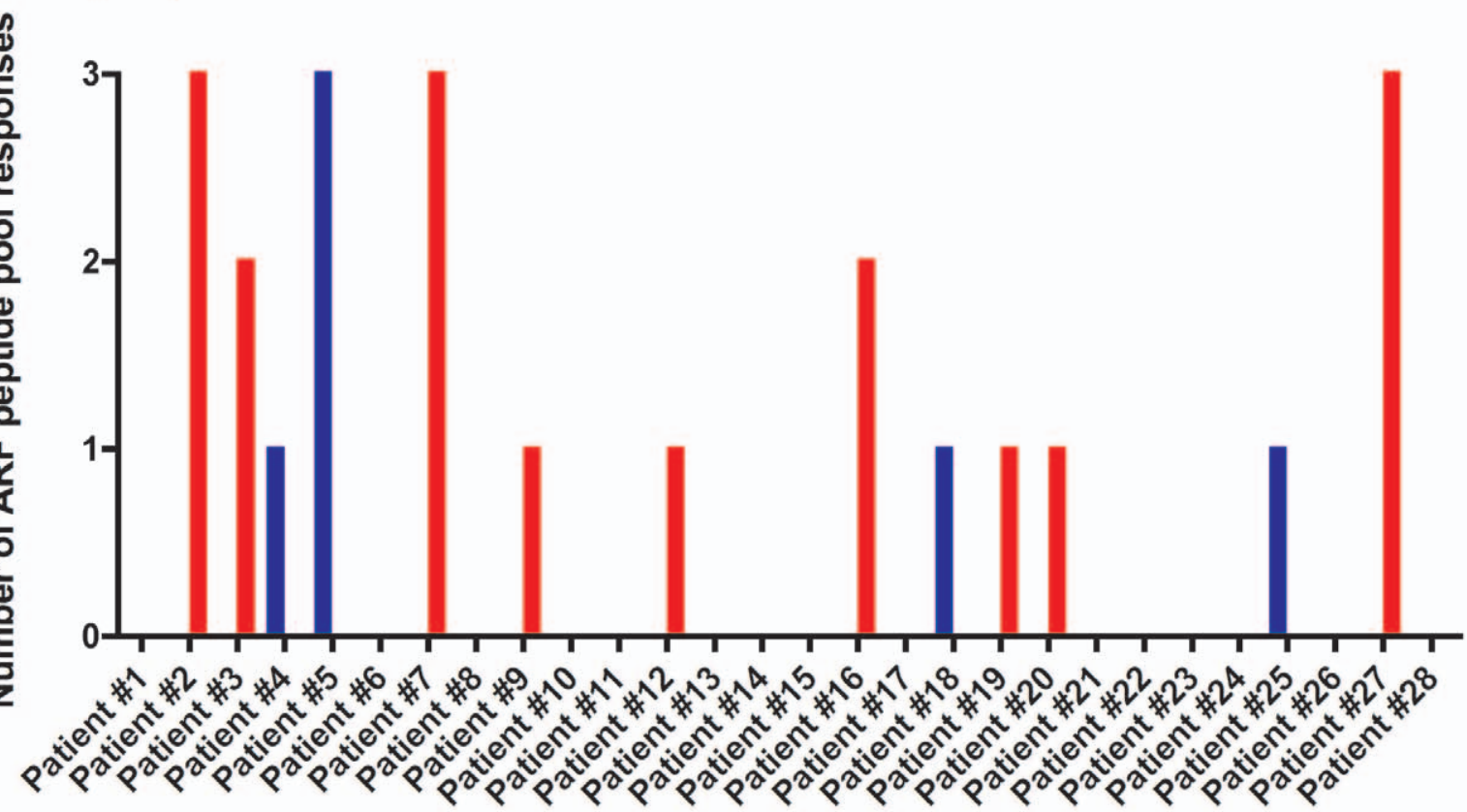

Patient ID

Figure 3. Breadth of ARF responses in acutely infected patients. A) Number of detectable responses observed for each individual ARF peptide-pool tested. B) Number of ARF peptide pools that induced detectable responses in each acutely infected individual. Blue bars represent patients On HAART and red bars represent patients Off HAART. We were unable to follow patients \#26, \#27 and \#28 before HAART interruption. doi:10.1371/journal.pone.0039311.g003

HIV-1 Gag p24 (32\% of responders (6/19) with an average response of $658 \mathrm{SFU})$.

Although ARF responses after HAART were diminished in all cases, they still remained at weak to moderate levels, suggesting that cryptic epitopes are still presented, even under suppressive HAART regimens. Overall, we observed a higher number of ARF responses after HAART introduction, suggesting that HAART favors the emergence of new CE responses and increases the 

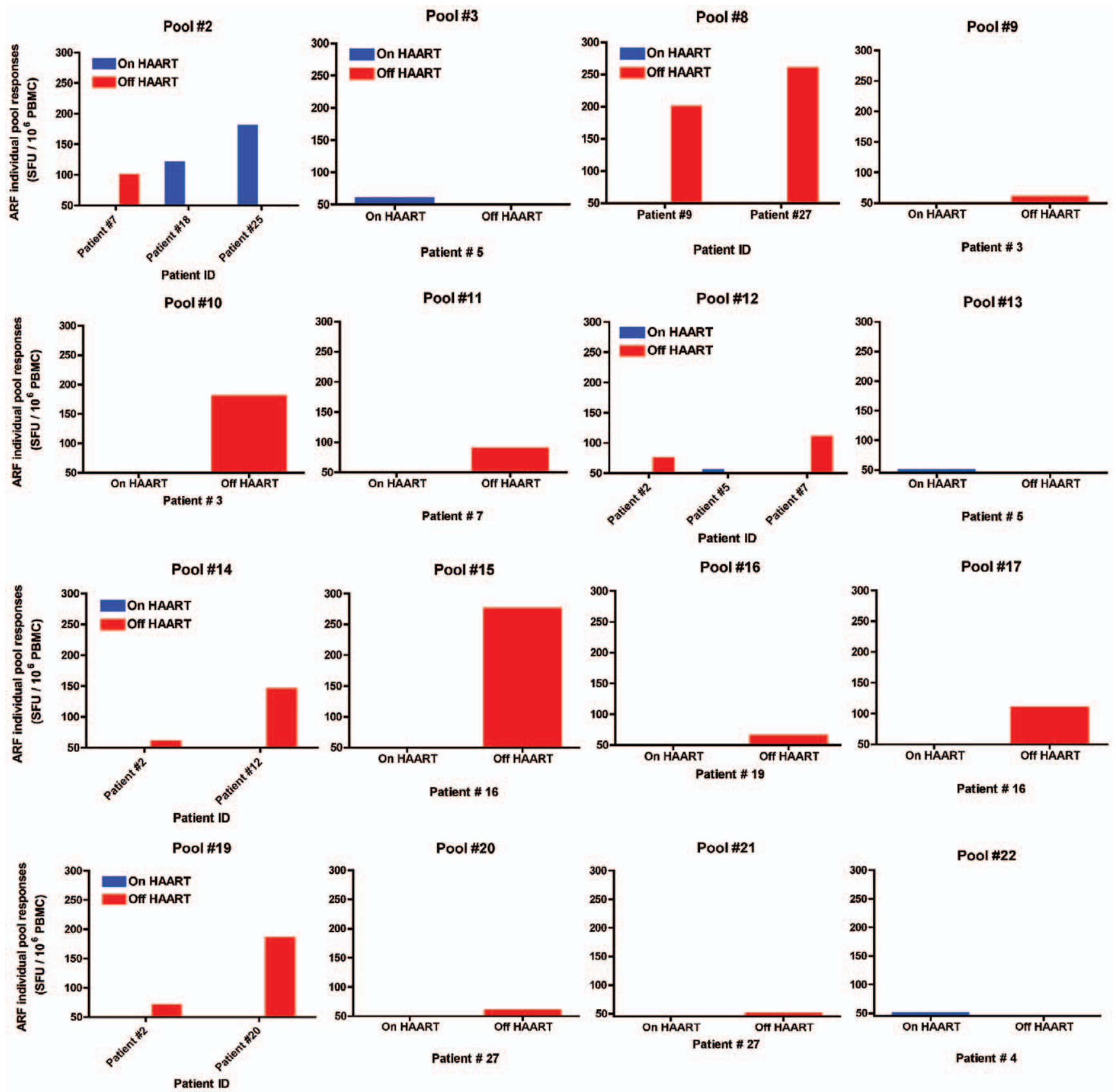

Figure 4. Overview of ARF responses in acutely infected patients. Out of 22 ARF peptide pools tested, 16 induced detectable responses. Each individual graph depicts the intensity of responses measured in an ELISPOT assay against IFN- $\gamma$ (SFU/million PBMC) for each peptide in the corresponding patient. Blue bars correspond to patients On HAART and red bars to patients Off HAART. Responders were only considered if the net response against the peptide pool was $>50$ SFU (cut-off) over background and greater than twice the background.

doi:10.1371/journal.pone.0039311.g004

breadth of ARF responses during chronic HIV-1 infection. In patient \#40, while responses were diminished in magnitude, the number of GE recognized was greater (Figure 7). In this patient before HAART, we detected 2 strong responses against ARF pool peptides \#1 and \#8. At a later time-point when this patient was on HAART, we were still able to detect the same responses against these 2 pool peptides, but at a lower magnitude. Interestingly, we detected 4 new ARF responses, which were absent before treatment. Responses against alternative spliced variants from TAT or REV (pool \#1), previously described in Elite Controllers, were only found in one chronically infected patient, before HAART and on HAART

\section{Discussion}

In this study, we identified new cryptic epitopes derived from sense and anti-sense transcription of HIV-1. We identified virologic events associated with the incorporation of ARF sequences into circulating viral sequences. Associated events such as recombination, gross deletions and point mutations are consistent with the plausible introduction of frameshift mutations 
A

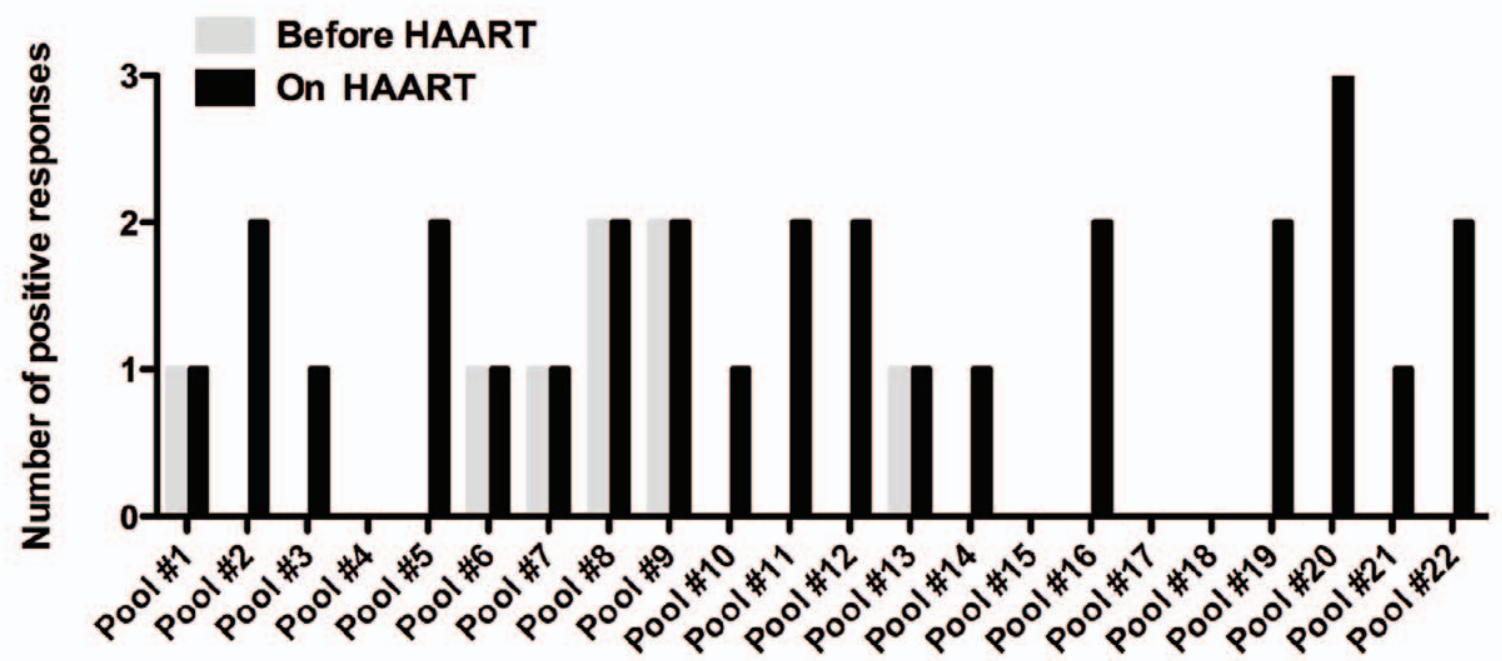

ARF peptide pool Number

$\mathrm{B}$

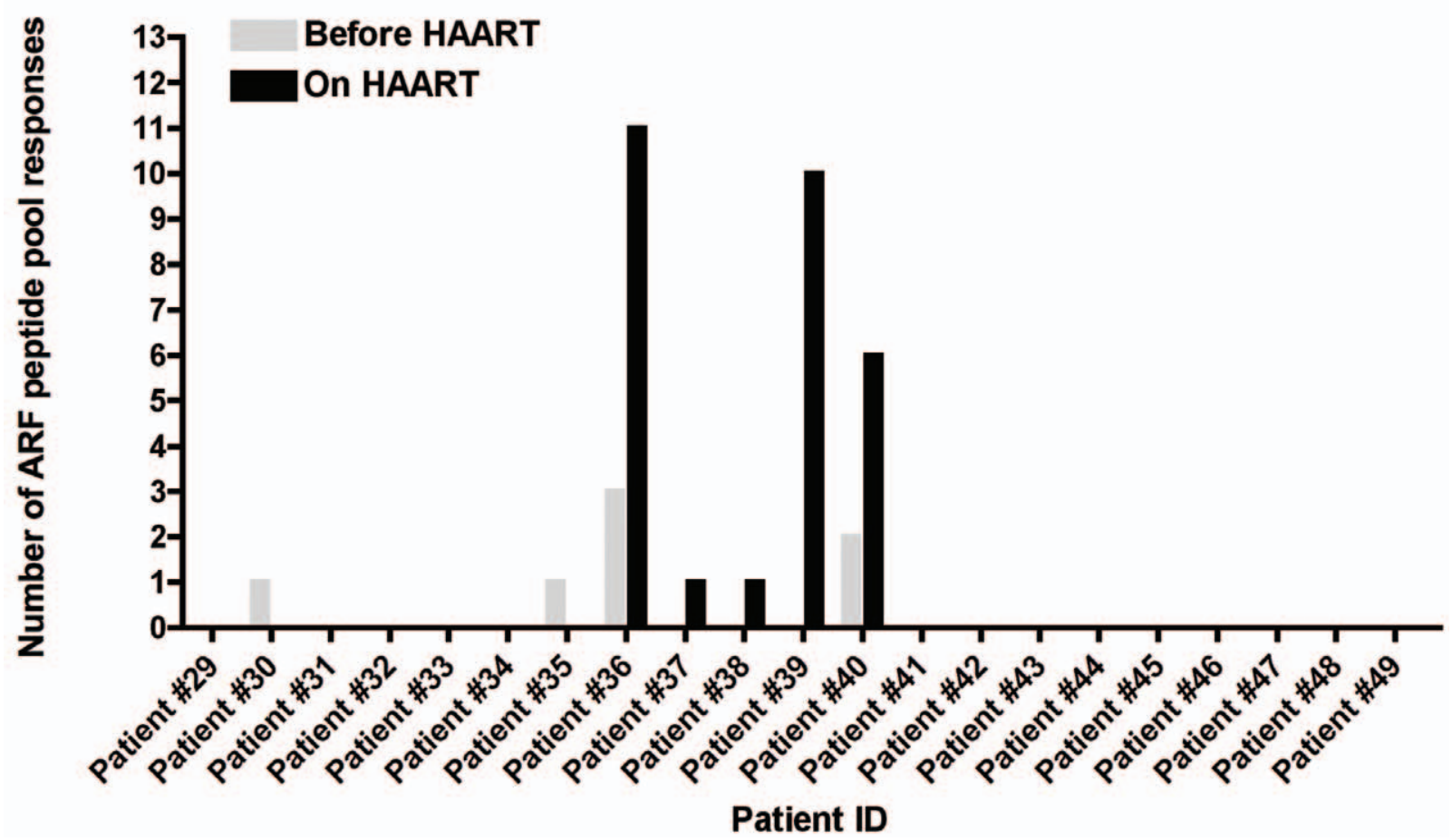

Figure 5. Breadth of ARF responses in chronically infected patients. A) Number of detectable responses observed for each individual ARF peptide-pool tested. B) Number of ARF peptide pools that induced detectable responses in each chronically infected individual. Grey bars represent patients Before HAART and black bars represent patients On HAART. Patients \#47 and \#48 were only tested before HAART introduction and patient \#49 was only tested after HAART.

doi:10.1371/journal.pone.0039311.g005

into circulating viral genomes. The origin of the ARF sequences incorporated into coding sequences is noteworthy for the fact that it does not conform to the expectations associated with random distribution of the originating events within the genome. The distribution is not likely to be an effect of each gene region's total ARF content, as the HIV-1 env nucleotide regions was shown to be the major contributor to known circulating viral ARF sequences, despite containing the smallest percentage of total ARF sequences within its bases. Thus, the env region makes a disproportionally large contribution to the total number of detected ARF sequences compared to its contribution to the total coding sequence. Accessory protein coding regions also exist in this area of the genome, limiting the number of reading frames that could possibly contain ARFs without intersecting with coding 

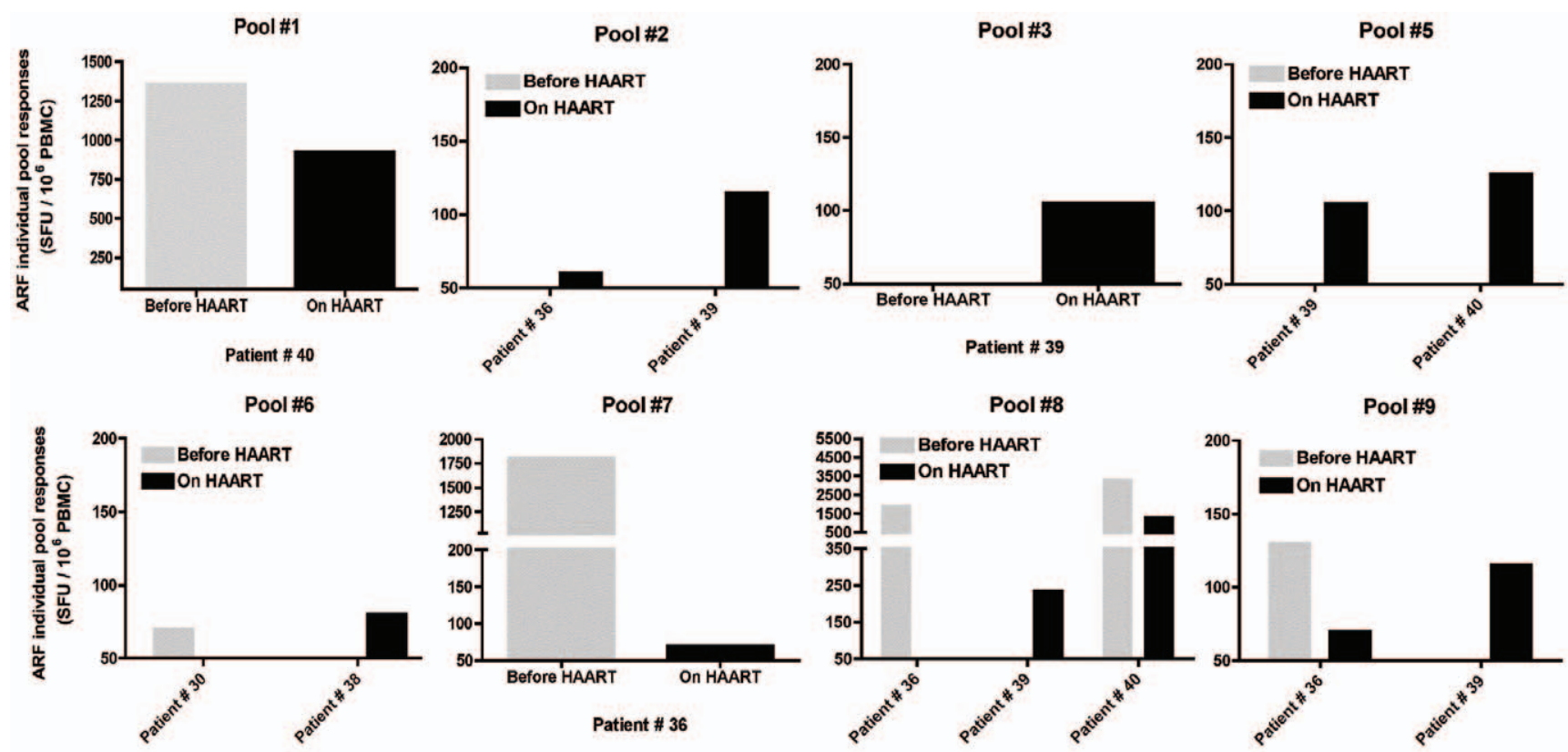

Pool \#8

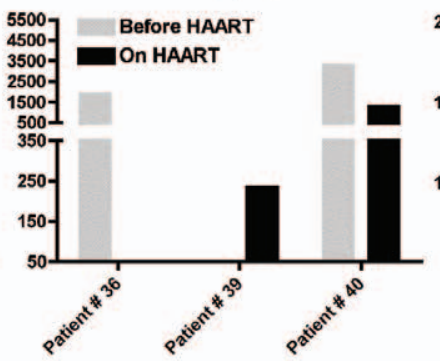

Pool \#9
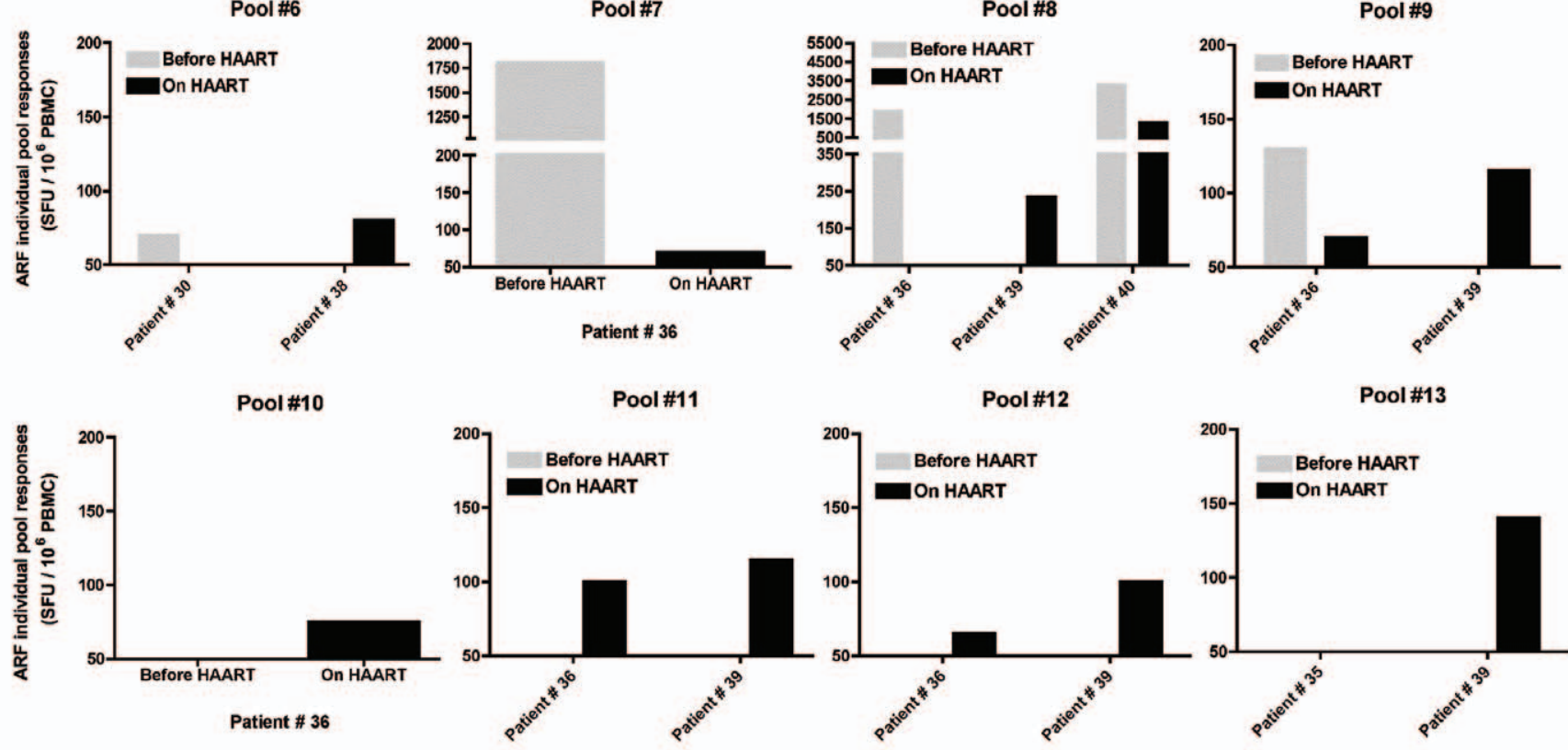

Pool \#14
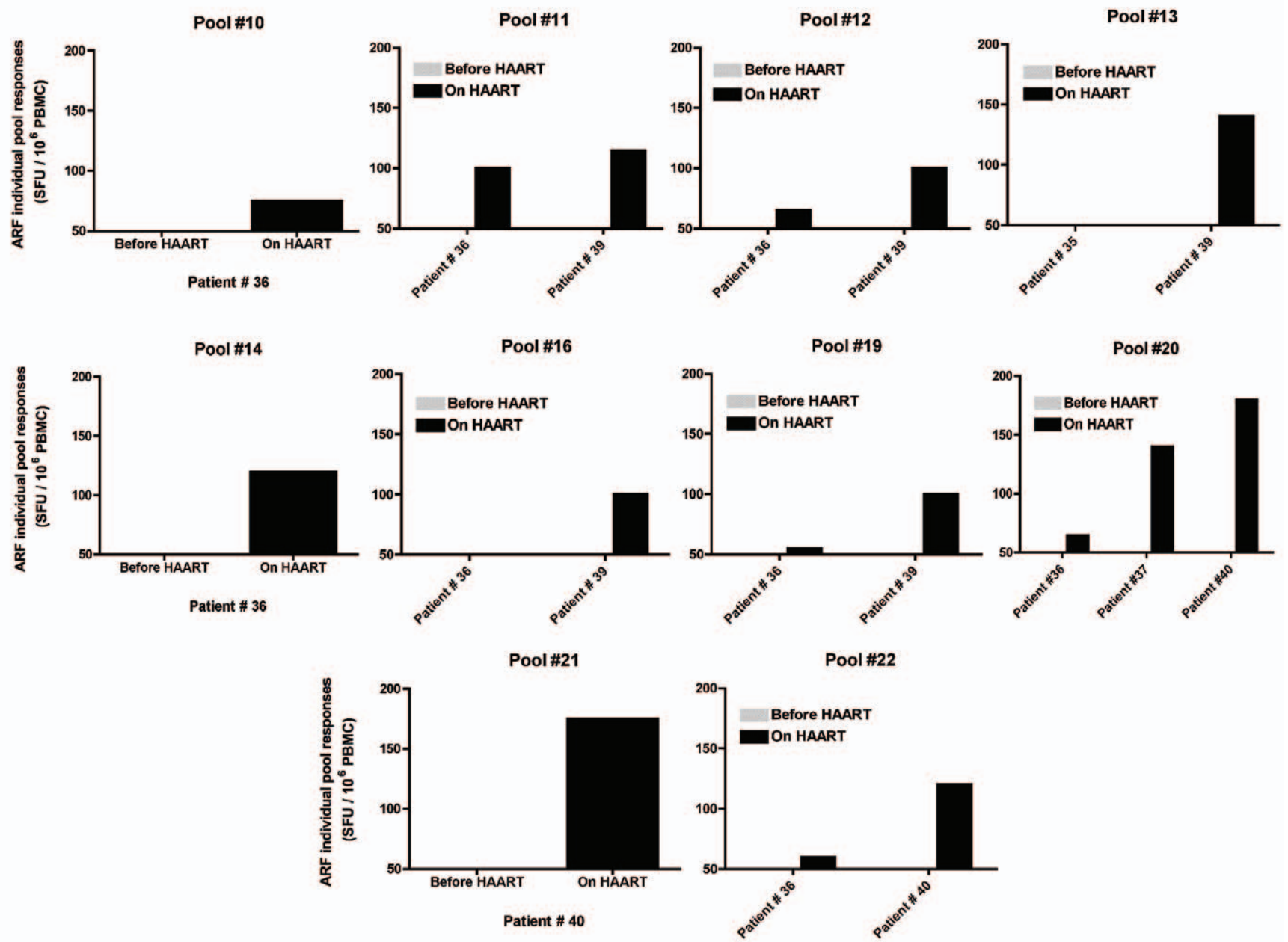

Figure 6. Overview of ARF responses in acutely infected patients. Out of 22 ARF peptide pools tested, 18 induced detectable responses. Each individual graph depicts the intensity of responses measure in an ELISPOT assay against IFN- $\gamma$ (SFU/million PBMC) for each peptide in the corresponding patient. Grey bars correspond to patients Before HAART and black bars to patients On HAART. Responders were only considered if the net response against the peptide pool was $>50$ SFU (cut-off) over background and greater than twice the background. doi:10.1371/journal.pone.0039311.g006 

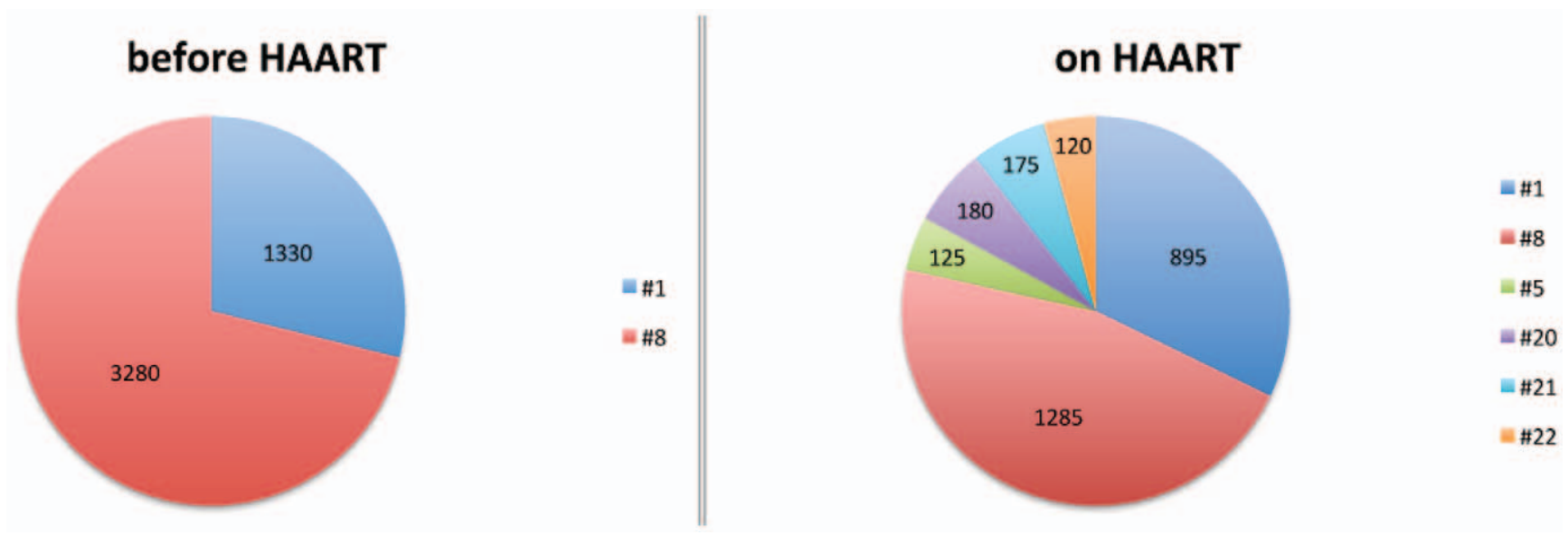

Figure 7. ARF responses in one HIV-1 chronically infected patients before and on HAART. In the pie charts each color represents a pool of immune response that the patient mounted against. Numbers inside the pie charts correspond to the magnitude of the response against the pool in SFU/million PBMC.

doi:10.1371/journal.pone.0039311.g007

sequence for accessory proteins or the env gene itself. The splicing events needed to create some of these accessory proteins may enhance the incorporation of ARF into viral proteins. This novel observation of incorporation of ARF regions into the Env protein could have an impact on the overall plasticity of its amino acid sequence. This plasticity makes a significant contribution to the immune escape of the virus from the neutralizing effects of antibodies targeting Env proteins.

The pol nucleotide region makes a disproportionally small contribution to the total number of ARFs considering the size of this coding region. This may imply constraints that do not permit the incorporation of ARF. As antiretroviral drugs target this region, it is interesting to consider how HAART could modify the dynamics of ARF inclusion in the region.

These circulating, modified viral genomes, together with the translational errors occurring in otherwise intact viral genomes as described previously, are the likely sources for the epitopes that we analyzed in this study. We implemented a number of measures to exclude structural and accessory proteins encoded in standard reading frames of HIV-1 by screening for BLAST similarity at the ORF and peptide levels. None of the ARF-encoded peptides shared more than 7 amino acids in common with any regions of HIV-1 structural or accessory proteins. Five peptides from three of the pools tested shared 6-7 amino acids in common with regions of structural or accessory proteins of HIV-1. While it is important to interpret the immunological results in light of this limited level of similarity, exclusion of these peptides from our analysis was not appropriate. Two of the most similar ARF-encoded peptides originated from a region of alternate reading frame sequence that was detectably incorporated into circulating viral sequences in the NCBI databases. Thus, the immune systems of HIV-1 positive individuals may be exposed to both the structural/accessoryencoded and ARF-encoded variants of these peptides. Additionally, these regions of amino acid similarity may help to elucidate a population of $\mathrm{T}$ cells that are potentially cross-reactive between $\mathrm{ARF}$ and standard reading frame-encoded peptides.

We evaluated the influence of HAART on HIV-1 ARF T cell responses over the course of HIV-1 infection. In HAART-treated patients, we observed that the frequency and magnitude of $\mathrm{T}$ cell responses are higher in chronically infected individuals $(26 \%$, $978 \mathrm{SFU})$ when compared to acutely infected patients $(16 \%$, $129 \mathrm{SFU})$. This suggests that ARF responses increase over the course of HIV-1 infection, and with time, HIV-infected cells have a higher chance of producing and presenting ARF peptides. In chronically HIV-1-infected individuals, HAART decreases the magnitude of ARF responses (from $2100 \mathrm{SFU}$ before to $978 \mathrm{SFU}$ after the introduction of HAART). When ARF responses were analyzed at the individual level, HAART increased the breadth of the responses, which may be due to the selective pressure exerted by drugs on the virus, potentially facilitating the expression of certain ARFs. In acutely infected patients enrolled in a HAART interruption program, we found that HAART interruption favors ARF responses. This could be explained by the fact that HAART exerts a selective pressure on the virus with the emergence of new ARF expression. These immunological results are interesting in light of the relative deficit of ARF incorporation into Pol proteins demonstrated by our database searches. HAART likely alters the dynamics of selective forces acting on the pol nucleotide region and may favor incorporation of some ARF that are otherwise generally disfavored in the region. ARF responses are also present in patients on HAART, even in the absence of detectable antiHIV-1 $\mathrm{T}$ cell responses (from the traditional reading frame), suggesting that ARF products are produced in cells from a latent reservoir. Thus, this therapy or vaccination strategy could specifically target latently infected cells and help in eradication strategies.

\section{Dynamics of ARF Responses}

Although certain pre-existing ARF responses disappeared after the interruption of HAART, new ARF responses emerged. The mechanism underlying ARF expression, mutation and conservation is complex and it involves direct and indirect effects of viral strain and natural evolution within the host, as well as the specifics of the HAART regimen together with patient's intrinsic characteristics. CTL and HAART both exert a selective pressure on HIV-1 by selecting for CTL or drug escape mutations. The mutational pressure exerted on one location of the HIV-1 genome potentially affects the 3 reading frames, and therefore affects ARFs. ARF T cell responses may therefore be affected through immunological pressure exerted by a classical HIV-1 epitope at the same location, but on a different reading frame. Mutations in one frame do not necessarily lead to the disappearance of an ARF epitope. A non-synonymous change in the one coding frame targeted by the selective pressure may account for a synonymous 
change in the $2^{\text {nd }}$ or $3^{\text {rd }}$ frames where the ARF epitope is encoded. Therefore, an ARF epitope may be conserved and maintained due to the selective pressure on a different frame. HAART may shape HIV-1's genome by exerting selective pressure on one or more of the reading frames in a nucleotide region containing an ARF. Therefore, targeting ARF epitopes, especially those that could help the virus escape drug or immune pressure, could provide a new tool to combat viral resistance.

\section{ARF versus Classic HIV-1 Specific T Cell Responses}

In comparison to ARF responses, classically known HIV-1 T cell responses are higher and more frequent in acutely infected individuals. However, in chronically infected patients, the magnitude of ARF responses is similar to the responses to known HIV-1 epitopes. In early infection, the magnitude of ARF responses is below the responses observed for regular CTL HIV responses. We could expect that compared to immune-dominant, known HIV-1 epitopes, ARF peptides would be expressed and presented at a lower density. The similar magnitude of ARF and classic HIV-1 responses in chronically infected subjects could be due to the accumulation with time of the production and presentation of more $\mathrm{ARF}$ peptides and/or the viral escape to classic HIV-1 CTL epitopes.

\section{A Larger Spectrum of ARF Responses}

Our data is probably under-estimating the spectrum of ARF responses since we were not able to screen all of the potential peptides encoded within each ARF, but instead used in silico predicted epitopes. Because of limitations in cell numbers, we did not test all the selected peptides for immune responses (in particular, many potential antisense ARF identified on the 5' end of the genome, further from the 3' LTR). Other ARF without conventional AUG start codons have been described [27,31,39] and have not been explored in our present study.

\section{An ARF Vaccine as a Site-directed HIV Mutagenesis Tool}

Taking the phenomenon from a different perspective, the mutational pressure exerted by ARF immune responses could be used to mutate critical proteins of the virus, or to effectively limit the possible mutations permissible in other reading frames. Within the HIV genome, a region that is well conserved due to a high fitness cost for viral protein mutations could potentially contain ARF epitopes in the two other reading frames. Therefore, the immune mutational pressure exerted by an ARF vaccine through CE specific $T$ cells could force the virus to mutate the area containing the ARF epitopes, which would affect the crucial HIV protein encoded in a different frame, rendering the virus defective.

\section{ARF Responses and Viral Control}

The duration of infection and HAART play a role on the magnitude and breadth of ARF responses. As an observational cross sectional study, our data does not show whether ARF responses help in controlling HIV-1 infection. Previous studies have shown that the magnitude of the $\mathrm{CD}^{+} \mathrm{T}$ cell response

\section{References}

1. Borrow P, Lewicki H, Hahn BH, Shaw GM, Oldstone MB (1994) Virus-specific CD8+ cytotoxic T-lymphocyte activity associated with control of viremia in primary human immunodeficiency virus type 1 infection. J Virol 68: 6103-6110.

2. Friedrich TC, Valentine LE, Yant LJ, Rakasz EG, Piaskowski SM, et al. (2007) Subdominant CD8+ T-cell responses are involved in durable control of AIDS virus replication. J Virol 81: 3465-3476.

3. Jin X, Bauer DE, Tuttleton SE, Lewin S, Gettie A, et al. (1999) Dramatic rise in plasma viremia after CD8(+) T cell depletion in simian immunodeficiency virusinfected macaques. J Exp Med 189: 991-998. poorly correlates with immune control of HIV-1 infection [10,37] whereas the breadth of the CTL response seems to be better associated with viral control [50,51]. Previous in vitro studies have shown viral suppression by ARF CTLs [30], and viral escape from an $\mathrm{ARF} \mathrm{CD}^{+} \mathrm{T}$ cell response has been described in monkey studies, supporting their immunogenicity in vivo [30]. Recently, human data suggested that responses to ARF-encoded HIV-1 epitopes contribute to viral control in vivo, and drives viral evolution on a population level [26,27]. We have previously reported more frequent $\mathrm{CE}$ responses in patients with wellcontrolled HIV-1 infection [32].

ARF responses could potentially be used as a diagnostic tool to monitor HIV-1 immunity through T cell responses against ARF peptides, and could be a surrogate marker to measure the ability of an anti-retroviral drug regimen to work against the latent reservoir.

\section{Supporting Information}

Table S1 Viral load, $\mathrm{CD4}^{+}$and $\mathrm{CD8}^{+} \mathrm{T}$ cell counts for each individual patient in both the Acute and Chronic groups.

(XLSX)

Table S2 Complete description of nucleotide and amino acid sequences used in the study.

(XLSX)

Table S3 BLAST searches for the selected forward ORFs.

(PDF)

Table S4 ARF individual peptides. Table lists the number of the ARF peptide, peptide name, peptide sequence and number of pool.

(PDF)

Table S5 ARF pooled peptides. Table lists the number of peptide pool, the pool content and the total number of peptides in the pool.

(PDF)

\section{Acknowledgments}

Gag p24 full protein peptides were kindly provided by the NIH AIDS Reference and Reagent Program. We thank Dr. John Boscardin for the help with the statistical analysis models performed.

\section{Author Contributions}

Conceived and designed the experiments: SC RASR NJM JLL SEP AMH JCM HD WCK JNM SGD GES FMH MAH EGK KEG DFN. Performed the experiments: SC RASR JLL SEP AMH JCM MAH KEG. Analyzed the data: SC RASR NJM JLL AMH JCM HD WCK MAH EGK KEG DFN. Contributed reagents/materials/analysis tools: JNM SGD GES CDP FMH. Wrote the paper: SC RASR NJM JLL SEP AMH JCM HD WCK JNM SGD FMH MAH EGK KEG DFN.

4. Schmitz JE, Kuroda MJ, Santra S, Sasseville VG, Simon MA, et al. (1999) Control of viremia in simian immunodeficiency virus infection by CD8+ lymphocytes. Science 283: 857-860.

5. Liu J, O'Brien KL, Lynch DM, Simmons NL, La Porte A, et al. (2009) Immune control of an SIV challenge by a T-cell-based vaccine in rhesus monkeys. Nature 457: 87-91.

6. McElrath MJ, De Rosa SC, Moodie Z, Dubey S, Kierstead L, et al. (2008) HIV1 vaccine-induced immunity in the test-of-concept Step Study: a case-cohort analysis. Lancet 372: 1894-1905. 
7. Addo MM, Altfeld M, Rosenberg ES, Eldridge RL, Philips MN, et al. (2001) The HIV-1 regulatory proteins Tat and Rev are frequently targeted by cytotoxic T lymphocytes derived from HIV-1-infected individuals. Proc Natl Acad Sci U S A 98: 1781-1786.

8. Addo MM, Yu XG, Rathod A, Cohen D, Eldridge RL, et al. (2003) Comprehensive epitope analysis of human immunodeficiency virus type 1 (HIV-1)-specific T-cell responses directed against the entire expressed HIV-1 genome demonstrate broadly directed responses, but no correlation to viral load. J Virol 77: 2081-2092.

9. Altfeld M, Addo MM, Eldridge RL, Yu XG, Thomas S, et al. (2001) Vpr is preferentially targeted by CTL during HIV-1 infection. J Immunol 167: 27432752.

10. Betts MR, Ambrozak DR, Douek DC, Bonhoeffer S, Brenchley JM, et al. (2001) Analysis of total human immunodeficiency virus (HIV)-specific CD4(+) and CD8(+) T-cell responses: relationship to viral load in untreated HIV infection. J Virol 75: 11983-11991.

11. Novitsky V, Cao H, Rybak N, Gilbert P, McLane MF, et al. (2002) Magnitude and frequency of cytotoxic T-lymphocyte responses: identification of immunodominant regions of human immunodeficiency virus type 1 subtype C. J Virol 76: 10155-10168.

12. Yu XG, Addo MM, Rosenberg ES, Rodriguez WR, Lee PK, et al. (2002) Consistent patterns in the development and immunodominance of human immunodeficiency virus type 1 (HIV-1)-specific CD8+ T-cell responses following acute HIV-1 infection. J Virol 76: 8690-8701.

13. Bullock TN, Eisenlohr LC (1996) Ribosomal scanning past the primary initiation codon as a mechanism for expression of CTL epitopes encoded in alternative reading frames. J Exp Med 184: 1319-1329.

14. Fetten JV, Roy N, Gilboa E (1991) A frameshift mutation at the NH2 terminus of the nucleoprotein gene does not affect generation of cytotoxic $\mathrm{T}$ lymphocyte epitopes. J Immunol 147: 2697-2705.

15. Probst-Kepper M, Stroobant V, Kridel R, Gaugler B, Landry C, et al. (2001) An alternative open reading frame of the human macrophage colony-stimulating factor gene is independently translated and codes for an antigenic peptide of 14 amino acids recognized by tumor-infiltrating CD8 T lymphocytes. J Exp Med 193: 1189-1198.

16. Rimoldi D, Rubio-Godoy V, Dutoit V, Lienard D, Salvi S, et al. (2000) Efficient simultaneous presentation of NY-ESO-1/LAGE-1 primary and nonprimary open reading frame-derived CTL epitopes in melanoma. J Immunol 165: 72537261 .

17. Saeterdal I, Bjorheim J, Lislerud K, Gjertsen MK, Bukholm IK, et al. (2001) Frameshift-mutation-derived peptides as tumor-specific antigens in inherited and spontaneous colorectal cancer. Proc Natl Acad Sci U S A 98: 13255-13260.

18. Wang RF, Parkhurst MR, Kawakami Y, Robbins PF, Rosenberg SA (1996) Utilization of an alternative open reading frame of a normal gene in generating a novel human cancer antigen. J Exp Med 183: 1131-1140.

19. Saulquin X, Scotet E, Trautmann L, Peyrat MA, Halary F, et al. (2002) +1 Frameshifting as a novel mechanism to generate a cryptic cytotoxic $\mathrm{T}$ lymphocyte epitope derived from human interleukin 10. J Exp Med 195: 353358 .

20. Mayrand SM, Green WR (1998) Non-traditionally derived CTL epitopes: exceptions that prove the rules? Immunol Today 19: 551-556.

21. Weiss RB, Dunn DM, Atkins JF, Gesteland RF (1987) Slippery runs, shifty stops, backward steps, and forward hops: $-2,-1,+1,+2,+5$, and +6 ribosomal frameshifting. Cold Spring Harb Symp Quant Biol 52: 687-693.

22. McBratney S, Chen CY, Sarnow P (1993) Internal initiation of translation. Curr Opin Cell Biol 5: 961-965.

23. Bullock TN, Patterson AE, Franlin LL, Notidis E, Eisenlohr LC (1997) Initiation codon scanthrough versus termination codon readthrough demonstrates strong potential for major histocompatibility complex class I-restricted cryptic epitope expression. J Exp Med 186: 1051-1058.

24. Bruce AG, Atkins JF, Gesteland RF (1986) tRNA anticodon replacement experiments show that ribosomal frameshifting can be caused by doublet decoding. Proc Natl Acad Sci U S A 83: 5062-5066.

25. Malarkannan S, Horng T, Shih PP, Schwab S, Shastri N (1999) Presentation of out-of-frame peptide/MHC class I complexes by a novel translation initiation mechanism. Immunity 10: 681-690.

26. Bansal A, Carlson J, Yan J, Akinsiku OT, Schaefer M, et al. (2010) CD8 T cell response and evolutionary pressure to HIV-1 cryptic epitopes derived from antisense transcription. J Exp Med 207: 51-59.

27. Berger CT, Carlson JM, Brumme CJ, Hartman KL, Brumme ZL, et al. (2010) Viral adaptation to immune selection pressure by HLA class I-restricted CTL responses targeting epitopes in HIV frameshift sequences. J Exp Med 207: 6175 .
28. Cardinaud S, Moris A, Fevrier M, Rohrlich PS, Weiss L, et al. (2004) Identification of cryptic MHC I-restricted epitopes encoded by HIV-1 alternative reading frames. J Exp Med 199: 1053-1063.

29. Maness NJ, Sacha JB, Piaskowski SM, Weisgrau KL, Rakasz EG, et al. (2009) Novel translation products from simian immunodeficiency virus SIVmac239 Env-encoding mRNA contain both Rev and cryptic T-cell epitopes. J Virol 83: $10280-10285$.

30. Maness NJ, Valentine LE, May GE, Reed J, Piaskowski SM, et al. (2007) AIDS virus specific CD8+ T lymphocytes against an immunodominant cryptic epitope select for viral escape. J Exp Med 204: 2505-2512.

31. Maness NJ, Wilson NA, Reed JS, Piaskowski SM, Sacha JB, et al. (2010) Robust, vaccine-induced CD8(+) T lymphocyte response against an out-of-frame epitope. J Immunol 184: 67-72.

32. Garrison KE, Champiat S, York VA, Agrawal AT, Kallas EG, et al. (2009) Transcriptional errors in human immunodeficiency virus type 1 generate targets for T-cell responses. Clin Vaccine Immunol 16: 1369-1371.

33. Landry S, Halin M, Lefort S, Audet B, Vaquero C, et al. (2007) Detection, characterization and regulation of antisense transcripts in HIV-1. Retrovirology 4: 71 .

34. Ludwig LB, Ambrus JL, Jr., Krawczyk KA, Sharma S, Brooks S, et al. (2006) Human Immunodeficiency Virus-Type 1 LTR DNA contains an intrinsic gene producing antisense RNA and protein products. Retrovirology 3: 80.

35. Michael NL, Vahey MT, d'Arcy L, Ehrenberg PK, Mosca JD, et al. (1994) Negative-strand RNA transcripts are produced in human immunodeficiency virus type 1-infected cells and patients by a novel promoter downregulated by Tat. J Virol 68: 979-987.

36. Ho O, Green WR (2006) Cytolytic CD8+ T cells directed against a cryptic epitope derived from a retroviral alternative reading frame confer disease protection. J Immunol 176: 2470-2475.

37. Masemola A, Mashishi T, Khoury G, Mohube P, Mokgotho P, et al. (2004) Hierarchical targeting of subtype $\mathrm{C}$ human immunodeficiency virus type 1 proteins by CD8+ T cells: correlation with viral load. J Virol 78: 3233-3243.

38. Meiklejohn DA, Karlsson RK, Karlsson AC, Chapman JM, Nixon DF, et al. (2004) ELISPOT cell rescue. J Immunol Methods 288: 135-147.

39. Schwab SR, Shugart JA, Horng T, Malarkannan S, Shastri N (2004) Unanticipated antigens: translation initiation at CUG with leucine. PLoS Biol 2: e366.

40. Schmitt M, Harrer E, Goldwich A, Bauerle M, Graedner I, et al. (2000) Specific recognition of lamivudine-resistant HIV-1 by cytotoxic T lymphocytes. AIDS 14: 653-658.

41. Samri A, Haas G, Duntze J, Bouley JM, Calvez V, et al. (2000) Immunogenicity of mutations induced by nucleoside reverse transcriptase inhibitors for human immunodeficiency virus type 1-specific cytotoxic T cells. J Virol 74: 9306-9312.

42. Mueller SM, Schaetz B, Eismann K, Bergmann S, Bauerle M, et al. (2007) Dual selection pressure by drugs and HLA class I-restricted immune responses on human immunodeficiency virus type 1 protease. J Virol 81: 2887-2898.

43. Mason RD, Bowmer MI, Howley CM, Gallant M, Myers JC, et al. (2004) Antiretroviral drug resistance mutations sustain or enhance CTL recognition of common HIV-1 Pol epitopes. J Immunol 172: 7212-7219.

44. Manosuthi W, Butler DM, Perez-Santiago J, Poon AF, Pillai SK, et al. Protease polymorphisms in HIV-1 subtype CRF01_AE represent selection by antiretroviral therapy and host immune pressure. AIDS 24: 411-416.

45. Mahnke L, Glifford D (2006) Cytotoxic T cell recognition of an HIV-1 reverse transcriptase variant peptide incorporating the $\mathrm{K} 103 \mathrm{~N}$ drug resistance mutation. AIDS Res Ther 3: 21.

46. Karlsson AC, Deeks SG, Barbour JD, Heiken BD, Younger SR, et al. (2003) Dual pressure from antiretroviral therapy and cell-mediated immune response on the human immunodeficiency virus type 1 protease gene. J Virol 77: 67436752 .

47. John M, Moore CB, James IR, Mallal SA (2005) Interactive selective pressures of HLA-restricted immune responses and antiretroviral drugs on HIV-1. Antivir Ther 10: 551-555.

48. Gatanaga H, Ode H, Hachiya A, Hayashida T, Sato H, et al. (2010) Impact of human leukocyte antigen-B*51-restricted cytotoxic T-lymphocyte pressure on mutation patterns of nonnucleoside reverse transcriptase inhibitor resistance. AIDS 24: F15-22.

49. Mueller SM, Spriewald BM, Bergmann S, Eismann K, Leykauf M, et al. (2011) Influence of major HIV-1 protease inhibitor resistance mutations on CTL recognition. J Acquir Immune Defic Syndr 56: 109-117.

50. Kiepiela P, Ngumbela K, Thobakgale C, Ramduth D, Honeyborne I, et al. (2007) CD8+ T-cell responses to different HIV proteins have discordant associations with viral load. Nat Med 13: 46-53.

51. Goepfert PA, Lumm W, Farmer P, Matthews P, Prendergast A, et al. (2008) Transmission of HIV-1 Gag immune escape mutations is associated with reduced viral load in linked recipients. J Exp Med 205: 1009-1017. 


\section{TITLE:}

Cryptic peptides immune response in the early phase of HIV-1 infection.

\section{AUTHORS AND AFFILIATIONS}

Marisa Ailin Hong, MSc

Institute Adolfo Lutz, São Paulo, Brazil \& Division of Clinical Immunology and Allergy, University of São Paulo, São Paulo, Brazil

e-mail: marisahong@gmail.com

Corresponding author. Mailing address: Institute Adolfo Lutz. Avenida Dr. Arnaldo, 351 - 10th floor, room 1003, São Paulo, SP, Brazil, 01246-902.

Phone: +55 1130682953

Leandro Fagundes Tarosso, MSc

Division of Clinical Immunology and Allergy, University of São Paulo, São Paulo, Brazil

e-mail: leandro.tarosso@gmail.com

Claudia Satiko Tomiyama, BSc

Division of Clinical Immunology and Allergy, University of São Paulo, São Paulo, Brazil

e-mail: satikotomiyama@gmail.com

Helena Tomiyama, BSc

Division of Clinical Immunology and Allergy, University of São Paulo, São Paulo, Brazil 
e-mail: helena.tomiyama@gmail.com

Douglas Nixon, $\mathrm{MD}, \mathrm{PhD}$

Division of Experimental Medicine, Department of Medicine, University of California San Francisco, San Francisco, California, USA

e-mail: $\underline{\text { douglas.nixon@ucsf.edu }}$

Esper George Kallas, MD, PhD

Division of Clinical Immunology and Allergy, University of São Paulo, São Paulo, Brazil

e-mail: esper.kallas@usp.br

\section{SHORT TITLE:}

Cryptic peptide response to HIV-1

\section{SOURCES OF SUPPORT}

This project was funded by the International AIDS Vaccine Initiative (IAVI). Gag p24 full protein peptides were kindly provided by the NIH AIDS Reference and Reagent Program. 


\section{ABSTRACT ( $<250$ words)}

Background: A second and unconventional source of peptides that bind to MHC class I molecule has been described to produce cryptic peptides (CP), which can elicit CD8+ T cell response and then exert mutation pressure on HIV-1, leading to virus escape. Some rare patients are naturally able to control disease progression, either maintaining CD4+ $\mathrm{T}$ cells over 500 cells/uL or viral load under 2.000 copies $/ \mathrm{mL}$, without being treated with HAART, for at least 12 months. Understanding their immune response to cryptic peptides might be a great value to help on developing better prevention strategies. Methodology and Principal findings: Immune response to cryptic peptides, derived from sense and antisense transcription of HIV-1, was evaluated in pools using samples from Elite (aviremic) or HIV (viremic) controllers and progressors. Immune response to $\mathrm{CP}$ are more frequent, with a larger breadth and of greater magnitude in controllers than in progressors, and this response is inversed seen in a later time point, when controllers seems to lose this response, while progressors developed it, showing $\mathrm{CP}$ immune response to different pools, suggesting that immune response to $\mathrm{CP}$ might play some role in pressuring the virus mutation escape. Conclusions and Significance: $\mathrm{CP}$ can elicit immune response and help to explain how some virus selection happens, either by changing expression of crucial HIV-1 proteins or generating defective virus. They can be included in vaccine design for enhancing the magnitude and breadth of $\mathrm{T}$ cell immune response and consequently the protection against infection or progression of HIV-1 infection.

\section{KEYWORDS:}

HIV-1; T cell responses; Alternative Reading Frame (ARF); Cryptic Epitope (CE); ELISPOT, early infection 


\section{INTRODUCTION}

CD8+ T cell lymphocytes plays important role in anti-HIV-1 immunity by recognizing short peptides with eight to 11 aminoacids presented by MHC class I moleculeexpressing cells ${ }^{1,2}$. Identity and nature of such peptides have been elucidated, mostly those encoded in open reading frames (ORFs) of HIV-1 genes. Yet, a secondary and non-conventional source of peptides, encoded in alternative reading frames (ARFs), as well as their contribution to the total $\mathrm{CD} 8+\mathrm{T}$ cell response have recently been described $^{3-6}$.

The cryptic peptides expression's mechanisms are the initiation codon scanthrough ${ }^{7}$, initiation starting from non-AUG codon, translation of untranslated regions (UTRs or introns), and others. Cryptic peptides can also be presented by MHC class I and elicit T cell response, then it means that those peptides are relevant for immune surveillance.

In murine AIDS and SIV infection models a protective cytotoxic CD8+ T cell response have been observed ${ }^{1,7-12}$ and represent one-quarter of the anti-SIV CD8+ $\mathrm{T}$ cell responses in rhesus macaques ${ }^{13}$. In HIV infection, it is observed that cryptic peptides are immunogenic during primary and chronic infections, and they can mutate during the first year of infection, so they are important to select variants ${ }^{7,14}$.

The intensity and breadth of immune response exerted by CD8+ T cells are not equal observed among patients. Elite controllers (EC), for example, are described to be able to control the viral load without receiving HAART, and mostly maintaining CD4+ T cells counting above 500 cells/ $\mu \mathrm{L}$ over months and years in the infection course ${ }^{15}$. Evaluating CD8+ T cell response to cryptic peptides in samples from EC patients, starting at earlier phase of infection might support the idea that including these peptides in a vaccine design can enhance its efficacy. 


\section{METHODS}

\section{Subjects}

Fourty-six recently HIV-1-infected subjects were selected for this study from a cohort in São Paulo, Brazil ${ }^{16}$, which started accrual in 2002 based on the Serologic Testing Algorithm for Recent HIV Seroconversion (STARHS) strategy. All patients provided informed written consent and the University of São Paulo Institutional Review Board approved this study. Peripheral blood mononuclear cells (PBMC) were obtained at patients second to fifth clinical visit and, for those responders, 18 out of 46 , at second time point, after the average of $6 \pm 0.4$ years $(5.3-6.7$ years $)$ later.

For initial analysis, subjects were divided into three groups those who spontaneously developed control of HIV-1 replication, presenting undetectable (<399 copies/mL) or low $(<2,000$ copies/mL) plasma HIV-1 load and sustained CD4+ T cell counts in the first 30 months of follow-up, named aviremic $(n=13$, AC) and viremic $(n=6, V C)$ controllers, respectively, and others patients, who presented plasma viremia over 2,000 copies/mL during this same initial period of clinical follow-up, grouped as progressors $(n=27$, Vir $)$. Details of studied patients at first time of sample collection are described in the Table 1.

\section{IFN- $\gamma$ release ELISPOT assays}

Patients' cellular immune responses against to cryptic peptides were measured in cryopreserved PBMC by IFN- $\gamma$ release ELISPOT assays, as previously described ${ }^{17}$. The obtained data represent the average of two replicate wells minus the average of four replicate control wells (background wells, with no peptide added), and are reported as the number of spot-forming cells (SFC) per million PBMCs (SFC/million PBMCs). In each well, 100,000 cells were added and peptide were tested at $5 \mu \mathrm{M} /$ well. Responses 
were considered positive when the SFC count was greater than 5 spots $(50 \mathrm{SFC} /$ million PBMCs) and greater than twice the background. The same individual ran all experiments to avoid errors.

Cryptic peptides used in this study, or alternative open-reading frames (ARF), starting with an AUG codon in HIV-1 HX-B2, were identified, predicted and synthesized as previously described ${ }^{18}$. A total of 199 peptides (forward and reverse ORF) were tested in pools. Details of these cryptic peptides, their sequence and the list of each pool's contents were previously published ${ }^{18}$.

\section{Statistical analysis}

Statistical analyses were done using Chi-2 or $t$-Test, and additional Kaplan-Meier was performed using Prism 6.0. 


\section{RESULTS}

\section{Patients}

Forty-six patients, three women and 43 men, aging from 20 to 58 years old were studied in a prospective cohort, obtained in three months intervals. Samples were collected at month $3(n=3), 6(n=21), 9(n=8), 12(n=13)$ and $15(n=1)$, and cryopreserved in liquid nitrogen until the day of experiments.

According to STAHRS, the time of infection varied from 14 to 496 days, with an average of 54, 125, 224, 343, 496 days after HIV-1 acquisition.

Thirty-two $(69.6 \%)$ out of 46 patients were asymptomatic. The median and 25-75 quartiles of CD4+ and CD8+ T cell counts of all three groups are described in Table 1.

CCR5 $\Delta 32$ alelle was observed in seven (17\%) out of 41 patients who had this data, and two of them were in the controller group.

By August 2011, nine out of 46 patients had started HAART, representing $19 \%$ of the total. The follow up of 42 patients were up to 23 visits, which is approximately 67 months after STAHRS (170 days). Another four were followed for 4 visits only.

\section{HIV-1 recently infected individuals respond to against Cryptic peptides stimuli}

Using IFN- $\gamma$ release ELISPOT assay, T cell response against 199 cryptic peptides predicted from alternative reading frame (ARF) of HIV-1 genome were screened in 46 HIV-1-infected patients early after infection. Peptides were combined in 19 pools for $175 \mathrm{ARF}$ antisense peptides (five to 11 peptides per pool), two pools for $22 \mathrm{ARF}$ sense peptides (11 peptides in each pool) and one pool of two splicing variants (one in Tat and other in Rev).

When we grouped patients as controllers (aviremic and viremic controllers) and progressors, according to the viral load, we observed a significant higher frequency of 
responders to cryptic peptides among controllers (47.4\%; six out of 13 aviremic controllers and three out of six viremic controllers) compared to progressors $(33.3 \%$; nine out of 27 patients) $\left(\mathrm{p}=0.03, \mathrm{Chi}^{2}\right.$ test $)$.

Eight out of 18 patients who presented immune response against cryptic peptides responded to two or more ARF pools. Controllers presented a higher, but not significant, breadth of immune response, once $66.6 \%$ (six out of nine) were able to respond to two or more pools of cryptic peptides, compared to $44.4 \%$ of progressors (four out of nine), as demonstrated in Fig. 1 ( $\mathrm{p}=0.18, \mathrm{Chi}^{2}$ test).

All the 22 cryptic peptides or ARFs pools were able to elicit IFN- $\gamma$ production in at least one of the 46 tested patients and by an average of four (one to seven) patients. Mean magnitude of response produced against cryptic peptide pools was $238 \pm 146$ SFC/million PBMC and ranged from 60 to 655 SFC/million PBMC.

Total T cell response to cryptic peptide in the controller group was twice (mean: 290 SFC/million PBMC) higher than the response observed in progressor group (mean: 147 SFC/million PBMC) $(\mathrm{p}<0.001, t$-Test). Only three pools elicited higher response in progressor than in controller group, pools\# 11, 20 and 21. For all others peptides, the response observed was higher in controller group. The mean of response to each pool is represented in Fig.2.

A higher frequency of responders was observed against cryptic peptides pool \#15 ( $n=7)$, followed by pools \#2 ( $\mathrm{n}=6)$, \#11 ( $\mathrm{n}=6)$ and \#21 $(\mathrm{n}=5)$. The distribution of controllers and progressors who responded was equal for pools \#2 and \#11. Magnitude of $\mathrm{T}$ cell responses to pool \#11 was similar comparing the two groups (controller= 258 SFC/million PBMC and progressor= $272 \mathrm{SFC} /$ million PBMC), however the response to pool \#2 was significant higher in controller group (223 SFC/million PBMC) than in progressor group (112 SFC/million PBMC) group ( $\mathrm{p}=0.035, t$-Student). Five out of 7 
responders to pool \#15 were controllers, who presented a significant higher average response to this cryptic peptide pool (318 SFC/million PBMC) compared to progressor (153 SFC/million PBMC). Regarding pool \#21, it was not possible to perform statistical analysis, because there was only one progressor who responded to this pool. Details of each cryptic peptide, pools and magnitude of response to each pool are shown in

\section{Supplemental Table 1.}

Controllers presented higher total immune response to cryptic peptides (mean=1,709 SFC/million PBMC, range of sum's mean=90-6,635 SFC/million PBMC) than progressors $($ mean $=507 \mathrm{SFC} /$ million $\mathrm{PBMC}$, range of sum's mean $=60-1,360$ SFC/million PBMC); the difference of response between the two groups was not significant $(\mathrm{p}=0.18, t$-Test $)$.

\section{Clinical progression markers CD4+ and viral load}

The sum of SFC/million PBMC was used to correlate the $\mathrm{T}$ cell immune response to cryptic peptides and CD4+ and CD8+ T cell counts and viral load. However, immune response to cryptic peptides was not correlated to the $\mathrm{T}$ cell counts (both CD4+ and $\mathrm{CD} 8+)$ and viral load (CV), either evaluating all patients at once or grouping them as controllers and progressors, as shown in Fig.3.

Additional analysis with Kaplan-Meier has shown more rapid decline of CD4+ T cell count to lower 350 cells/uL associated to higher magnitude and breadth cryptic peptide response, but it was not significant (data not shown).

\section{T cell immune response to cryptic peptide in the later phase of infection}

Fifteen out of 18 patients who responded to cryptic peptides had a sample collected in a later time point for analysis six out of 15 evaluated patients had responded, one from 
controllers group (one out of seven tested) and five from progressor group (five out of eight tested).

In contrast to what was observed in early infection, the magnitude of response to cryptic peptide was significantly higher $(\mathrm{p}=0.02)$ in the progressors group (mean= $296.7 \pm$ 192.5 SFC/million PBMC) compared to controllers group (mean= $165.0 \pm 10.8$ SFC/million PBMC).

The controller patient responded to pools \#13, \#18 and \#22. On the other hand, we observed that three progressors had responded to pool \#17 and two responded to pool \#14, as shown in Fig. 4. There was not a common pool to which controllers and progressors had responded to.

Comparing early and later infection, the average of all patients' immune response to cryptic peptide had decreased, with lower frequency and magnitude in later infection (data not shown).

Comparing both groups, that the total magnitude immune response to cryptic peptides had increased over $40 \%$ among progressors, and $27 \%$ with the only controller, as shown in Fig.5, even when the immune response to positive control (gag) was maintained over the time (early infection $=1,449 \pm 830 \mathrm{SFC} /$ million $\mathrm{PBMC}$ and later infection $=1,282 \pm$ 956 SFC/million PBMC).

\section{DISCUSSION}

In this study, $\mathrm{T}$ cell responses to cryptic peptides from both sense and antisense transcription of HIV-1 using IFN- $\gamma$ release ELISPOT assays was found in early infection. Frequency, magnitude and breadth in early HIV-1 infection were evaluated by comparing spontaneous not treated viral load controller patients and regular progressor patients. We observed higher frequency and magnitude of $\mathrm{T}$ cell responses to cryptic 
peptide in controllers $(47.4 \%$; $290 \mathrm{SFC} /$ million $\mathrm{PBMC})$ compared to progressors (33.3\%; 147 SFC/million PBMC). These data suggest cryptic peptides are able to elicit immune response to protect against HIV-1 disease progression, and so, it could be added to a vaccine in order to increase total $\mathrm{T}$ cell immune response.

Looking the breadth of cryptic peptides response, we observed a not significant difference in number of pools eliciting immune responses in the controllers group (5.6 pools) compared to the progressors group (3.4 pools). This suggests that expression of cryptic peptides might be facilitated when HIV-1 viral load controlled, as observed in this study in treatment naïve or patients under HAART ${ }^{18}$. On the other hand, total T cell immune response to cryptic peptides in all patients or individually was not correlated to CD4+ or CD8+ T cell count and plasma HIV-1 viral load, reinforcing high expression of cryptic peptides under some pressure on the virus.

When we followed patients during 6 years $( \pm 0.4)$ and tested later time point samples from those who presented responses in early HIV-1 infection phase, the magnitude of immune response to cryptic peptides was "lost" in controller group (from 290 $\mathrm{SFC} /$ million $\mathrm{PBMC}$ in earlier infection to $165 \mathrm{SFC} /$ million $\mathrm{PBMC}$ in later infection) and "gained" in progressor group (from 147 SFC/million PBMC to 297 SFC/million PBMC). It is important to say that cryptic peptides able to elicit immune response in these two time points were diverse. It might be due the natural selection of virus and peptides expression control over the time. Tests with other cryptic peptides, especially those encoded out of conventional AUG start codons ${ }^{1,10,19}$ were not performed to verify possible response to different cryptic peptides of those tested in controller group and to help explain how these patients (15 of 19) still maintained the viral load under 2,000 copies/mL after more than 5 years of follow up. Some progressors who had shown immune response to cryptic peptides in earlier infection had shown increased $\mathrm{T}$ immune 
response to cryptic peptides (4 out of 8 patients tested in later infection), with higher average magnitude and larger breadth, but to different cryptic peptides seen in earlier infection. Therefore, while some cryptic peptides responses were lost, new ones emerged. These data corroborate to virus selection and control of peptides expression. Therefore, including cryptic peptides into a vaccine candidate might increase $\mathrm{T}$ cell immune response, particularly targeting viruses in early encounter with the host.

Selective CTL escape mutations affects all reading frames, including those encoding cryptic peptides. The mechanism of how immune pressure at one reading frame can affect another is not clear. Also, it is not clear if cryptic peptides are really not functional proteins.

Compared to cryptic peptides responses, classical $\mathrm{T}$ cell immune responses to Gag were maintained over the time, with not significant changes, neither in the controller nor the progressor groups. However, the magnitude of cryptic peptides responses in earlier infection were higher compared to later infection among controllers and similar when we looked at the progressor group. However, cryptic peptide responses was slightly lower than Gag response, suggesting that the cryptic peptides responses are part of total T cell immune responses, as expected.

We hypothesize that if cryptic peptides are included in vaccine, it might be possible to model virus fitness by affecting the translation and expression of crucial HIV-1 protein, generating not infectious or defective virus.

The magnitude of responses to cryptic epitopes did not correlate to HIV-1 control, as described for CD8+ T cell response ${ }^{20,21}$. Viral suppression and escape of ARF CD8+ T cell responses in monkey studies has been described supporting immunogenicity in vitro of cryptic peptides ${ }^{10}$. Responses to HIV-1 cryptic peptides contribute to viral 
control in vivo in human and drives viral evolution on a population level ${ }^{1,8}$, with higher frequency among patients who had a better control of HIV-1 infection ${ }^{12}$.

Cryptic peptides responses could be contribute to the total $\mathrm{T}$ cell immune response induced by a vaccine, helping on controlling HIV-1 infection progression. 


\section{REFERENCES}

1. Berger CT, Carlson JM, Brumme CJ, et al. Viral adaptation to immune selection pressure by HLA class I-restricted CTL responses targeting epitopes in HIV frameshift sequences. The Journal of experimental medicine. 2010;207(1):61-75.

2. Berger AC, Roche PA. MHC class II transport at a glance. Journal of cell science. 2009;122(Pt 1):1-4.

3. Bullock TNJ. Ribossomal scanning past primary initiation codon of CTL epitopes by ARF. 1996.

4. Probst-Kepper M, Stroobant V, Kridel R, et al. An Alternative Open Reading Frame of the Human Macrophage Colony-Stimulating Factor Gene is Independently Translated and Codes for an antigenic peptide of 14 amino acids recognized by Tumor-infiltrating CD8 T lymphocytes. 2011.

5. Rimoldi D, Rubio-Godoy V, Dutoit V, et al. Efficient Simultaneous Presentation of NY-ESO-1/LAGE-1 Primary and Nonprimary Open Reading Frame-Derived CTL Epitopes in Melanoma. The Journal of Immunology. 2000;165(12):72537261.

6. Saeterdal I, Bjorheim J, Lislerud K, et al. Frameshift-mutation-derived peptides as tumor-specific antigens in inherited and spontaneous colorectal cancer. Proceedings of the National Academy of Sciences of the United States of America. 2001;98(23):13255-13260.

7. Maness NJ, Sacha JB, Piaskowski SM, et al. Novel translation products from simian immunodeficiency virus SIVmac239 Env-encoding mRNA contain both Rev and cryptic T-cell epitopes. Journal of virology. 2009;83(19):10280-10285.

8. Bansal A, Carlson J, Yan J, et al. CD8 T cell response and evolutionary pressure to HIV-1 cryptic epitopes derived from antisense transcription. The Journal of experimental medicine. 2010;207(1):51-59.

9. Cardinaud S, Moris A, Fevrier M, et al. Identification of cryptic MHC Irestricted epitopes encoded by HIV-1 alternative reading frames. The Journal of experimental medicine. 2004;199(8):1053-1063.

10. Maness NJ, Valentine LE, May GE, et al. AIDS virus specific CD8+ T lymphocytes against an immunodominant cryptic epitope select for viral escape. The Journal of experimental medicine. 2007;204(11):2505-2512.

11. Maness NJ, Wilson NA, Reed JS, et al. Robust, vaccine-induced CD8(+) T lymphocyte response against an out-of-frame epitope. Journal of immunology. 2010;184(1):67-72.

12. Garrison KE, Champiat S, York VA, et al. Transcriptional errors in human immunodeficiency virus type 1 generate targets for T-cell responses. Clinical and vaccine immunology : CVI. 2009;16(9):1369-1371.

13. Maness NJ, Walsh AD, Piaskowski SM, et al. CD8+ T cell recognition of cryptic epitopes is a ubiquitous feature of AIDS virus infection. Journal of virology. 2010;84(21):11569-11574.

14. Ho O, Green WR. Cytolytic CD8+ T Cells Directed against a Cryptic Epitope Derived from a Retroviral Alternative Reading Frame Confer Disease Protection. The Journal of Immunology. 2006;176(4):2470-2475.

15. Okulicz JF, Lambotte O. Epidemiology and clinical characteristics of elite controllers. Current opinion in HIV and AIDS. 2011;6(3):163-168.

16. Kallas EG, Bassichetto KC, Oliveira SM, et al. Establishment of th Serologic Testing Algorithm for Recent Human Immunodeficiency Virus (HIV) 
Seroconversion (STARHS) Strategy in the City of São Paulo, Brazil. The Brazilialn Journal of Infectious Diseases. 2004;8(6):8.

17. Meiklejohn DA, Karlsson RK, Karlsson AC, Chapman JM, Nixon DF, Schweighardt B. ELISPOT cell rescue. Journal of immunological methods. 2004;288(1-2):135-147.

18. Champiat S, Raposo RA, Maness NJ, et al. Influence of HAART on alternative reading frame immune responses over the course of HIV-1 infection. PloS one. 2012;7(6):e39311.

19. Schwab SR, Shugart JA, Horng T, Malarkannan S, Shastri N. Unanticipated antigens: translation initiation at CUG with leucine. PLoS biology. 2004;2(11):e366.

20. Betts MR, Ambrozak DR, Douek DC, et al. Analysis of total human immunodeficiency virus (HIV)-specific CD4(+) and CD8(+) T-cell responses: relationship to viral load in untreated HIV infection. Journal of virology. 2001;75(24):11983-11991.

21. Masemola A, Mashishi T, Khoury G, et al. Hierarchical Targeting of Subtype C Human Immunodeficiency Virus Type 1 Proteins by CD8+ T Cells: Correlation with Viral Load. Journal of virology. 2004;78(7):3233-3243. 
Table 1: Characteristics of studied population in early phase of infection: age, gender, race, symptoms, CD4+ T cell count, CD8+ T cell count, HIV-1 viral load, HLA-allelesARFs. CCR5 genotype, HAART.

\begin{tabular}{|c|c|c|c|c|}
\hline & \multicolumn{4}{|c|}{ Group } \\
\hline & $\begin{array}{c}\text { Aviremic Controller } \\
\text { (AC) }\end{array}$ & $\begin{array}{c}\text { Viremic Controller } \\
\text { (VC) }\end{array}$ & $\begin{array}{c}\text { Progressor } \\
\text { (Vir) }\end{array}$ & $\mathbf{P}$ \\
\hline $\mathbf{N}$ & 13 & 6 & 27 & \\
\hline \multicolumn{5}{|l|}{ Age (years old) } \\
\hline Median & 35 & 34 & 30 & 0.2637 \\
\hline Interquartile range (25-75\%) & $27.5-39.5$ & $28.5-37.5$ & $25-35$ & \\
\hline \multicolumn{5}{|l|}{ Gender } \\
\hline Female & 0 & 1 & 2 & \\
\hline Male & 13 & 5 & 25 & \\
\hline \multicolumn{5}{|l|}{ Race } \\
\hline White & 6 & 1 & 17 & \\
\hline Mulato / Negro & 5 & 5 & 8 & \\
\hline Others / Not informed & 2 & --- & 2 & \\
\hline \multicolumn{5}{|l|}{ Symptoms } \\
\hline Asymptomatic & 8 & 5 & 19 & \\
\hline Symptomatic & 3 & 1 & 8 & \\
\hline Not informed & 2 & --- & --- & \\
\hline \multicolumn{5}{|l|}{ CD4 $($ cells $/ \mu \mathrm{L})$} \\
\hline Median & 621 & 608 & 513 & 0.4792 \\
\hline Interquartile range (25-75\%) & $503.5-863$ & $457-669$ & $415.5-712$ & \\
\hline \multicolumn{5}{|l|}{ CD8 $($ cells $/ \mu \mathrm{L})$} \\
\hline Median & 793 & 806,5 & 921 & 0.2251 \\
\hline Interquartile range $(25-75 \%)$ & $408-949,5$ & $482-1023$ & $646-1213$ & \\
\hline \multicolumn{5}{|l|}{ HIV-1 viral Loal (copies/mL)* } \\
\hline Median & 399 & 1,120 & 22,900 & $<0.0001$ \\
\hline Interquartile range (25-75\%) & $399-399$ & $547.5-1,635$ & $7,145-77,850$ & \\
\hline \multicolumn{5}{|l|}{ HLA alelles - ARFs } \\
\hline HLA-A*02 & 4 & 2 & 14 & \\
\hline HLA-B*07 & 2 & --- & 7 & \\
\hline HLA-B*57 & 8 & 1 & 3 & \\
\hline HLA-B*58 & 1 & --- & 2 & \\
\hline \multicolumn{5}{|l|}{ CCR5 } \\
\hline$(+/+)$ & $9(69.2 \%)$ & $4(66.7 \%)$ & $20(74.1 \%)$ & \\
\hline$(+/ \Delta-32)$ & $2(15.4 \%)$ & --- & $5(18.5 \%)$ & \\
\hline Not informed & 2 & 2 & 2 & \\
\hline \multicolumn{5}{|l|}{ Under HAART } \\
\hline Yes & $1(7.7 \%)$ & $1(16.7 \%)^{*}$ & $7(25.9 \%)^{*}$ & \\
\hline No & $12(92.3 \%)$ & $5(83.7 \%)$ & $20(74.1 \%)$ & \\
\hline
\end{tabular}


FIGURE 1

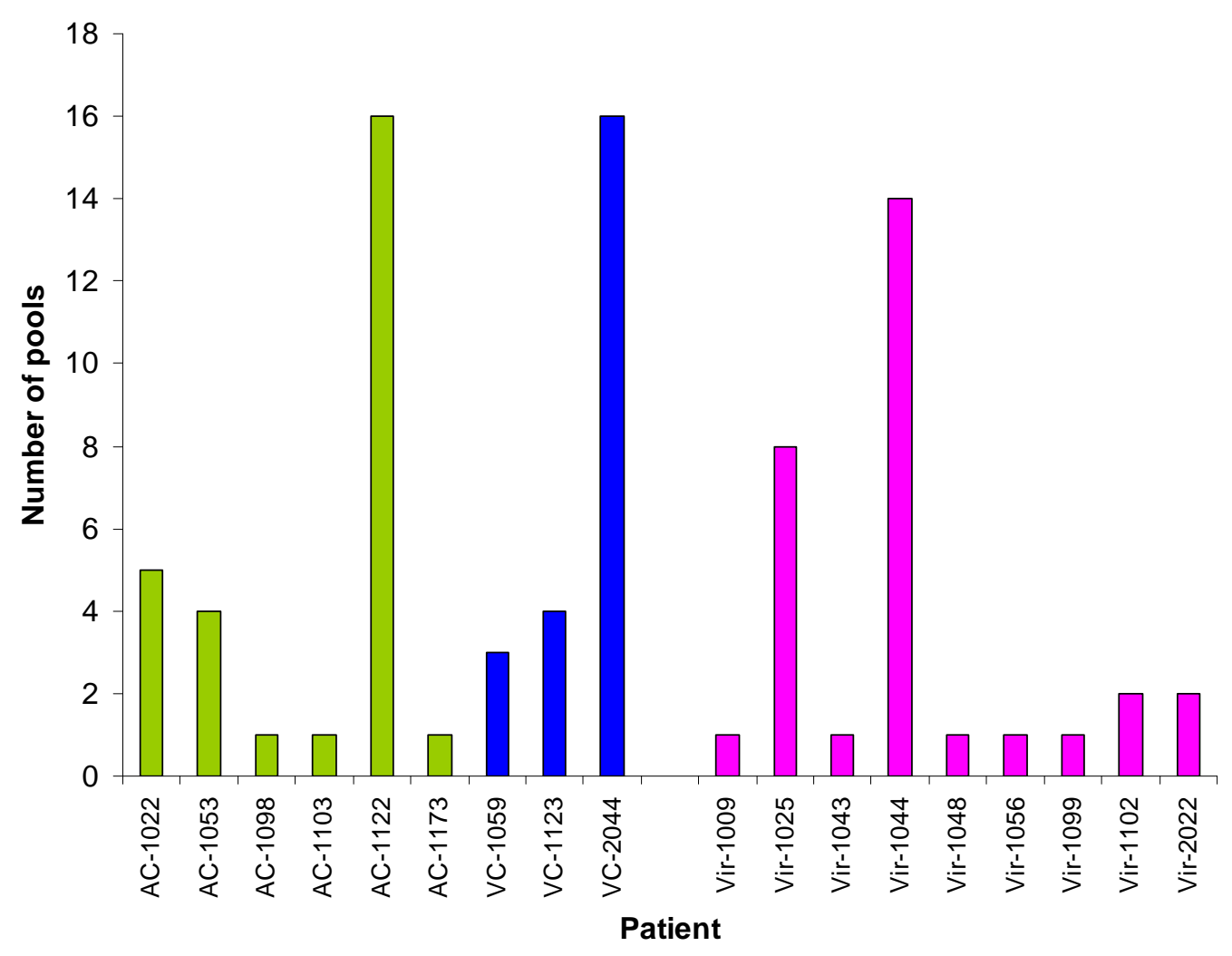


FIGURE 2

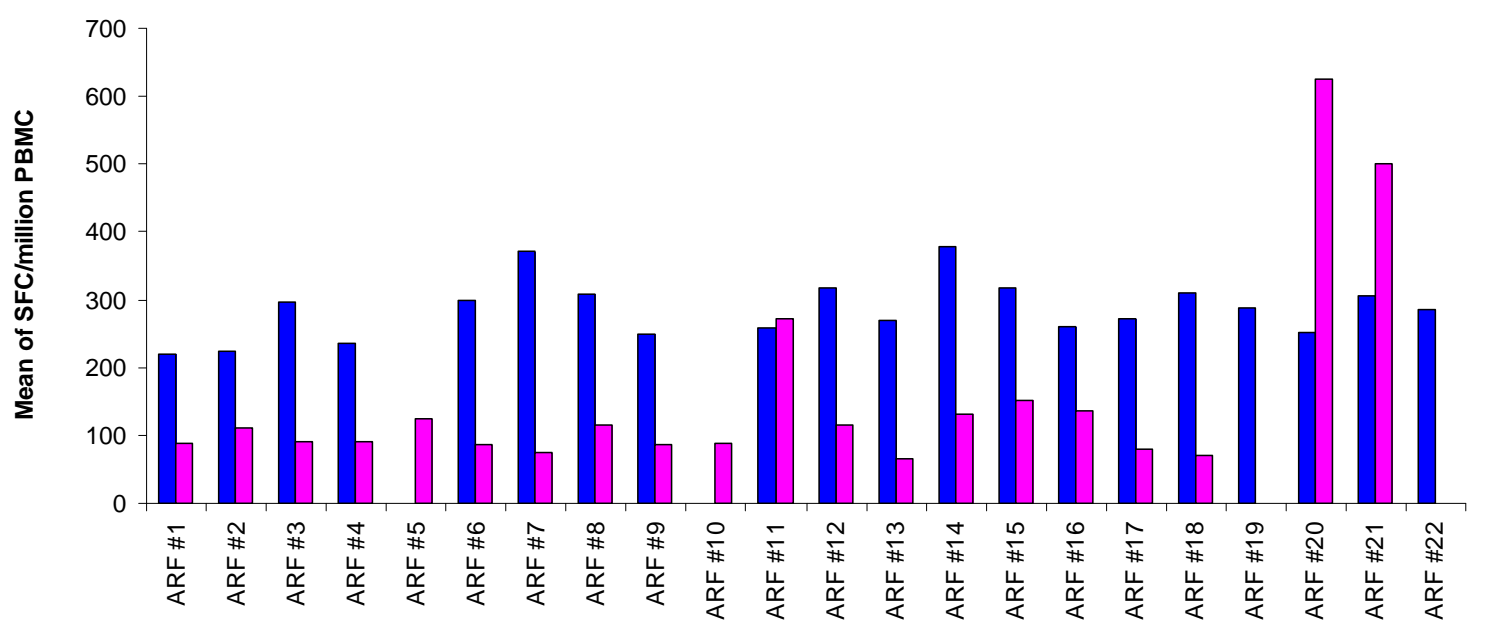

Pool of Cryptic Peptide (ARF) 
FIGURE 3

(A)

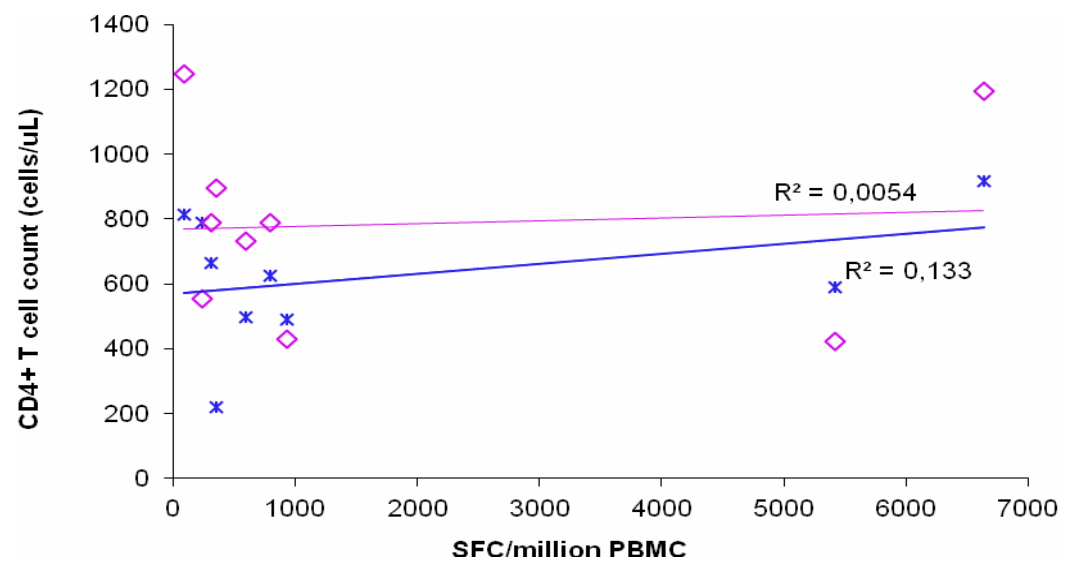

(B)

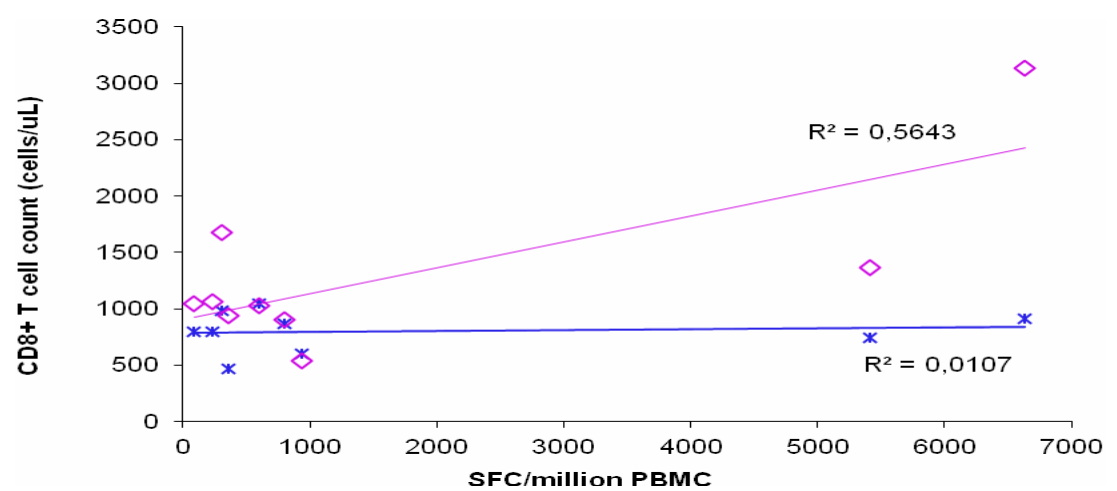

(C)

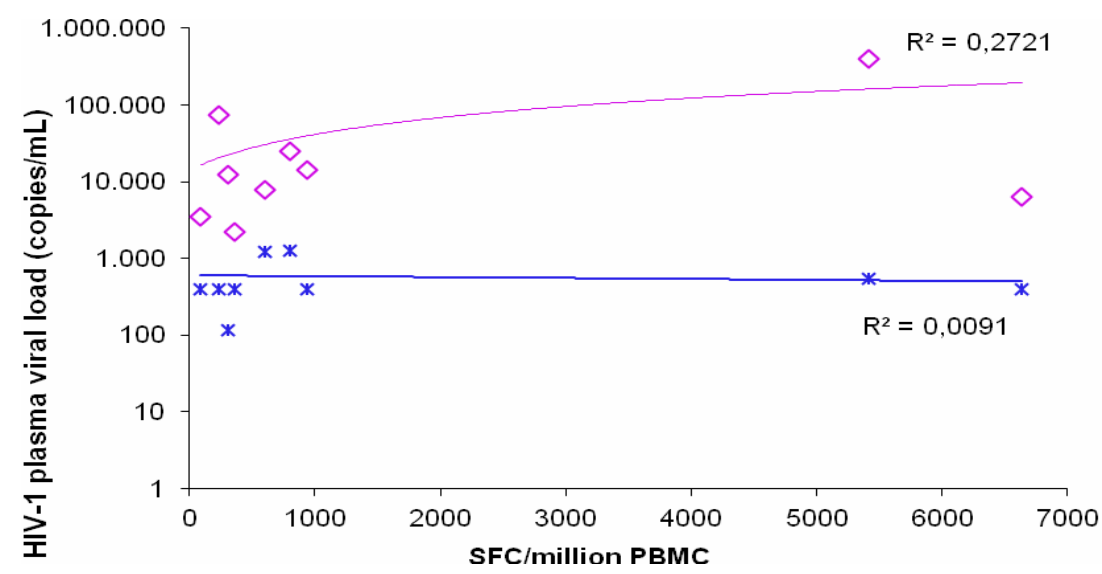




\section{FIGURE 4}

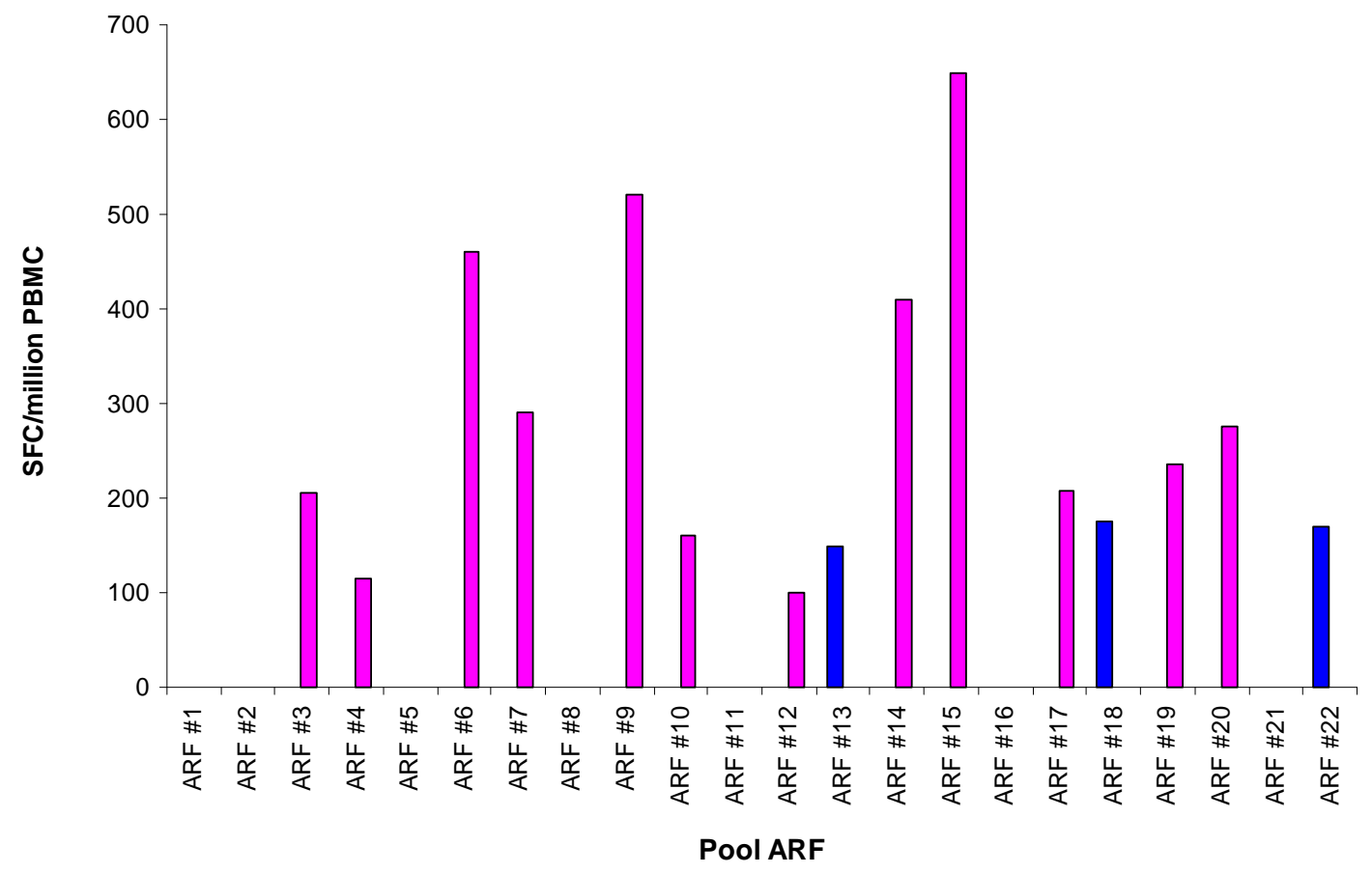




\section{FIGURE 5}

(A)

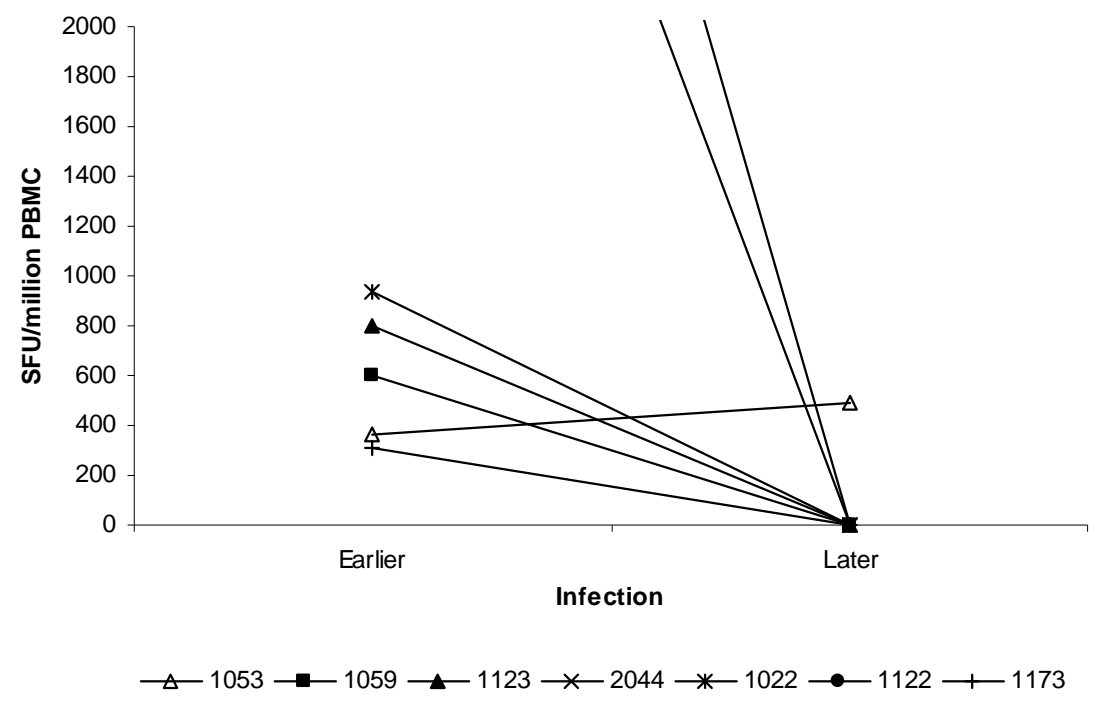

(B)

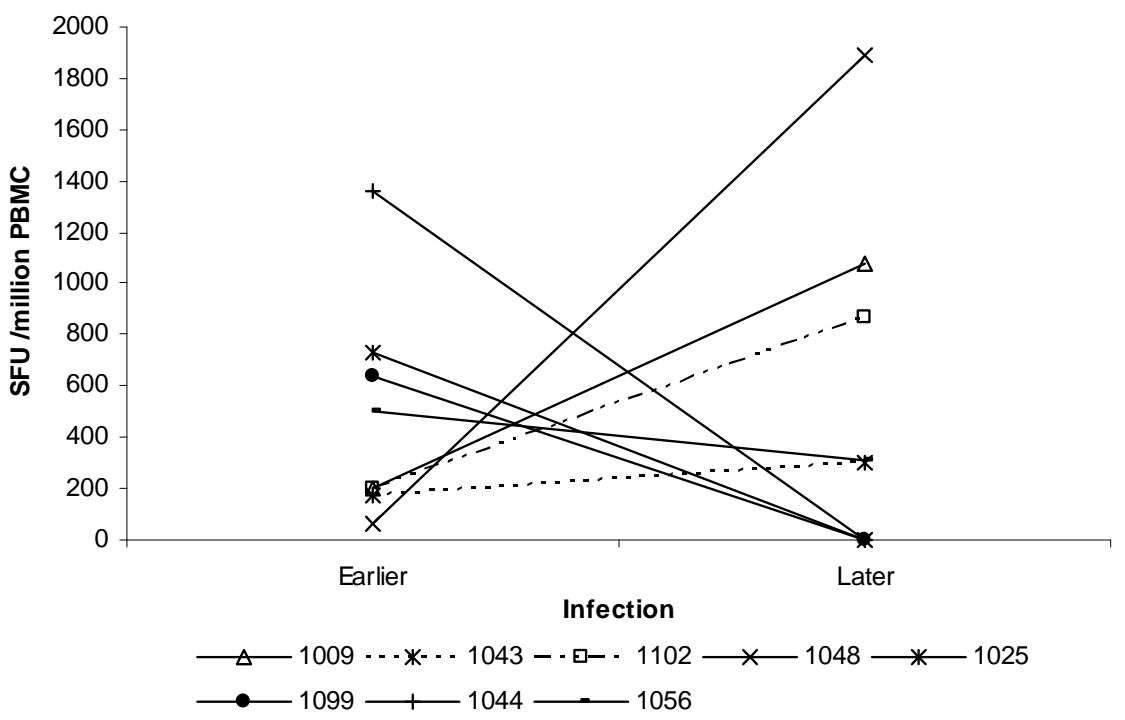




\section{FIGURE LEGENDS}

Figure 1: T cell response to cryptic peptides among controllers and progressors HIV-1 patients. Number of cryptic peptide pools that induced detectable responses in each individual responder. Green (aviremic, AC) and blue (viremic, VC) bars represent each controller, and pink bars represent each progressor patients (Vir).

Figure 2: Magnitude of $\mathrm{T}$ cell response to each cryptic peptides pool. Blue bars represent controller group's response (aviremic and viremic) and pink bars represent progressor group's response. ARF is cryptic peptides pool number.

Figure 3: Correlation of $T$ cell response to cryptic peptide and CD4+ $T$ cell count (A), CD8+ T cell count (B) and viral load (C) in controller (blue line) and progressor (pink line) group. Statistical analysis had shown not significant for all correlation, $\mathrm{p}>0.05$.

Figure 4: Breadth of T cell response. Results are represented as average of SFC/million PBMC for each pool. Pink bars represent controllers and blue bars represent progressors. ARF is cryptic peptides pool number.

Figure 5: Immune response in the early and late infection against cryptic peptides in controller (A) and progressor (B) patients. Earlier phase sample of patient $1122(6,635$ SFC/million PBMC) and 2044 (5,100 SFC/million PBMC) had high responses to cryptic peptide, so data were hide in the graphic. 
Supplemental Table 1: ARF individual peptides. Table lists the number of the cryptic peptides pool, number of peptides in each pool, pool content, each cryptic peptide sequence and T cell immune response (SFC/million PBMC) to each pool.

\begin{tabular}{|c|c|c|c|c|c|c|c|c|c|c|c|}
\hline \multirow[b]{2}{*}{ POOL \# } & \multirow[b]{2}{*}{ POOL CONTENT } & \multirow[b]{2}{*}{$\begin{array}{l}\text { \# peptides } \\
\text { in the pool }\end{array}$} & \multicolumn{6}{|c|}{ Responders ( $n$ and mean of SFU/million PBMC) } & \multirow[b]{2}{*}{ Peptide name } & \multirow[b]{2}{*}{ Sequence } & \multirow[b]{2}{*}{ HLA } \\
\hline & & & Total & $\begin{array}{c}\text { SFU/million } \\
\text { PBMC }\end{array}$ & Controller & $\begin{array}{l}\text { SFU/ million } \\
\text { PBMC }\end{array}$ & Progressor & $\begin{array}{c}\text { SFU/million } \\
\text { PBMC }\end{array}$ & & & \\
\hline 1 & $\begin{array}{l}\text { Tat and Rev splicing } \\
\text { variants peptides }\end{array}$ & 2 & 3 & 131,7 & 1 & 220,0 & 2 & 87,5 & $\begin{array}{l}\text { Splice TAT leader } \\
\text { Splice REV leader }\end{array}$ & $\begin{array}{l}\text { SRDIHHYRFR } \\
\text { RIFTIIVSD }\end{array}$ & \\
\hline \multirow{11}{*}{2} & & 11 & 6 & 167,5 & 3 & 223,3 & 3 & 111,7 & A2ORF_08K19 & KLQNGIECI & HLA-A2 \\
\hline & & & & & & & & & A2ORF_45KI9 & KLGDGFIDI & HLA-A2 \\
\hline & & & & & & & & & A2ORF_62AL9 & AMCKINPTL & HLA-A2 \\
\hline & & & & & & & & & A2ORF_65VV9 & VQMSAQYNV & HLA-A2 \\
\hline & & & & & & & & & A2ORF_33TV9 & TVIGEQWLV & HLA-A2 \\
\hline & Hiv Art sense AL and Br & & & & & & & & A2ORF_65AL9 & AQYNVHMEL & HLA-A2 \\
\hline & & & & & & & & & B7ORF_03OF9* & QPRSDTHVF & HLA-B7 \\
\hline & & & & & & & & & B7ORF_70ML9 & MPLPSVDKL & HLA-B7 \\
\hline & & & & & & & & & B7ORF_-37YQ9 & YPGSSSCSQ & HLA-B7 \\
\hline & & & & & & & & & B7ORF_37RF9 & RAGNSIFSF & HLA-B7 \\
\hline & & & & & & & & & B7ORF_7OLV9 & LPSVDKLDV & HLA-B7 \\
\hline & & & & & & & & & B580RF_37RF9 & RAGNSIFSF & HLA-B58 \\
\hline & & & & & & & & & B580RF_32RW9 & RSRNLLCRW & HLA-B58 \\
\hline & & & & & & & & & B58ORF_37SY9 & ssscsaWIY & HLA-B58 \\
\hline & & & & & & & & & B580RF_65MM9 & MSAQYNVHM & HLA-B58 \\
\hline & & & & & & & & & B580RF_37KY9 & KMASKNNTY & HLA-B58 \\
\hline 3 & HIV ARF sense B58 peptides & 11 & 3 & 228,3 & 2 & 297,5 & 1 & 90,0 & B580RF_03R19 & RSDTHVFSI & HLA-B58 \\
\hline & & & & & & & & & B58ORF_-33NW9 & NITVIGEQW & HLA-B58 \\
\hline & & & & & & & & & B580RF_71R19 & RSSDLEEEI & HLA-B58 \\
\hline & & & & & & & & & B580RF_20KF9 & KNDRGNWRF & HLA-B58 \\
\hline & & & & & & & & & B580RF_23KW9 & KGRENFKNW & HLA-B58 \\
\hline & & & & & & & & & B580RF_67SW9 & SNVCPSHQW & HLA-B58 \\
\hline & & & & & & & & & A2ORF_092YL9 & YLYNSLLQL & HLA-A2 \\
\hline & & & & & & & & & A2ORF_092KL9 & KISDSLLLL & HLA-A2 \\
\hline & & & & & & & & & A2ORF_092AL9 & ALFSLCTTL & HLA-A2 \\
\hline & & & & & & & & & A2ORF_092VL9 & VLLNSCVEL & HLA-A2 \\
\hline 4 & HIV ARF 92 antisense A2 & 10 & 2 & 1625 & 1 & 2350 & 1 & 900 & A2ORF_092HL9 & HMFIICFIL & HLA-A2 \\
\hline 4 & peptides & & & 162,5 & & 235,0 & & 90,0 & A2ORF_092TL9 & TLYLYNSLL & HLA-A2 \\
\hline & & & & & & & & & A2ORF_092SL9 & SLLLLPPSL & HLA-A2 \\
\hline & & & & & & & & & A2ORF_092SL9 & SLISPPPGL & HLA-A2 \\
\hline & & & & & & & & & A2ORF_092RV9 & RVIVSLPSV & HLA-A2 \\
\hline & & & & & & & & & A2ORF_092SV9 & SVIEAAPIV & HLA-A2 \\
\hline & & & & & & & & & A2ORF_092FV9 & FILHGRVIV & HLA-A2 \\
\hline & & & & & & & & & A2ORF_092SI9 & SLVNSSPVI & HLA-A2 \\
\hline & & & & & & & & & A2ORF_092LV9 & LLLLPPSLV & HLA-A2 \\
\hline & & & & & & & & & A2ORF_092TA9 & TLLFALVGA & HLA-A2 \\
\hline 5 & HIV ARF 92 antisense A2 & 9 & 1 & 125,0 & 0 & - & 1 & 125,0 & B70RF_092AA9 & APKNPRNKA & HLA-B7 \\
\hline & & & & & & & & & B7ORF_092F19 & FPTFCHMFI & HLA-B7 \\
\hline & & & & & & & & & B7ORF_092SL9 & SPVIFDEHL & HLA-B7 \\
\hline & & & & & & & & & B7ORF_092CI9 & CPLMGGAYI & HLA-B7 \\
\hline & & & & & & & & & B7ORF_0921C9 & IPDNNCLAC & HLA-B7 \\
\hline & & & & & & & & & B58ORF_092IM9 & IAFPTFCHM & HLA-B58 \\
\hline & & & & & & & & & B58ORF_092GF9 & GAYIAFPTF & HLA-B58 \\
\hline & & & & & & & & & B580RF_092FF9 & FSLCTTLLF & HLA-B58 \\
\hline & & & & & & & & & B580RF_092LF9 & LVNSSPVIF & HLA-B58 \\
\hline 6 & HIV ARF 92 antisense B58 & 9 & 4 & 138,8 & 1 & 300,0 & 3 & 85,0 & B58ORF_092AF9 & ASIALSKLF & HLA-B58 \\
\hline & & & & & & & & & B58ORF_092GL9 & GSIFTTLYL & HLA-B58 \\
\hline & & & & & & & & & B580RF_092IF9 & IVSLPSVLF & HLA-B58 \\
\hline & & & & & & & & & B580RF_092KF9 & KAPIPTALF & HLA-B58 \\
\hline & & & & & & & & & B580RF_092LF9 & LMGGAYIAF & HLA-B58 \\
\hline & & & & & & & & & A2ORF_128SV9** & SVNCFTSLV & HLA-A2 \\
\hline & & & & & & & & & A2ORF_128VV9 & VIFCTASV & HLA-A2 \\
\hline & & & & & & & & & A2ORF_128SL9 & SLVWAPLIL & HLA-A2 \\
\hline & & & & & & & & & A2ORF_128IV9 & IQVACQYSV & HLA-A2 \\
\hline 7 & HIV ARF ILs antisense AL & 9 & 4 & 223,8 & 2 & 372,5 & 2 & 75,0 & A2ORF_128MT9 & MLSVVIFCT & HLA-A2 \\
\hline & & & & & & & & & A2ORF_128GL9 & GVFPHITML & HLA-A2 \\
\hline & & & & & & & & & A2ORF_128CV9 & CMGSLNLGV & HLA-A2 \\
\hline & & & & & & & & & A2ORF_128PVg & PLILAYFPV & HLA-A2 \\
\hline & & & & & & & & & A2ORF_128LA9 & LVWAPLILA & HLA-A2 \\
\hline & & & & & & & & & B70RF_128FV9 & FPHITMLSV & HLA-B7 \\
\hline & & & & & & & & & B7ORF_128HL9 & HVSFCMGSL & HLA-B7 \\
\hline & & & & & & & & & B58ORF_128LF9*** & LAYFPVFRF & HLA-B58 \\
\hline 8 & HIV ARF 128 antisense B7 & 8 & 4 & 2600 & 3 & 3083 & 1 & 1150 & B580RF_1281F9 & ITMLSVVIF & HLA-B58 \\
\hline & and B58 peptides & 8 & 4 & 200,0 & 3 & 308,3 & 1 & 115,0 & B580RF_128SY9 & SGIQVACQY & HLA-B58 \\
\hline & & & & & & & & & B580RF_128HM9 & HVSHVSFCM & HLA-B58 \\
\hline & & & & & & & & & B580RF_128VW9 & VNCFTSLVW & HLA-B58 \\
\hline & & & & & & & & & B58ORF_128LF9 & LLLAYFPVF & HLA-B58 \\
\hline
\end{tabular}




\begin{tabular}{|c|c|c|c|c|c|c|c|c|c|c|c|}
\hline \multirow{10}{*}{9} & & & & & & & & & A2ORF_141VI9 & VLYGFSGPI & HLA-A2 \\
\hline & & & & & & & & & A2ORF_141FL9 & FTGTVSIGL & HLA-A2 \\
\hline & & & & & & & & & B7ORF_141SF9 & SVQISTNAF & HLA-B7 \\
\hline & & & & & & & & & B7ORF_141GF9 & GPSIPGFNF & HLA-B7 \\
\hline & HIV ARF 141 antisense A2, & 10 & 4 & 208,8 & 3 & 250,0 & 1 & 85,0 & B7ORF_141FQ9 & FPSFSISVQ & HLA-B7 \\
\hline & $\mathrm{B} 7$ and $\mathrm{B} 58$ peptides & 10 & 4 & 208,8 & 3 & 250,0 & 1 & 85,0 & B580RF_141FF9 & FSGPIFEIF & HLA-B58 \\
\hline & & & & & & & & & B58ORF_141SF9 & SVNGHCLTF & HLA-B58 \\
\hline & & & & & & & & & B58ORF_141VF9 & VSIGLMGKF & HLA-B58 \\
\hline & & & & & & & & & B58ORF_141QF9 & QISTNAFIF & HLA-B58 \\
\hline & & & & & & & & & B58ORF_141FL9 & FSSVNGHCL & HLA-B58 \\
\hline & & & & & & & & & A2ORF_153FL9 & FVYSLLMFL & HLA-A2 \\
\hline & & & & & & & & & A2ORF_153MV9 & MVVAVPVFV & HLA-A2 \\
\hline 10 & HIV ARF 153 antisense A2, & 5 & 2 & 87,5 & 0 & -- & 2 & 87,5 & A2ORF_153AL9 & AVPVFVYSL & HLA-A2 \\
\hline & & & & & & & & & B7ORF_153VL9 & VPVFVYSLL & HLA-B7 \\
\hline & & & & & & & & & B58ORF_153VY9 & VVAVPVFVY & HLA-B58 \\
\hline & & & & & & & & & B7ORF_083SL9 & SPVPPRPRL & HLA-B7 \\
\hline & & & & & & & & & B7ORF_083RP9 & RPRLPGKSP & HLA-B7 \\
\hline & & & & & & & & & B7ORF_083RP9 & RARHSPVPP & HLA-B7 \\
\hline & & & & & & & & & B7ORF_084RM9 & RMQLSGHVM & HLA-B7 \\
\hline 11 & antisense $A 2, B 7$ and $B 58$ & 10 & 6 & 265,0 & 3 & 258,3 & 3 & 2717 & B58ORF_086LY9 & LSSSHSFPY & HLA-B58 \\
\hline & & & & & & 208,3 & 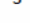 & 27,1 & B580RF_086CW9 & CCSHPICCW & HLA-B58 \\
\hline & & & & & & & & & A2ORF_087ML9 & MLLPPYLLL & HLA-A2 \\
\hline & & & & & & & & & A2ORF_087LA9 & LLPPYLLLA & HLA-A2 \\
\hline & & & & & & & & & A2ORF_087AL9 & AQLVSFFPL & HLA-A2 \\
\hline & & & & & & & & & B7ORF_087PL9 & PPYLLLAQL & HLA-B7 \\
\hline & & & & & & & & & A2ORF_085LV9 & LLSYLAQLV & HLA-A2 \\
\hline & & & & & & & & & A2ORF_085PL9 & PLLSYLAQL & HLA-A2 \\
\hline & & & & & & & & & A2ORF_085GL9 & GVTSWCSLL & HLA-A2 \\
\hline & & & & & & & & & B580RF_085TW9 & TSWCSLLYW & HLA-B58 \\
\hline 12 & HIV ARF 85, 95 antisense A2 & 9 & 4 & 266,3 & 3 & 316,7 & 1 & 115,0 & B58ORF_085LL9 & LSYLAQLVL & HLA-B58 \\
\hline & & & & & & & & & B580RF_085VY9 & VTSWCSLLY & HLA-B58 \\
\hline & & & & & & & & & B580RF_085AW9 & AGSQGVTSW & HLA-B58 \\
\hline & & & & & & & & & B58ORF_085LY9 & LIYWPLLSY & HLA-B58 \\
\hline & & & & & & & & & A2ORF_095VV9 & VLaVLLNOV & HLA-A2 \\
\hline & & & & & & & & & A2ORF_088AL9 & AMAVALSKL & HLA-A2 \\
\hline & & & & & & & & & A20RF_088CV9 & CTTSITLSV & HLA-A2 \\
\hline & & & & & & & & & A2ORF_088LI9 & LQAPCTTSI & HLA-A2 \\
\hline & & & & & & & & & A2ORF_088KS9 & KLTALFFSS & HLA-A2 \\
\hline 13 & HIV ARF 88 antisense A2, & 10 & 4 & 218.8 & 3 & 2700 & 1 & 65,0 & B7ORF_088AL9 & APCTTSITL & HLA-B7 \\
\hline 13 & $\mathrm{~B} 7$ and $\mathrm{B} 58$ peptides & 10 & 4 & 218,8 & 3 & $2 / 0,0$ & 1 & 65,0 & B7ORF_088VV9 & VPSATAMAV & HLA-B7 \\
\hline & & & & & & & & & B7ORF_088SL9 & SATAMAVAL & HLA-B7 \\
\hline & & & & & & & & & B7ORF_088VL9 & VALSKLTAL & HLA-B7 \\
\hline & & & & & & & & & B580RF_088LM9 & LSVPSATAM & HLA-B58 \\
\hline & & & & & & & & & B58ORF_088LF9 & LSKLTALFF & HLA-B58 \\
\hline & & & & & & & & & A2ORF_089S19 & SLSPPSSSI & HLA-A2 \\
\hline & & & & & & & & & B7ORF_0891L9 & IPSGLSGPL & HLA-B7 \\
\hline & & & & & & & & & B7ORF_0895s9 & SPPSSSIPS & HLA-B7 \\
\hline & & & & & & & & & A2ORF_090VL9 & VMLNOFHKL & HLA-A2 \\
\hline & HIV ARF $89,90,93,94$ & & & & & & & & A2B58ORF_090FM9 & FIYHSQFVM & HLA-A2/HLA-B58 \\
\hline 14 & antisense $\mathrm{A} 2, \mathrm{~B} 7$ and $\mathrm{B} 58$ & 11 & 5 & 280,0 & 3 & 378,3 & 2 & 132,5 & B580RF_090NW9 & NSCSFFSCW & HLA-B58 \\
\hline & & & & & & & & & B7ORF_093SL9 & SPQQIVLLL & HLA-B7 \\
\hline & & & & & & & & & A2ORF_094FI9 & FLLLYYYII & HLA-A2 \\
\hline & & & & & & & & & A2ORF_094MI9 & MVOFLLLYI & HLA-A2 \\
\hline & & & & & & & & & B7ORF_094CV9 & CPSYLLLQV & HLA-B7 \\
\hline & & & & & & & & & B580RF_094LF9 & LLYIYIIHF & HLA-B58 \\
\hline & & & & & & & & & A2ORF_097LV9 & LIFPIFPIV & HLA-A2 \\
\hline & & & & & & & & & A2ORF_-097CI9 & CLIFPIFPI & HLA-A2 \\
\hline & & & & & & & & & A2ORF_097LI9 & LLGLVQLI & HLA-A2 \\
\hline & & & & & & & & & A2ORF_097TV9 & TIMVLALSV & HLA-A2 \\
\hline & & & & & & & & & A2ORF_097FV9 & FLVLLLGLV & HLA-A2 \\
\hline 15 & HIV ARF 92 antisense A2 & 11 & 7 & 270,7 & 5 & 318,0 & 2 & 152,5 & A2ORF_097RL9 & RILFLVLLL & HLA-A2 \\
\hline & & & & & & & & & A2ORF_097VL9 & VLLLGLVQL & HLA-A2 \\
\hline & & & & & & & & & A2ORF_097KS9 & KLTDLITTS & HLA-A2 \\
\hline & & & & & & & & & A2ORF_097AL9 & ALSVKLTDL & HLA-A2 \\
\hline & & & & & & & & & B580RF_097TF9 & TSSSARLPF & HLA-B58 \\
\hline & & & & & & & & & B580RF_0971L9 & ITTSSSARL & HLA-B58 \\
\hline & & & & & & & & & B7ORF_097GF9 & GPLWIRILF & HLA-B7 \\
\hline & & & & & & & & & B7ORF_097WL9 & WIRILFLVL & HLA-B7 \\
\hline & & & & & & & & & A2ORF_098Q19 & QLYYYGFSI & HLA-A2 \\
\hline & HIV ARF $97,98,99$ & & & & & & & & B58ORF_098LY9 & LSHISYFSY & HLA-B58 \\
\hline 16 & antisense $\mathrm{A} 2, \mathrm{~B} 7$ and $\mathrm{B} 58$ & 9 & 3 & 218,3 & 2 & 260,0 & 1 & 135,0 & A2ORF_099FL9 & FFLYCCWVL & HLA-A2 \\
\hline & & & & & & & & & A2ORF_099FV9 & FFFLYCCWV & HLA-A2 \\
\hline & & & & & & & & & B580RF_099VF9 & VLSGYGFFF & HLA-B58 \\
\hline & & & & & & & & & B58ORF_099SY9 & SGYGFFFLY & HLA-B58 \\
\hline & & & & & & & & & B58ORF_099GW9 & GFFFLYCCW & HLA-B58 \\
\hline & & & & & & & & & A2ORF_100ML9 & MVLALSVKL & HLA-A2 \\
\hline & & & & & & & & & B58ORF_101LW9 & LYCADICTW & HLA-B58 \\
\hline & & & & & & & & & A2ORF_103VV9 & VMTEVLQLV & HLA-A2 \\
\hline & & & & & & & & & A2ORF_103GV9 & GQACVMTEV & HLA-A2 \\
\hline 17 & $\begin{array}{l}\text { HIV ARF } 100,101,103,105 \\
\text { antisense A2 and B58 }\end{array}$ & 10 & 4 & 2238 & 3 & 2717 & 1 & 800 & A2ORF_103CL9 & CVMTEVLQL & HLA-A2 \\
\hline 17 & antisense A2 and B58 & 10 & 4 & 223,8 & 3 & 271,1 & 1 & 80,0 & B58ORF_103MF9 & MGIGSKDTF & HLA-B58 \\
\hline & & & & & & & & & A2ORF_105YI9 & YLCIICFSI & HLA-A2 \\
\hline & & & & & & & & & B58ORF_105HW9 & HIYQTYFLW & HLA-B58 \\
\hline & & & & & & & & & B580RF_105IF9 & IMYLCIICF & HLA-B58 \\
\hline & & & & & & & & & B58ORF_105KY9 & KIFCHIYQY & HLA-B58 \\
\hline
\end{tabular}




\begin{tabular}{|c|c|c|c|c|c|c|c|c|c|c|c|}
\hline \multirow{10}{*}{18} & \multirow{10}{*}{$\begin{array}{l}\text { HIV ARF } 104,110 \text { antisense } \\
\text { A2 and B58 peptides }\end{array}$} & \multirow{10}{*}{10} & \multirow{10}{*}{3} & \multirow{10}{*}{230,0} & \multirow{10}{*}{2} & \multirow{10}{*}{310,0} & \multirow{10}{*}{1} & \multirow{10}{*}{70,0} & A2ORF 104 FI9 & FISPFSIII & HLA-A2 \\
\hline & & & & & & & & & A2ORF-104IV9 & IILPLLLLV & HLA-A2 \\
\hline & & & & & & & & & A2ORF_104LI9 & LILKEQFFI & HLA-A2 \\
\hline & & & & & & & & & A2ORF_104VV9 & VLVSFFKSV & HLA-A2 \\
\hline & & & & & & & & & A2B58ORF_104FL9 & FSIIILPLL & HLA-A2/HLA-B58 \\
\hline & & & & & & & & & A2ORF_104IL9 & ILPLLLLVL & HLA-A2 \\
\hline & & & & & & & & & B58ORF_104VF9 & VSFFKSVHF & HLA-B58 \\
\hline & & & & & & & & & B580RF_104KF9 & KLTQSGVNF & HLA-B58 \\
\hline & & & & & & & & & B580RF_104SF9 & SGVNFTHGF & HLA-B58 \\
\hline & & & & & & & & & A2ORF_110TI9 & TMDHTTIAI & HLA-A2 \\
\hline \multirow{10}{*}{19} & \multirow{10}{*}{$\begin{array}{c}\text { HIV ARF } 106,112,114 \\
\text { antisense A2, B7 and B58 } \\
\text { peptides }\end{array}$} & \multirow{10}{*}{10} & \multirow{10}{*}{3} & \multirow{10}{*}{288,3} & \multirow{10}{*}{3} & \multirow{10}{*}{288,3} & \multirow{10}{*}{-} & \multirow{10}{*}{-- } & B580RF_106MF9 & MSFFHMLKF & HLA-B58 \\
\hline & & & & & & & & & B580RF_106HF9 & HMLKFSVTF & HLA-B58 \\
\hline & & & & & & & & & A2ORF_112SI9 & SLSPLLPAI & HLA-A2 \\
\hline & & & & & & & & & B7ORF_112TL9 & TVLMSSSSL & HLA-B7 \\
\hline & & & & & & & & & B58ORF_112SL9 & SSSSLSPLL & HLA-B58 \\
\hline & & & & & & & & & A2B58ORF_114LL9 & LTSWMLPGL & HLA-A2/HLA-B58 \\
\hline & & & & & & & & & A2ORF_114ALI & AIGTSSFRL & HLA-A2 \\
\hline & & & & & & & & & B7ORF_114KI9 & KATLFTIAI & HLA-B7 \\
\hline & & & & & & & & & B7ORF_114TF9 & TIAIGTSSF & HLA-B7 \\
\hline & & & & & & & & & B580RF_114TW9 & TSSFRLTSW & HLA-B58 \\
\hline \multirow{7}{*}{20} & \multirow{7}{*}{$\begin{array}{c}\text { HIV ARF } 115,116,117,119, \\
120 \text { antisense A2, B7 and } \\
\text { B58 peptides }\end{array}$} & \multirow{7}{*}{7} & & & & & & & B70RF_115IL9 & IPISFIDML & HLA-B7 \\
\hline & & & & & & & & & B7ORF_116NF9 & NPRKMSNSF & HLA-B7 \\
\hline & & & & & & & & & B580RF_116ML9 & MSNSFILKL & HLA-B58 \\
\hline & & & 4 & 345,0 & 3 & 251,7 & 1 & 625,0 & A2ORF_117LI9 & LLVPSIVEI & HLA-A2 \\
\hline & & & & & & & & & B7ORF_117LI9 & LPCYVLLDI & HLA-B7 \\
\hline & & & & & & & & & B7ORF_119MQ9 & MPVSFSCMQ & HLA-B7 \\
\hline & & & & & & & & & B58ORF $120 M F 9$ & MSIKPSPSF & HLA-B58 \\
\hline & & & & & & & & & A2ORF_121FL9 & FQSGFLLSL & HLA-A2 \\
\hline & & & & & & & & & A2ORF_121SA9 & SLLSCITTA & HLA-A2 \\
\hline & & & & & & & & & A2ORF_121LL9 & LLGTTFMSL & HLA-A2 \\
\hline & & & & & & & & & A2ORF_121MT9 & MIFAFLLGT & HLA-A2 \\
\hline & & & & & & & & & A2ORF_121FS9 & FLLGTTFMS & HLA-A2 \\
\hline 21 & HIV ARF 121 antisense A2, & 11 & 5 & 344,0 & 4 & 305,0 & 1 & 500,0 & B70RF_121AF9 & APSPFQRSF & HLA-B7 \\
\hline & & & & & & & & & B70RF_121GL9 & GPFQSGFLL & HLA-B7 \\
\hline & & & & & & & & & B70RF_121SG9 & SPFQRSFAG & HLA-B7 \\
\hline & & & & & & & & & B580RF_121FF9 & FAFLLGTTF & HLA-B58 \\
\hline & & & & & & & & & B58ORF_121FF9 & FAGPFOSGF & HLA-B58 \\
\hline & & & & & & & & & B58ORF_121RS9 & RSFAGPFQS & HLA-B58 \\
\hline & & & & & & & & & A2ORF_123IA9 & IMSTILSPA & HLA-A2 \\
\hline & & & & & & & & & A2ORF_123WA9 & WMNTAICTA & HLA-A2 \\
\hline & & & & & & & & & A2ORF_123FT9 & FLLKLWMNT & HLA-A2 \\
\hline 22 & $\begin{array}{l}\text { HIV ARF } 123 \text { antisense A2, } \\
\text { B7 and B58 peptides }\end{array}$ & 7 & 2 & 285,0 & 2 & 285,0 & - & -- & B7ORF_123SL9 & SVAIMSTIL & HLA-B7 \\
\hline & & & & & & & & & B7ORF_123YL9 & YPPIPPFLL & HLA-B7 \\
\hline & & & & & & & & & B580RF_123SY9 & STILSPALY & HLA-B58 \\
\hline & & & & & & & & & B580RF_123AF9 & ALYPPIPPF & HLA-B58 \\
\hline
\end{tabular}

*Cardineau et al., 2004. J. Exp. Med.

***Bansai et al., 2010, J. Exp. Med.

***Peptide close to AYFPVFRFL, Bansai et al., 2010, J. Exp. Med. 